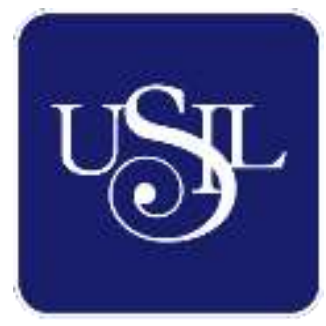

UNIVERSIDAD

SAN IGNACIO

DE LOYOLA

ESCUELA DE POST GRADO

Maestría en Dirección de Marketing y Gestión Comercial

\title{
PLAN DE MARKETING PARA LEGO STORE (COMEXA) EN EL PERÚ
}

Tesis para optar el grado de Maestro en Dirección de Marketing Y Gestión Comercial

\section{ALCÁNTARA ÁLVAREZ, BERNARDO ARTURO RAMÍREZ BUSTAMANTE, CARLOS ENRIQUE RODRÍGUEZ CASTRO, RODOLFO JUAN}

Asesor:

Dra. Niria marleny goñi ávila

Lima - Perú

2016 


\section{Tabla de Contenidos}

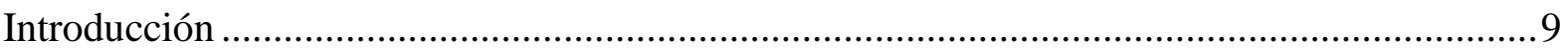

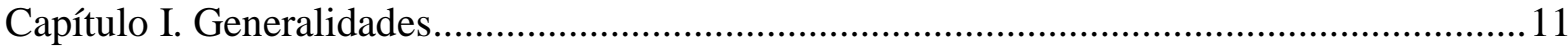

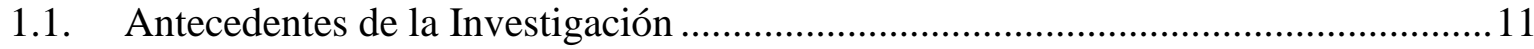

1.2. Determinación del Problema u Oportunidad ................................................................ 12

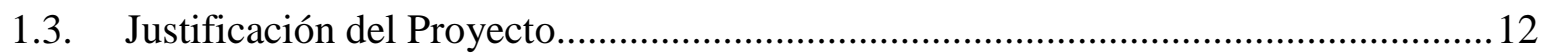

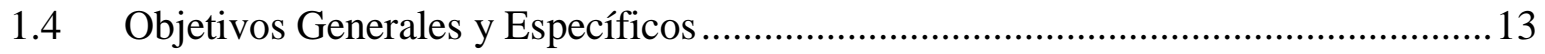

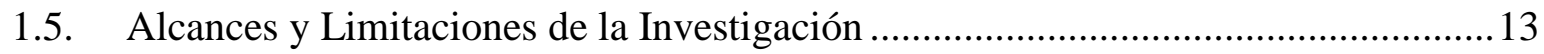

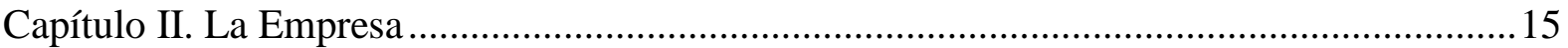

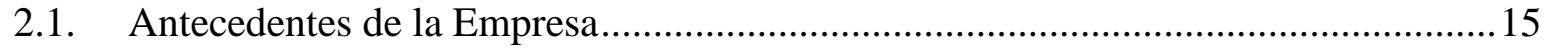

2.2. Estructura Organizacional Actual de la Empresa ..................................................... 16

2.3. Situación de Mercado y Financiera Actual de la Empresa...................................... 17

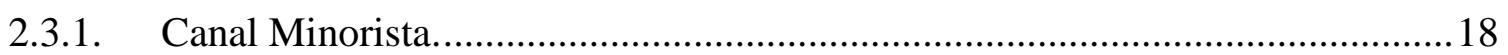

2.3.2. Canal Mayorista (Moderno y Tradicional)..................................................... 18

2.4. Visión, Misión y Valores de la Empresa ......................................................................23

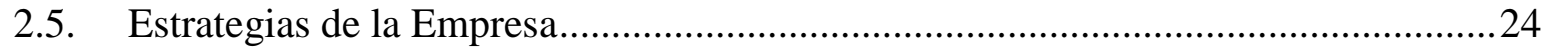

2.5.1. Estrategias Genéricas - Diferenciación...............................................................2 24

2.5.2. Estrategia de Crecimiento - Crecimiento Intensivo..........................................25

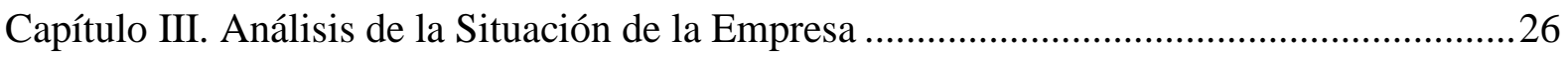

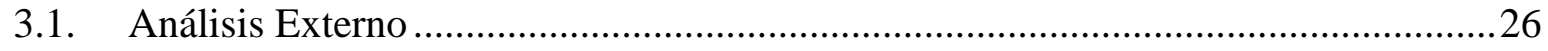

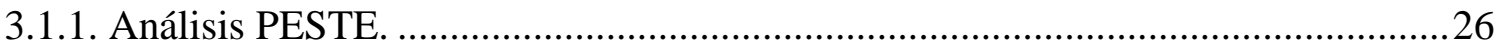

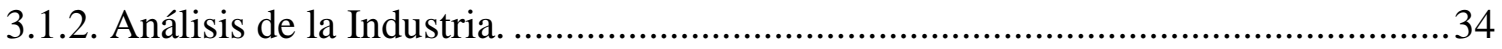

3.1.3. Modelo de las Cinco Fuerzas de Porter. ................................................................... 37

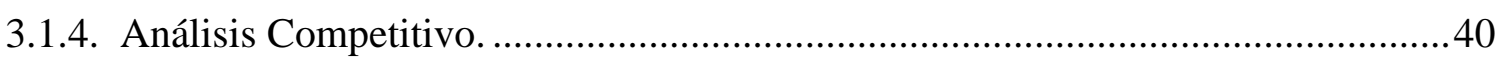

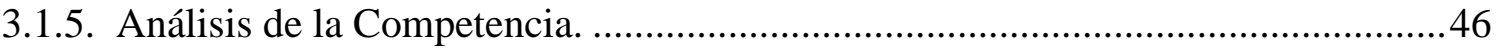

3.1.6. Matriz de Evaluación de Factores Externos (MEFE)........................................... 47

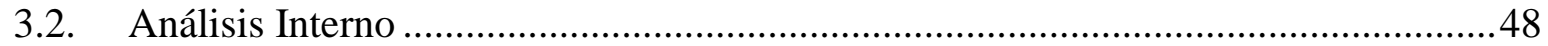

3.2.1. Análisis de la Cadena de Valor de COMEXA para la UEN LEGO. .....................48

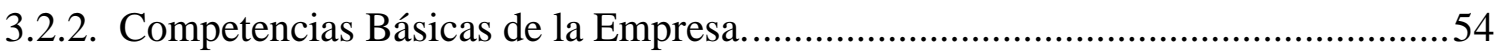

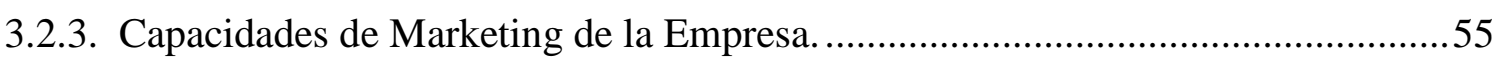

3.2.4. Matriz de Evaluación de Factores Internos (MEFI). ............................................56

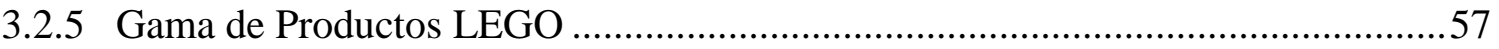

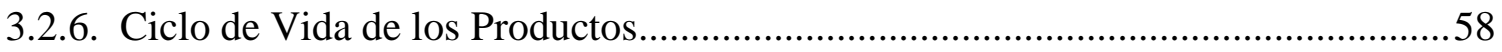




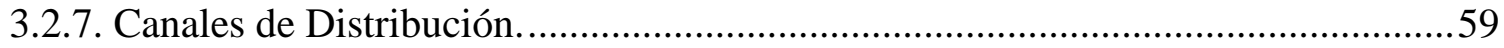

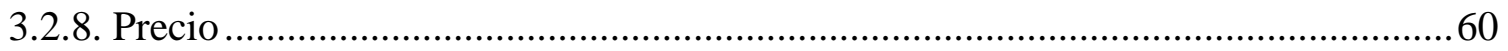

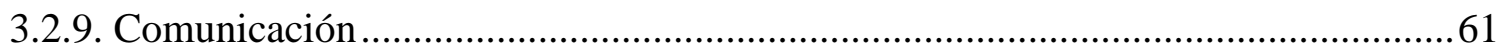

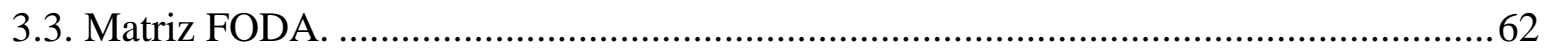

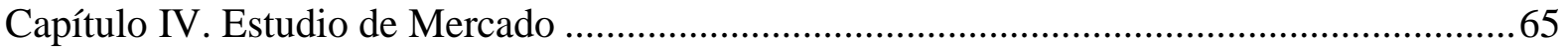

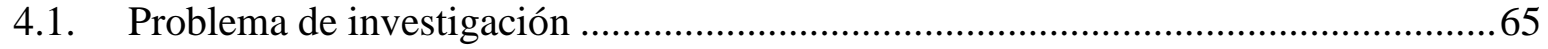

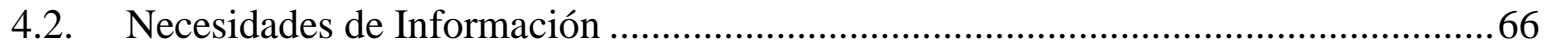

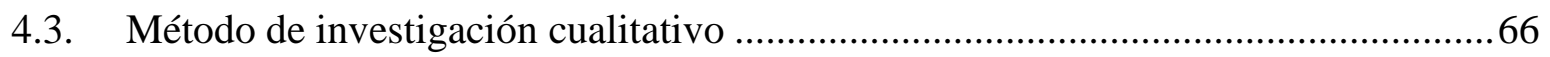

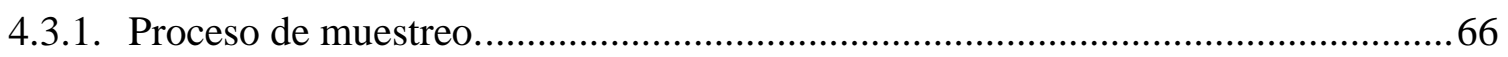

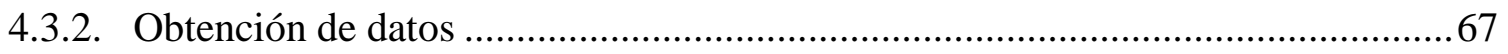

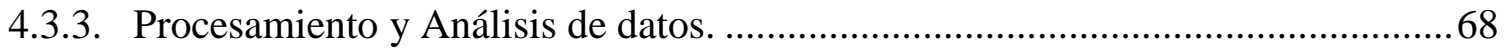

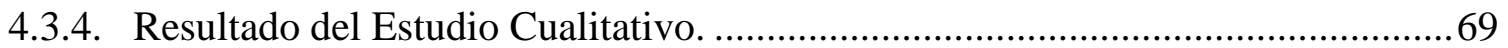

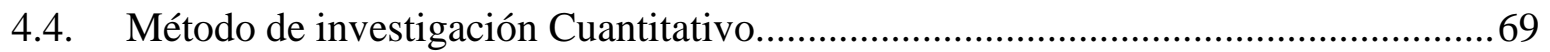

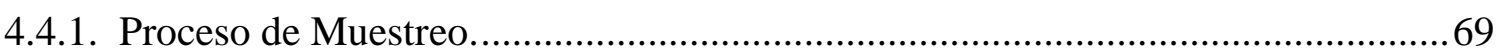

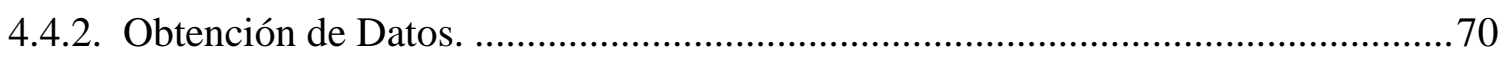

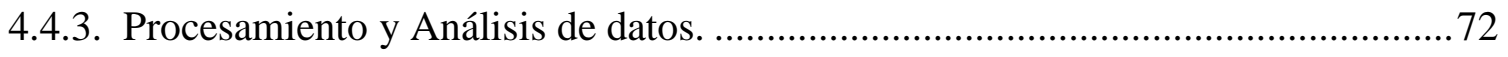

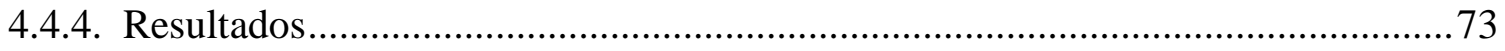

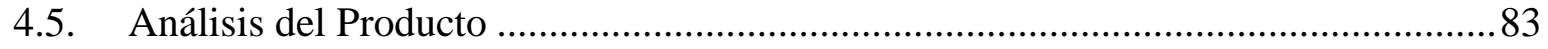

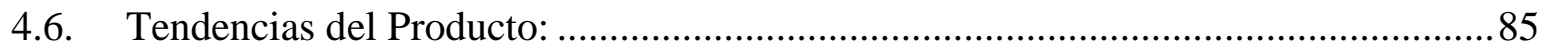

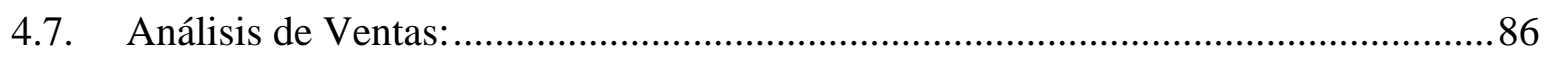

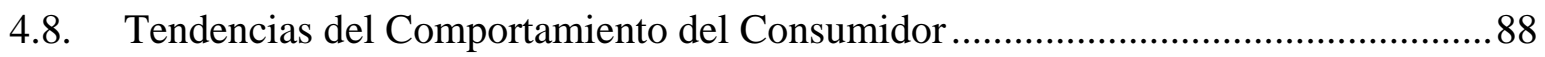

4.9. Tendencias de Medios, Distribución y Precios: ........................................................ 88

Capítulo V. Formular Objetivos de Marketing ..................................................................... 90

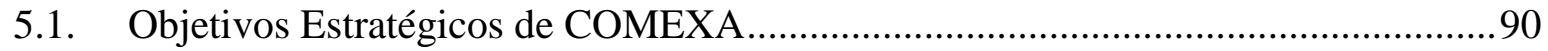

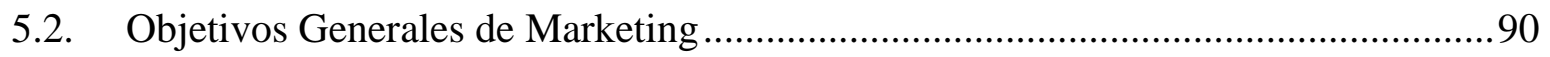

Capítulo VI. Formular las Estrategias de Marketing .............................................................92

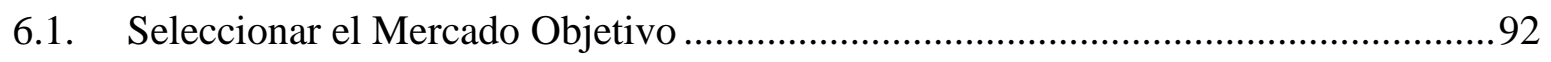

6.2. Desarrollar el Posicionamiento del Producto .......................................................... 92

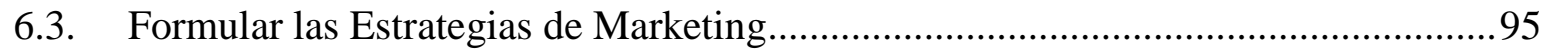

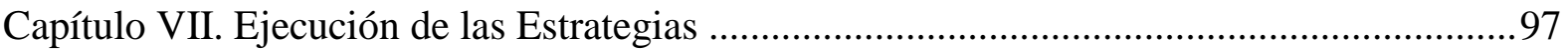

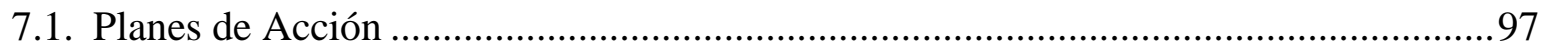

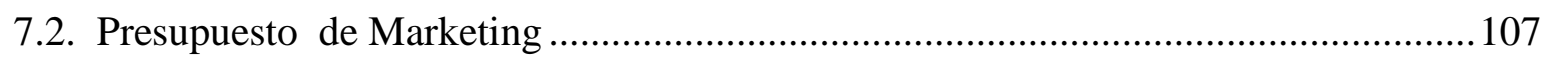

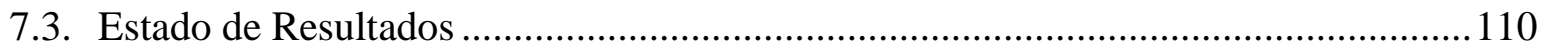




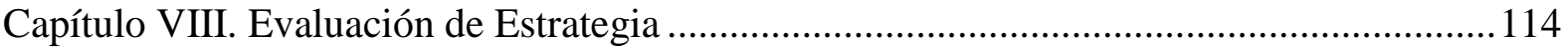

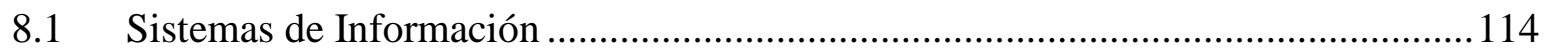

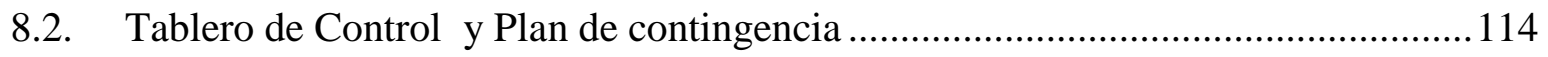

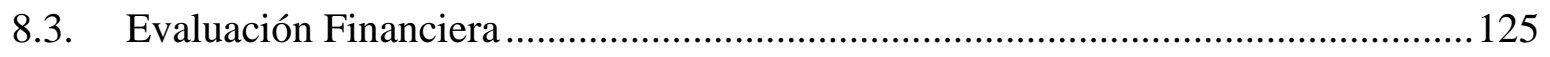

Capítulo IX. Conclusiones y Recomendaciones .................................................................129

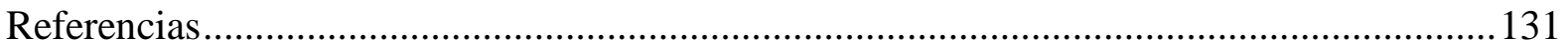

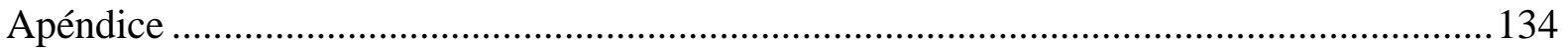

Apéndice 1: Guía de indagación del grupo de enfoque. ................................................ 134

Apéndice 2: Transcripción del grupo de enfoque. .......................................................... 137

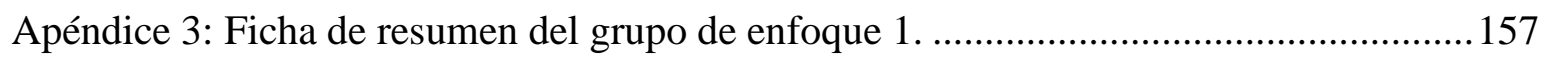

Apéndice 4: Ficha de resumen grupo de enfoque 2 ......................................................... 159

Apéndice 5: Cuestionario para la encuesta de LEGO...................................................... 161 


\section{Lista de Tablas}

Tabla 1 Histórico de Ventas de COMEXA 2011-2015 expresado en soles.

Tabla 2 Ventas del total de tiendas de COMEXA expresado en soles.

Tabla 3 Ventas del Canal Mayorista de COMEXA, expresado en soles

Tabla 4 Resultado Operativo de Comexa 2010 -2015

Tabla 5 Crecimiento por Canal en Soles.

Tabla 6 Crecimiento por Canal en \%

Tabla 7 Proyección de Ventas de LEGO en Soles

Tabla 8 Participación de LEGO en el mercado.

Tabla 9. Análisis del Sector Retail en el mundo. .35

Tabla 10 Segmentos del Sector Juguetes.

Tabla 11 Segmentos de los productos LEGO.

Tabla 12 Matriz Mckinsey/GE - Atractivo del Sector.

Tabla 13 Matriz Mckinsey/GE Posición Competitiva......

Tabla 14 Matriz de Evaluación de Factores Externos - MEFE. 48

Tabla 15 Matriz de Evaluación de Factores Internos .57

Tabla 16 Precio Promedio y Margen por Segmentos.

Tabla 17 Margen por Canal.

Tabla 18 Matriz FODA - Fortalezas.

Tabla 19 Matriz FODA - Oportunidades.

Tabla 20 Matriz FODA - Debilidades

Tabla 21 Matriz FODA - Amenazas......

Tabla 22 Potencial del Mercado para los productos de la marca LEGO.

Tabla 23 Mapa de Atributos de los productos de la marca LEGO. .94

Tabla 24 Resumen de Objetivos, Estrategias y Acciones .98 
Tabla 25 Calendario y Presupuesto. 108

Tabla 26 Estado de Resultados Escenario sin Plan de Marketing. 111

Tabla 27 Estado de Resultados Escenario Pesimista

Tabla 28 Estado de Resultados Escenario Esperado.

Tabla 29 Estado de Resultados Escenario Optimista.

Tabla 30 Tablero de Control - LEGO Friends/LEGO Girls.

Tabla 31 Tablero de Control - LEGO Nexo Knight.

Tabla 32 Plan de Contingencia - Productos Estrellas

Tabla 33 Plan de Contingencia - Nueva Tienda LEGO STORE.

Tabla 34 Plan de Contingencia - Mall Virtual. 120

Tabla 35 Plan de Contingencia - Canal Web.

Tabla 36 Plan de Contingencia - Show Room

Tabla 37 Plan de Contingencia - App LEGO.

Tabla 38 Plan de Contingencia - Emailing.

Tabla 39 Plan de Contingencia - Precio.

Tabla 40 Evaluacion Financiera Sin Plan de Marketing

Tabla 41 Evaluación Financiera Pesimista. 126

Tabla 42 Evaluación Financiera Esperado. 126

Tabla 43 Escenario Pesimista vs. Escenario sin Plan de Marketing.

Tabla 44 Escenario Esperado vs. Escenario Sin Plan de Marketing. 


\section{Lista de Figuras}

Figura 1. Organigrama de la Empresa COMEXA 2016.

Figura 2. Porcentaje comparativo de ventas Mayoristas y Minoristas ..................................20

Figura 3. Porcentaje de Ventas Mayoristas vs. Minoristas 2011 -2015..................................20

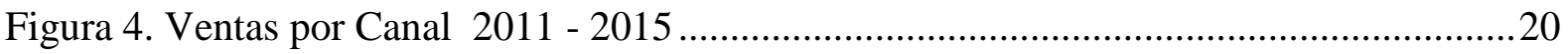

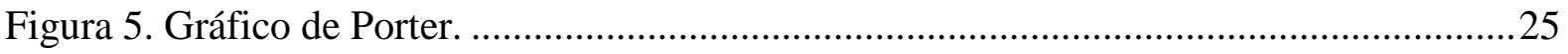

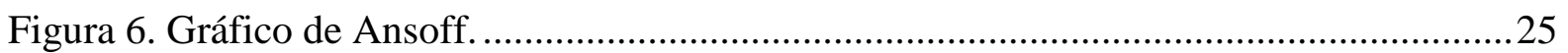

Figura 7. Producto Bruto Interno y Demanda Interna 2008 I - 2015 III. ...............................22

Figura 8. Inflación Esperada 2016 en la Alianza del Pacifico................................................28

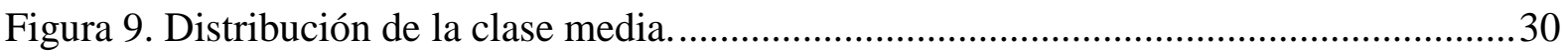

Figura 10. Nivel de atracción por país según Indice global de Desarrollo Retail 2014. .........36

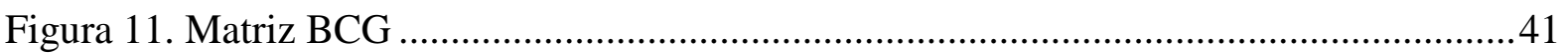

Figura 12.Matriz BCG para los productos de la marca LEGO............................................ 43

Figura 13. Matriz Mckinsey para los productos de la marca LEGO. ....................................46

Figura 14. Matriz amplitud y Profundidad de los productos de la marca LEGO...................58

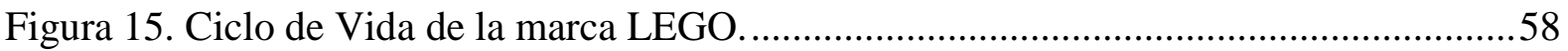

Figura 16. Canales de Distribución de la marca LEGO...........................................................59

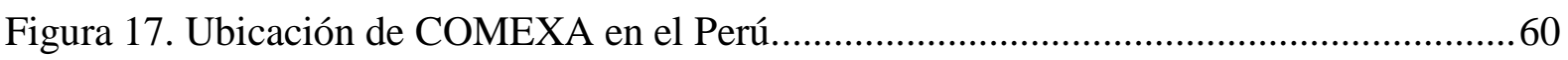

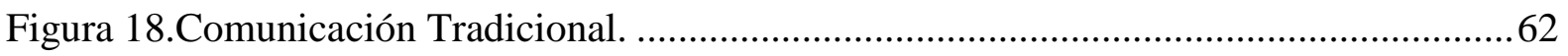

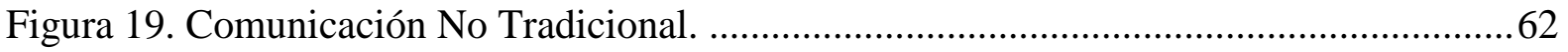

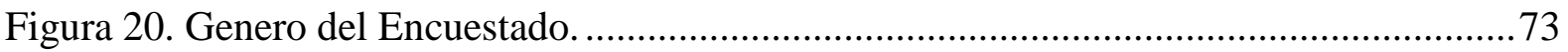

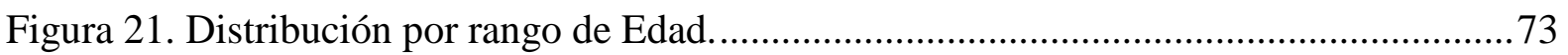

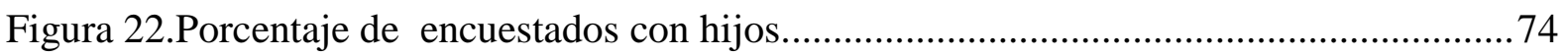

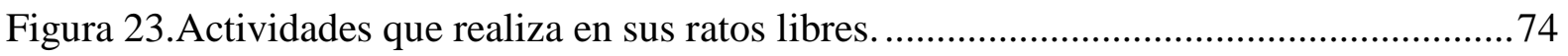

Figura 24. Actividades que realiza vs. tienen hijos. ......................................................... 74 


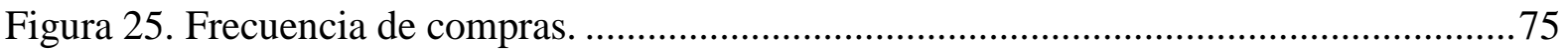

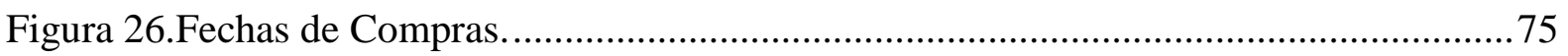

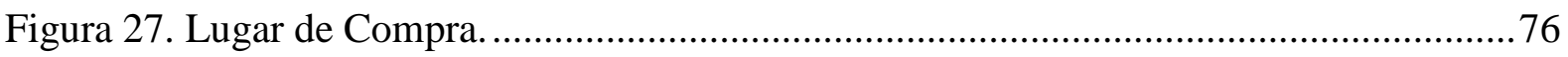

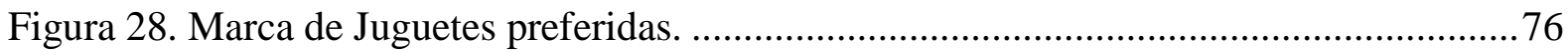

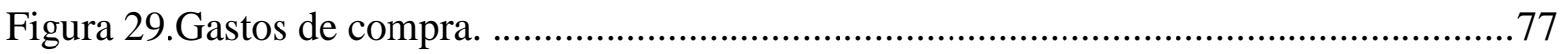

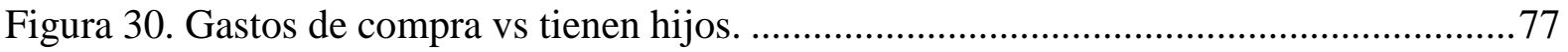

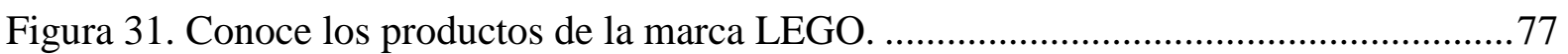

Figura 32. Compro los productos de la marca LEGO. ........................................................ 78

Figura 33. Lugar de compra de los productos de la marca LEGO. .................................... 78

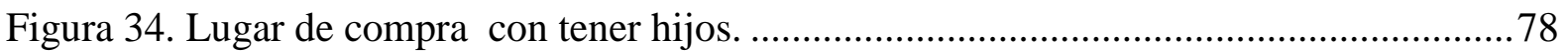

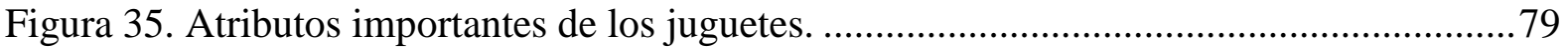

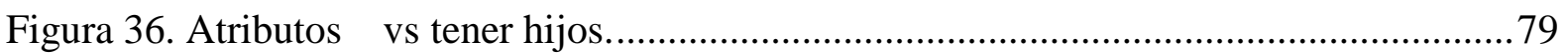

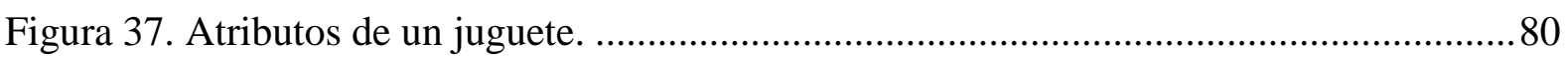

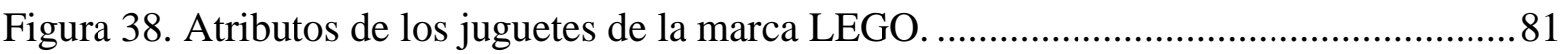

Figura 39. Atributos de los productos de la marca LEGO vs. tener hijos. .............................81

Figura 40. Intensión de compra de los productos de la marca LEGO. .................................. 81

Figura 41. Atributos de los productos de la marca LEGO..................................................... 83

Figura 42. Distribución de edad de los encuestados que lo consideran que LEGO es un

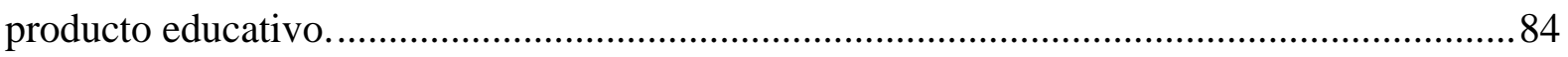

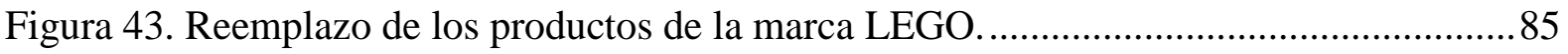

Figura 44. Razones por que no compro productos de la marca LEGO. ................................ 85

Figura 45. Mapa de atributos de los productos de la marca LEGO.......................................94

Figura 46. Mapa perceptual de los productos de la marca LEGO. .......................................95

Figura 47. Fotografía enmarcada con su personaje favorito............................................99 


\section{Introducción}

El presente trabajo ha sido elaborado como proyecto final para la maestría de marketing y dirección comercial de la universidad San Ignacio de Loyola - Esic para poder llevar a la práctica gran parte de los conocimientos adquiridos durante estos dos años de estudio. Comexa es una empresa de capitales extranjeros, que desde hace más de 5 años, comercializa la marca LEGO en el Perú y, siendo esta marca lo que en el marketing conocemos como Love Mark, es sumamente interesante poder desarrollar un plan de mercadeo del cual hasta ahora, LEGO carece.

A de más de la falta de planificación de marketing, tenemos un proceso de desaceleración de la economía en el Perú, lo cual, junto con ser una marca que se comercializa legalmente hace muy poco tiempo, colocan a LEGO en una situación frágil si no se planifica estratégicamente, para lograr posicionar la marca definitivamente en el mercado peruano.

Este trabajo está dividido en ocho capítulos y anexos, el primer capítulo trata sobre las generalidades de la investigación, el problema u oportunidad de negocio, así como los objetivos tanto generales como específicos. Después, en el capítulo dos, pasamos a hablar sobre la empresa, antecedentes, estructura, situación en el mercado, etc. En el capítulo tres, hacemos el análisis de la situación de la empresa y de la unidad estratégica de negocio Lego, en este capítulo se puede encontrar el análisis PESTE, un análisis interno, etc. Luego, ya en el capítulo cuatro, entramos en la investigación de mercado, tanto cualitativa como cuantitativa. En el capítulo cinco, se formulan los objetivos, tanto estratégicos como los de marketing para la empresa. En el capítulo seis, se plantean las estrategias, en el siete se planea la ejecución de dichas estrategias y en el capítulo ocho se hace la evaluación y se plantean los planes de contingencia. 
Finalmente, solo nos queda agradecer a la universidad, los profesores, los compañeros de estudio y nuestras familias, por la posibilidad de seguir creciendo profesionalmente gracias a sus conocimientos, aportes y apoyo incondicional en esta gran aventura que llamamos marketing. 


\section{Capítulo I. Generalidades}

\subsection{Antecedentes de la Investigación}

Comercial e Industrial SILFA S.A., fue fundada en el año en 1982 en Chile. En su plan de expansión, inició operaciones comerciales en el Perú bajo el nombre de COMEXA en el año 1999. COMEXA cuenta con dos unidades de negocios, UEN de bebes y UEN de Juguetes. Dentro de la UEN de Bebés, se comercializa las marcas Infanti, Chicco, Safety, Britax, Bebe Confort, entre otras. Para la UEN de Juguetes, COMEXA comercializa, Chicco Toys, Infanti Toys, Intex, Lego, Leap Frog entre otras. COMEXA, maneja dos canales de distribución para llegar a su consumidor final; un canal directo, compuesto por su propia red de tiendas y un canal de intermediación que lo compone (el canal moderno y canal tradicional).

Actualmente, la expansión geográfica de COMEXA se ha desarrollado de forma empírica, basándose en los indicadores de alta rentabilidad que la empresa ha tenido durante los últimos años. Esto ha generado, que la empresa empiece a crecer sin tener en cuenta un Plan de Marketing integral y sistémico, perdiendo así, oportunidades de incubación de negocios en nuevos nichos de mercado.

COMEXA, en los últimos 3 años ha logrado crecer, $16 \%, 16 \%$ y 18\% respectivamente, sin embargo, ese importante crecimiento ha sido dado, en parte, por el buen trabajo de desarrollo que se ha dado en la UEN de Bebés, con un crecimiento promedio de $22 \%$, contra un $11 \%$ de la UEN de Juguetes.

Al analizar, cuál era la marca de la UEN de Juguetes con mayor potencial para desarrollar, se pudo observar que la marca LEGO, era la que había conseguido, a pesar de un pobre plan de desarrollo, los mejores resultados en cuanto a crecimientos y rentabilidad. 
A nivel compañía, LEGO representa el 33\% de las ventas. Esta marca, pasó de tener una participación en la UEN de Juguetes de 73 \% en el 2012 a 80\% en el 2015.

El crecimiento en las ventas de LEGO se ha dado principalmente por el desarrollo de su canal propio, ya sea a través de la cadena de tiendas Baby Infanti Store o la cadena de tiendas Lego Store con un crecimiento promedio anual de $22 \%$.

Es importante mencionar que actualmente los productos de la marca Lego se comercializan en las 25 tiendas Baby Infanti Store (ubicadas a nivel nacional) y 3 tiendas Lego Store (solo en Lima).

Por otro lado es en el canal moderno y tradicional, donde la marca no ha logrado despegar como se espera, teniendo un crecimiento de solo $2 \%$ en los últimos 4 años.

\subsection{Determinación del Problema u Oportunidad}

Actualmente COMEXA, para la marca LEGO en el Perú, no maneja un Plan de Marketing definido y estructurado, por ello, LEGO ha tenido un pobre rendimiento en sus canales tradicionales y modernos; sin embargo, y a pesar de lo mencionado, en el canal propio, sobre todo en las tiendas LEGO STORE, la marca ha registrado importantes crecimientos, lo que nos indica un consumidor con mucho interés en adquirir los productos LEGO en sus tiendas especializadas.

Por un lado, el hecho de que la empresa no cuente con un Plan de Marketing definido, puede ser riesgoso ya que una adecuada gestión comienza siempre por una buena planificación.

\subsection{Justificación del Proyecto}

Los motivos que llevan a realizar este Plan de Marketing se basan por un lado, en la necesidad de llevar a cabo una estrategia clara y contundente, para la expansión de mercado de los productos de la marca LEGO a través de sus dos canales de distribución, repotenciando el canal moderno, y a la vez, construyendo un crecimiento sólido en torno al canal propio, el 
mismo que no debe descuidarse en vista que cada vez se hace más difícil cautivar a nuestros actuales clientes y para la compañía es importante continuar con la consolidación del mercado limeño.

Por otro lado, este plan conlleva una justificación académica, ya que nos permitirá aplicar todo lo aprendido durante los cursos de la maestría. Esto generará un beneficio académico, ya que permitirá a los estudiantes ser capaces de relacionar los objetivos de marketing con la estrategia de la empresa, así como desarrollar las capacidades directivas y funcionales para diseñar, implantar y controlar con éxito un Plan de Marketing.

\subsection{Objetivos Generales y Específicos}

1. Objetivo General.

Desarrollar un Plan de Marketing para los productos de la marca LEGO en el Perú.

2. Objetivos Específicos.

- Realizar un análisis externo e interno de COMEXA

- Desarrollar una investigación de mercados.

- Formular estrategias de marketing.

- Formular criterios para la implementación y control de las estrategias.

- Desarrollar un análisis financiero para el plan de marketing

\subsection{Alcances y Limitaciones de la Investigación}

Este Plan de Marketing estará enfocado en incrementar la venta de los productos de la marca LEGO en el Perú, principalmente en Lima.

Las limitaciones surgen en el momento de aplicar el plan de marketing en las provincias pequeñas del Perú, ya que el comportamiento del consumidor de estas provincias chicas, dista mucho del comportamiento del consumidor limeño, por ello el desarrollo de este 
plan estará enfocado principalmente en lograr potenciar las ventas de marca en Lima, para luego optar por hacer algún ingreso a provincias. 


\section{Capítulo II. La Empresa}

\subsection{Antecedentes de la Empresa}

Comercial e Industrial SILFA S.A., fue fundada en el año en 1982 en Chile. En su plan de expansión, inició operaciones comerciales en el Perú bajo el nombre de COMEXA en el año 1999. COMEXA, ingresó al mercado peruano, con su Unidad Estratégica de Negocios enfocada en el mercado de Bebés, con su marca bandera Infanti. En el año 2003, COMEXA opta por manejar un nuevo portafolio de productos, bajo una nueva UEN, es entonces que la empresa empieza a comercializar juguetes, usando el canal tradicional como plataforma comercial, entre las principales marcas figuraban, Leap Frog, Chicco Toys, Intex, entre otras.

COMEXA en el Perú maneja 2 tipos de formatos de tiendas propias a nivel nacional, un formato de tiendas LEGO Store dirigida a niños y un formato de tiendas Baby Infanti Store dirigida básicamente a madres con hijos menores de 3 años.

El Grupo LEGO es una compañía privada con sede en Billund (Dinamarca) y sus oficinas más importantes están ubicadas en Enfield (Estados Unidos), Londres (Reino Unido), Shanghái (China) y Singapur. Desde su fundación en 1932 por Ole Kirk Kristiansen y a partir del icónico ladrillo $\mathrm{LEGO}^{\circledR}$, la empresa se ha convertido en una de las líderes internacionales en la fabricación de juguetes (LEGO).

A partir del año 2011, COMEXA y Elite Brand, representante en Latinoamérica de la marca Danesa Lego, se unen como socios estratégicos para comercializar en el Perú la marca Lego. Es a partir de dicho año, que se apertura la primera tienda Lego Store en el Perú, ubicada en el centro comercial Jockey Plaza. Esta tienda en su primer año de operación, logro facturar casi tres millones de soles, convirtiéndose en la segunda tienda más importante para COMEXA. Esto conllevo a la apertura, en los años 2012 y 2015 de dos tiendas más, en los centros comerciales Plaza San Miguel y Plaza Lima Norte respectivamente, ambas tiendas 
lograron duplicar las expectativas comerciales de la empresa. Esto permitió a la marca LEGO solo en sus LEGO STORE crecer en promedio 20\% en el periodo 2012-2015.

Además de las tres tiendas LEGO STORE, la marca Lego se comercializa en el Perú en las tiendas Baby Infanti, propiedad de COMEXA que cuenta con 25 locales (20 en Lima y 5 en provincias), en las grandes tiendas por departamento como son SAGA, RIPLEY, OESHLE y PARIS, los principales supermercados como METRO, WONG, PLAZA VEA y TOTTUS y en el canal tradicional, en donde se negocia con grandes mayoristas de juguetes y tiendas especializadas.

\subsection{Estructura Organizacional Actual de la Empresa}

En el organigrama de COMEXA (ver Figura 1), podemos ver que el área de Marketing y Comercial dependen directamente de la Gerencia General.

La gestión de Marketing de la empresa, recae en dos divisiones, la división de Bebes con su marca estrella Infanti, y la división Juguetes que tiene como su principal marca a LEGO. La comercialización o venta de todo el portafolio de los productos de COMEXA recaen sobre los jefes de sus dos canales de distribución, el canal mayorista y el canal Retail.

El Jefe del canal Retail, se encarga del manejo de las tiendas, tanto de Infanti, como LEGO Store y el Gerente de Canal Mayorista, se encarga del manejo de los clientes del canal tradicional y del canal moderno. 


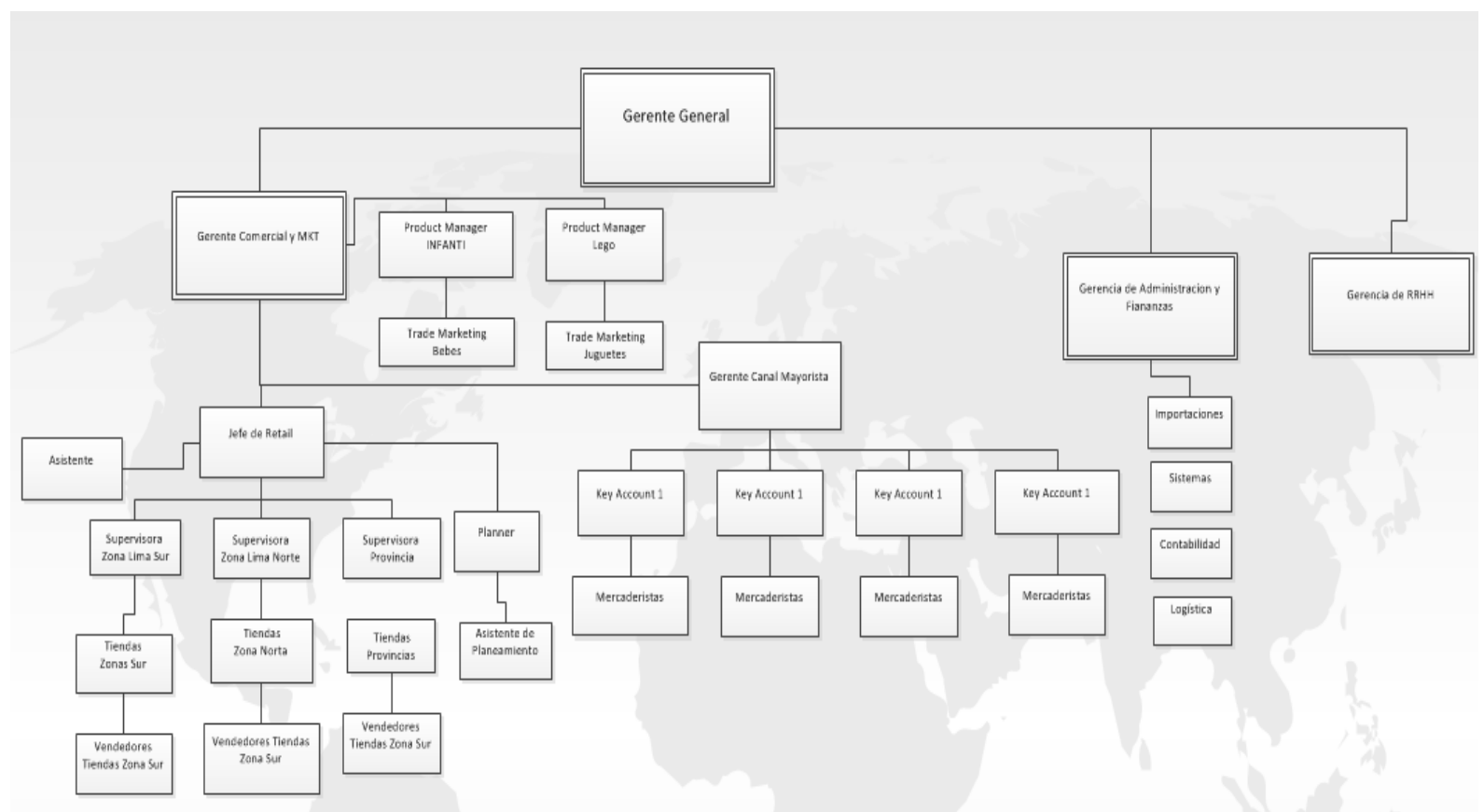

Figura 1. Organigrama de la Empresa COMEXA 2016

\subsection{Situación de Mercado y Financiera Actual de la Empresa}

COMEXA ha venido creciendo de manera continua en los últimos año, solo en el 2015, logro facturar SIN IGV, 76 millones de soles (ver Tabla 1).

Tabla 1

Histórico de Ventas de COMEXA 2011-2015 expresado en soles.

\begin{tabular}{lrrrrr}
\hline \multirow{2}{*}{ Canal } & \multicolumn{5}{c}{ Año } \\
\cline { 2 - 6 } & 2011 & 2012 & 2013 & 2014 & 2015 \\
\hline Mayorista & $16,228,537$ & $23,197,834$ & $23,750,768$ & $21,915,554$ & $22,361,293$ \\
Minorista & $18,760,778$ & $25,445,405$ & $32,603,991$ & $43,193,069$ & $54,174,558$ \\
Total & $34,989,315$ & $48,643,239$ & $56,354,759$ & $65,108,623$ & $76,535,850$ \\
\hline
\end{tabular}

Nota: Información interna de COMEXA.

Como podemos observar en la Tabla 1, los canales de distribución con los cuales trabaja Comexa para comercializar sus productos de dividen en Mayorista (Tiendas especializadas, Supermercados, Tiendas por departamento) y Minorista (tiendas propias Infanti y LEGO Store). A continuación, pasaremos a describir cada uno de estos canales y su importancia para la empresa y los objetivos de marketing. 


\subsubsection{Canal Minorista.}

La empresa tiene claramente identificado, que el desarrollo se está dando por su propia red de distribución o tiendas propias.

Esta canal, ha tenido crecimientos por encima del 30\% en los últimos 4 años (ver Tabla 1), mostrando así la preferencia cada vez más marcada de los consumidores a comprar en tiendas especializadas como las que manejamos en este canal (LEGO STORE-BABY INFANTI STORE).

En la Tabla 2 podemos revisar las ventas hechas por este canal en el último ejercicio, y detallado por cada una de las tiendas propias.

\subsubsection{Canal Mayorista (Moderno y Tradicional).}

El canal Mayorista, tiene bajo su estructura a las tiendas modernas compuestas por las grandes cadenas Retail, como Saga, Ripley, Oeshle, Wong, Metro, Plaza Vea, Tottus, así como el canal tradicional, compuesto por comerciantes que tienen grandes tiendas de juguetes en distintos punto de Lima y provincias, estas tiendas tienen un comportamiento en mucho de los casos como sub-distribuidores.

Este canal ha mostrado crecimientos muy pequeños, incluso en el 2014 tuvo un decrecimiento de $8 \%$, respecto a la venta que hizo en el 2013 y en el periodo 2015 solo creció 2\% (ver Tabla 1). Si revisamos las cifras del canal Mayorista Tradicional, podemos ver que su caída no se detiene desde el año 2012 con un promedio de decrecimiento anual del 4\% (ver Tabla 3). 
Tabla 2

Ventas del total de tiendas de COMEXA expresado en soles.

\begin{tabular}{|c|c|c|}
\hline Level 03 & Level 05 & 2015 \\
\hline \multicolumn{3}{|c|}{ ADMIN. CENTRAL TIENDAS } \\
\hline \multirow[t]{25}{*}{ BIS } & SALAVERRY & \\
\hline & ESPINAR & S/. 1,666,571 \\
\hline & BENAVIDES & $S / .1,220,436$ \\
\hline & JOCKEY PLAZA & S/. 3,225,692 \\
\hline & MEGA PLAZA & S/. 1,752,522 \\
\hline & TRUJILLO & $S / .2,448,799$ \\
\hline & BELLAVISTA & S/. 1,530,503 \\
\hline & SAN MIGUEL & S/. 3,220,980 \\
\hline & AREQUIPA & $S / .1,576,612$ \\
\hline & EL POLO & S/. 1,296,219 \\
\hline & MEGA PLAZA 2 & S/. 2,652,737 \\
\hline & JOCKEY PLAZA PREMIUM & $S / .1,857,210$ \\
\hline & CAJAMARCA & $S / .616,318$ \\
\hline & ICA & $S / .1,045,486$ \\
\hline & PRIMAVERA & $S / .1,984,520$ \\
\hline & C.C. SAN BORJA & S/. $2,263,370$ \\
\hline & CHICLAYO & S/. 1,648,248 \\
\hline & REAL SALAVERRY & S/. 3,111,955 \\
\hline & SANTA ANITA & S/. 1,628,906 \\
\hline & PIURA & $S / .1,329,611$ \\
\hline & LARCOMAR & $S / .1,080,119$ \\
\hline & 28 DE JULIO & S/. 725,053 \\
\hline & PLAZA LIMA NORTE & S/. 2,620,641 \\
\hline & BIS BRASIL & $S / .1,205,341$ \\
\hline & CUSCO & S/. 90,428 \\
\hline \multirow[t]{4}{*}{ LEGO } & JOCKEY LEGO & S/. 5,688,360 \\
\hline & LEGO SAN MIGUEL & \\
\hline & LEGO 3 SAN MIGUEL & S/. 3,322,539 \\
\hline & LEGO LIMA & $S / .1,414,432$ \\
\hline OUTLET & OUTLET & $S / .1,404,312$ \\
\hline EVENTOS & EVENTOS & \\
\hline COCINARTE & COCINARTE JOCKEY PLAZA & \\
\hline INTERNET & WEB BIS & S/. 546,639 \\
\hline Total & & $S / .54,174,558$ \\
\hline
\end{tabular}

Nota: Información interna de COMEXA.

Tabla 3

Ventas del Canal Mayorista de COMEXA, expresado en soles

\begin{tabular}{lrrrr}
\hline \multirow{2}{*}{ Canal } & \multicolumn{4}{c}{ Año } \\
\cline { 2 - 5 } & \multicolumn{1}{c}{2012} & 2013 & \multicolumn{1}{c}{2014} & \multicolumn{1}{c}{2015} \\
\hline Moderno & $\mathrm{S} / .14,926,054$ & $\mathrm{~S} / .15,123,040$ & $\mathrm{~S} / .14,303,964$ & $\mathrm{~S} / .15,037,441$ \\
Tradicional & $\mathrm{S} / .8,209,091$ & $\mathrm{~S} / .8,086,825$ & $\mathrm{~S} / .7,351,831$ & $\mathrm{~S} / .7,156,723$ \\
\hline Total & $\mathrm{S} / .23,135,145$ & $\mathrm{~S} / .23,209,865$ & $\mathrm{~S} / .21,655,795$ & $\mathrm{~S} / .22,194,164$ \\
\hline
\end{tabular}

Nota: Información interna de COMEXA. 


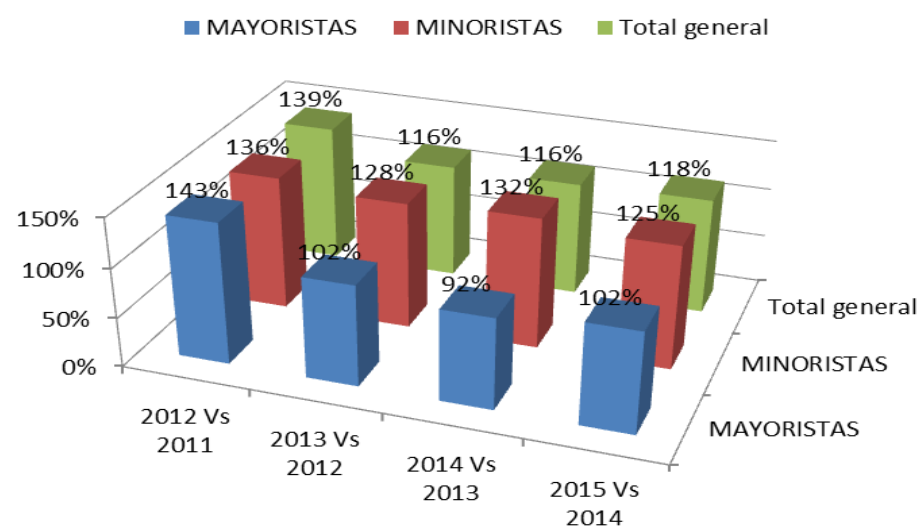

Figura 2. Porcentaje comparativo de ventas Mayoristas y Minoristas

Este crecimiento del canal Minorista (tiendas propias), se ve claramente en la participación que han tenido sobre las ventas de la compañía. Pasando de tener una participación de $54 \%$ en el 2011 a 71\% en el 2015 (ver Figuras 2, 3 y 4).

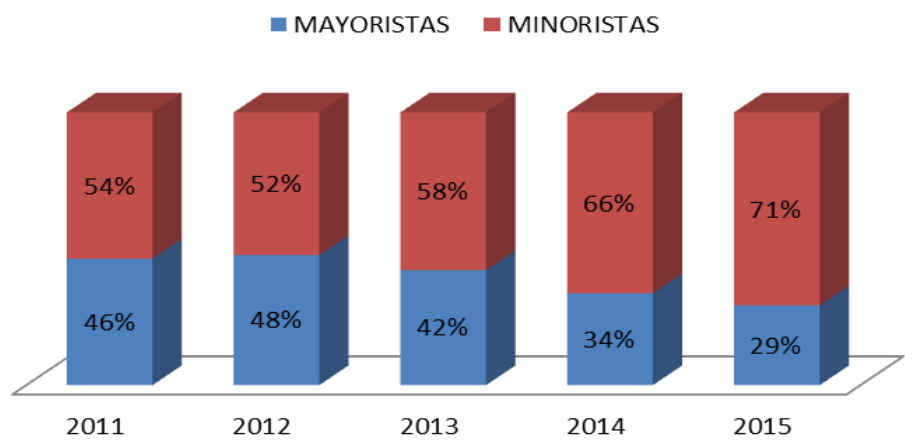

Figura 3. Porcentaje de Ventas Mayoristas vs. Minoristas 2011 -2015

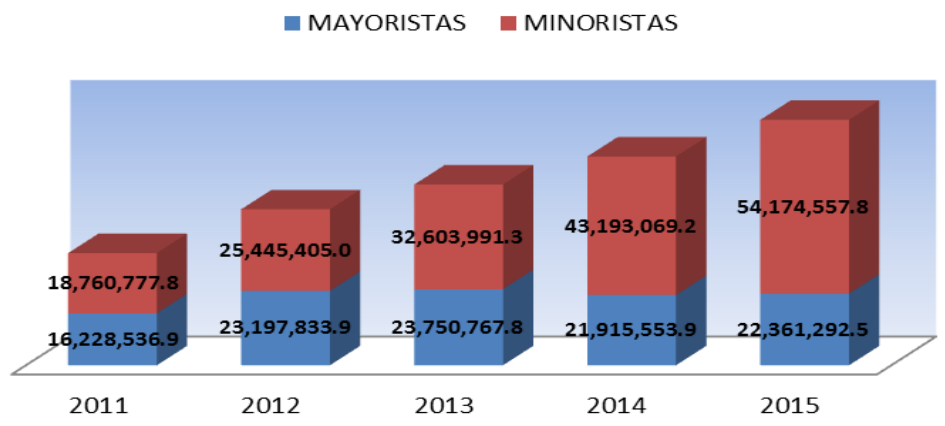

Figura 4. Ventas por Canal 2011 - 2015 
COMEXA financieramente ha venido obteniendo buenos resultados, con crecimientos importantes en su resultado operativo (ver Tabla 4).

Tabla 4

Resultado Operativo de Comexa 2010 -2015

\begin{tabular}{lrrrrrr}
\hline Año & 2010 & 2011 & 2012 & 2013 & 2014 & 2015 \\
\hline COMEXA & $25.8 \%$ & $25.7 \%$ & $25.4 \%$ & $25.3 \%$ & $24.7 \%$ & $24.6 \%$ \\
EBITDA S/. & - & $8,992,254$ & $12,355,383$ & $14,257,754$ & $16,081,830$ & $18,827,819$ \\
\hline
\end{tabular}

Nota: Información interna de COMEXA.

Este resultado, se ha conseguido por varios factores, entre ellos, el importante crecimiento del Canal minorista, la buena relación que se tiene Ingreso versus costo de venta (Margen), y una correcta administración de los gastos, habiendo en muchos casos desarrollado proyectos para la optimización de los recursos y para la generación de mayores ventas.

COMEXA en el 2016 espera llegar a facturar más de 100 millones de soles (Inc. IGV), basando su estrategia de crecimiento en el canal minorista o de tiendas propias. UEN LEGO

Las ventas de la marca LEGO en el Perú, han venido creciendo de manera sostenida en los últimos años (ver Tabla 5 y 6), sin embargo cuando analizamos la venta por canales, podemos observar un decrecimiento en algunos años para el canal moderno. Asimismo, se ha podido detectar que la tendencia o las proyecciones que se esperan en el 2016, son de desaceleración (ver Tabla 7), ya que de venir mostrando crecimientos por encima del $20 \%$ solo se está proyectando cerrar el 2016 con un crecimiento del 8\%. Esta desaceleración, tiene varias variables, desde el poco conocimiento del consumidor de LEGO, hasta la poca planificación para elaborar un plan de marketing que parta de un análisis profundo de las fortalezas, debilidades, oportunidades y amenazas de la unidad estratégica de negocios. 
Tabla 5

Crecimiento por Canal en Soles.

\begin{tabular}{lccrrrr}
\hline Level 02/ Año & \multicolumn{1}{c}{2011} & \multicolumn{1}{c}{2012} & \multicolumn{1}{c}{2013} & \multicolumn{1}{c}{2014} & \multicolumn{1}{c}{2015} & \multicolumn{1}{c}{2016} \\
\hline B2B (Moderno) & $5,895,718$ & $8,741,017$ & $8,100,262$ & $7,745,792$ & $8,971,819$ & $9,420,409$ \\
B2C (Propio) & $5,422,589$ & $8,398,247$ & $9,087,953$ & $12,782,775$ & $16,355,772$ & $17,991,348$ \\
\hline Total & $11,318,307$ & $17,139,264$ & $17,188,215$ & $20,528,567$ & $25,327,591$ & $27,411,757$ \\
\hline
\end{tabular}

Nota: Información interna de COMEXA.

Tabla 6

Crecimiento por Canal en \%

\begin{tabular}{|c|c|c|c|c|c|c|}
\hline Level 02/ Año & 2011 & 2012 & 2013 & 2014 & 2015 & 2016 \\
\hline B2B (Moderno) & & $148 \%$ & $93 \%$ & $96 \%$ & $116 \%$ & $105 \%$ \\
\hline B2C (Propio) & & $155 \%$ & $108 \%$ & $141 \%$ & $128 \%$ & $110 \%$ \\
\hline Total \% & & $151 \%$ & $100 \%$ & $119 \%$ & $123 \%$ & $108 \%$ \\
\hline
\end{tabular}

Nota: Información interna de COMEXA.

Tabla 7

Proyección de Ventas de LEGO en Soles

\begin{tabular}{|c|c|c|c|c|c|c|c|c|c|}
\hline \multirow[b]{2}{*}{ Canal/Año } & \multirow[b]{2}{*}{2011} & \multirow[b]{2}{*}{2012} & \multirow[b]{2}{*}{2013} & \multirow[b]{2}{*}{2014} & \multirow[b]{2}{*}{2015} & \multirow[b]{2}{*}{2016} & \multicolumn{3}{|c|}{ Proyeccion Sin Plan de Marketing } \\
\hline & & & & & & & 2017 & 2018 & 2019 \\
\hline Mayorista & $\mathrm{S} / .5,895,718$ & $S / .8,741,017$ & $\mathrm{~S} / .8,100,262$ & S/. 7,745,792 & S/. 8,971,819 & S/. 9,420,409 & S/. 10,265,704 & S/. 10,984,303 & S/. $11,643,361$ \\
\hline Minorista & $S / .5,422,589$ & S/. 8,398,247 & S/. 9,087,953 & S/. $12,782,775$ & S/. $16,355,772$ & S/. $17,991,350$ & S/. $19,064,878$ & $S / .20,399,420$ & S/. 21,623,385 \\
\hline Total S/. & $S / .11,318,306$ & $S / .17,139,264$ & $S / .17,188,216$ & S/. 20,528,567 & $S / .25,327,591$ & S/. 27,411,759 & S/. 29,330,582 & S/. $31,383,723$ & $S / .33,266,746$ \\
\hline Total \% & & $151 \%$ & $100 \%$ & $119 \%$ & $123 \%$ & $108 \%$ & $107 \%$ & $107 \%$ & $106 \%$ \\
\hline
\end{tabular}

El market share de LEGO ha venido creciendo en los últimos años, siendo de $7.1 \%$ en el año

2015 (ver Tabla 8). Esta participación ha sido la más alta que ha tenido LEGO en los últimos años, según las proyecciones del crecimiento de mercado, a partir del 2016 vendría un decrecimiento de market share de LEGO debido al que el crecimiento del mercado va ser más alta que el crecimiento de LEGO 
Tabla 8

Participación de LEGO en el mercado.

\begin{tabular}{cccc}
\hline Año & LEGO & Total & Market Share \\
\hline 2011 & S/. 11,318,306 & S/. 262,150,000 & $4.3 \%$ \\
2012 & S/. 17,139,264 & S/. 283,122,000 & $6.1 \%$ \\
2013 & S/. 17,188,216 & S/. 305,771,760 & $5.6 \%$ \\
2014 & S/. 20,528,567 & S/. 330,233,501 & $6.2 \%$ \\
2015 & S/. 25,327,591 & S/. 356,652,181 & $7.1 \%$ \\
2016 & S/. 27,411,759 & S/. 410,150,008 & $6.7 \%$ \\
2017 & S/. 29,330,582 & S/. 471,672,509 & $6.2 \%$ \\
2018 & S/. 31,383,723 & S/. 542,423,386 & $5.8 \%$ \\
2019 & S/. 33,266,746 & S/. 623,786,893 & $5.3 \%$ \\
\hline
\end{tabular}

Nota: Información interna de COMEXA.

\subsection{Visión, Misión y Valores de la Empresa}

\section{Visión}

Ser la mejor empresa comercializadora en Latinoamérica de productos para bebés y niños.

\section{Misión.}

Llevar a las familias peruanas los mejores artículos para bebés y niños que permitan desarrollar sus habilidades y creatividad, teniendo como fundamento ser responsables con el planeta, la sociedad y los colaboradores.

Valores.

Creatividad.

Se basa en la auto-expresión y en el poder de decisión del individuo de una manera abierta. 
Imaginación.

Implica ideas infinitas, curiosidad, descubrimiento y exploración, las ideas cobran vida.

Aprendizaje.

Aprender a través del juego estimulante, práctico e inteligente.

Calidad.

Mantenemos altos estándares de calidad en todas nuestras marcas.

\subsection{Estrategias de la Empresa}

En COMEXA podemos diferenciar claramente dos estrategias, la diferenciación y crecimiento. El detalle de estas dos estrategias lo podemos revisar a continuación.

\subsubsection{Estrategias Genéricas - Diferenciación.}

La estrategia que utiliza COMEXA, analizada bajo la teoría de las estrategias genéricas de PORTER (Porter, 1990), es la estrategia de diferenciación (ver Figura 5), ya que está dirigida a todo el sector de bebes y Juguetes, donde sus productos son percibidos como únicos, exclusivos y/o de alto valor, ya que fomenta el hecho de desarrollar la creatividad, imaginación, aprendizaje y diversión.

Empleando la estrategia de diferenciación, se logra crear una alta lealtad y fidelidad del cliente con respecto al producto, siendo el valor percibido (beneficios) mucho mayor con respecto al valor del producto. 


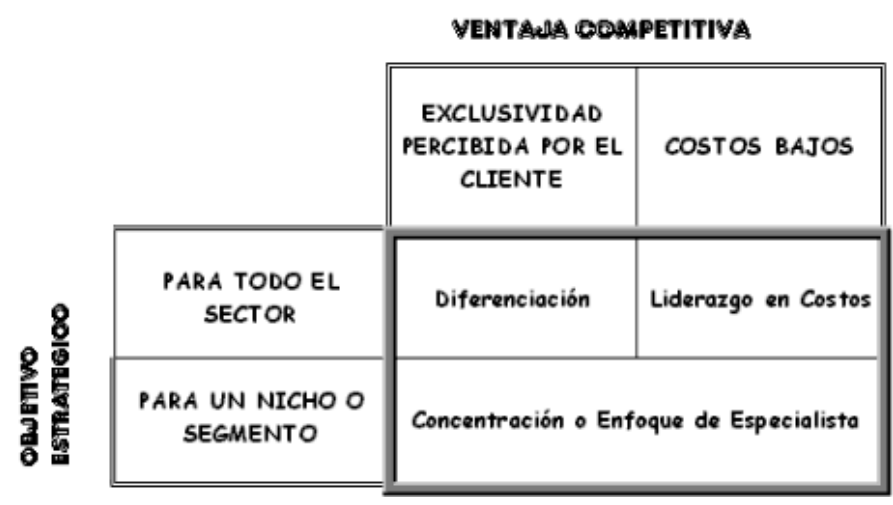

Figura 5. Gráfico de Porter.

\subsubsection{Estrategia de Crecimiento - Crecimiento Intensivo.}

A través de la estrategia de crecimiento intensivo (Ansoff, 1957), COMEXA busca crecer en el mercado interno peruano, teniendo como primer objetivo el desarrollo de nuestros productos en la ciudad de Lima donde ya se encuentra operando actualmente. Asimismo, se desea explotar completamente las oportunidades que brinda la coyuntura actual del país, del sector retail y del crecimiento sostenido de la empresa en los últimos años, aprovechando el alto valor de la marca LEGO e Infanti.

La estrategia de Crecimiento Intensivo se puede subdividir en 3 estrategias, siendo la estrategia de penetración de mercado la que COMEXA está ejecutando actualmente (ver Figura 6). A través de esta, se ha logrado que los productos LEGO, se sigan dando a conocer en el mercado peruano y se comercialicen en tiendas propias y especializadas.

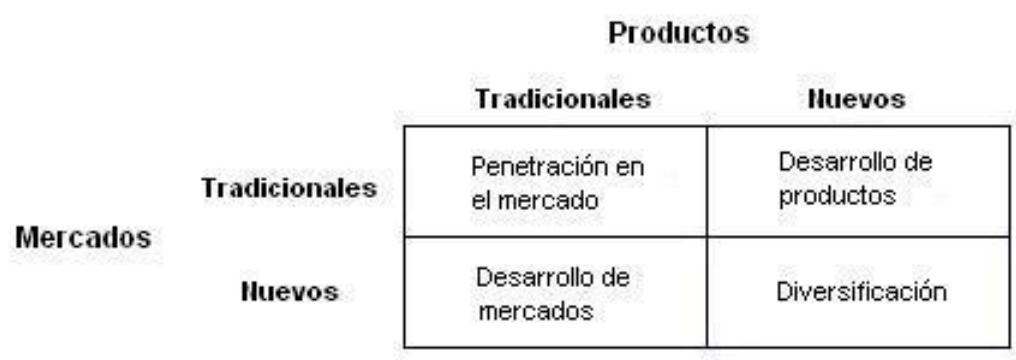

Figura 6. Gráfico de Ansoff. 


\section{Capítulo III. Análisis de la Situación de la Empresa}

La evaluación externa se enfoca principalmente en la investigación del entorno y el análisis de la industria. De esta forma, se pueden revelar, identificar y evaluar las tendencias y acontecimientos que están fuera del control de influencia.

\subsection{Análisis Externo}

Para la realización del análisis externo se realiza un Análisis PESTE y la Matriz de Evaluación de Factores Externos (EFE).

\subsubsection{Análisis PESTE.}

Este análisis nos permite evaluar los factores externos clave con un enfoque global y estructural, permitiendo realizar un análisis crítico de la información política, gubernamental, y legal (P); económica y financiera $(\mathrm{E})$; social, cultural, y demográfica $(\mathrm{S})$; tecnológica $(\mathrm{T})$; y, ecológica y ambiental (E).

\subsubsection{Fuerzas Políticas y Legales (P).}

Legales: En el marco de cumplimiento a la Ley $N^{\circ} 28376$, y la Ley general $N^{\circ} 26482$ en los artículos 96, 97, 98 y 99 dictado por la Dirección General de Salud Ambiental / Ministerio de Salud, donde claramente indica: "Se prohíbe y sanciona la fabricación, importación, distribución y comercialización de juguetes y útiles de escritorios tóxicos o peligrosos" (DIGESA - Dirección General de Salud Ambiental, 2015).

Ley de promoción de las inversiones extranjeras decreto legislativo $\mathrm{N}^{\circ} 662 \mathrm{El}$ Congreso de la República mediante la Resolución Legislativa Nº 25312 ha ratificado el Convenio Constitutivo de la Agencia Multilateral de Garantía a las Inversiones Extranjeras (MIGA) con el objeto de crear un clima favorable a las inversiones extranjeras, que 
contribuyan a la expansión de la economía de la libre empresa en el país (Ley de promoción de las inversiones extranjeras Decreto Legislativo $\mathrm{N}^{\circ} 662$ )

Políticos: Se avecinan probables cambios en la política peruana a partir de Julio del 2016, fecha en que se elegirá a un nuevo mandatario. Este ambiente generara incertidumbre, en los posibles inversionistas, lo que se traducirá en inversiones cautas en la primera mitad de dicho año.

\subsubsection{Fuerzas Económicas y Financieras (E).}

\section{Producto Bruto Interno}

Actualmente la economía Peruana se encuentra en fase de desaceleración siendo no muy alentadores debido a diversos factores tales como las próximas elecciones presidenciales y la presencia del fenómeno del niño. En el tercer trimestre del año 2015, tuvo un crecimiento de 2,9\% respecto al año anterior, en el mismo periodo (ver Figura 7).

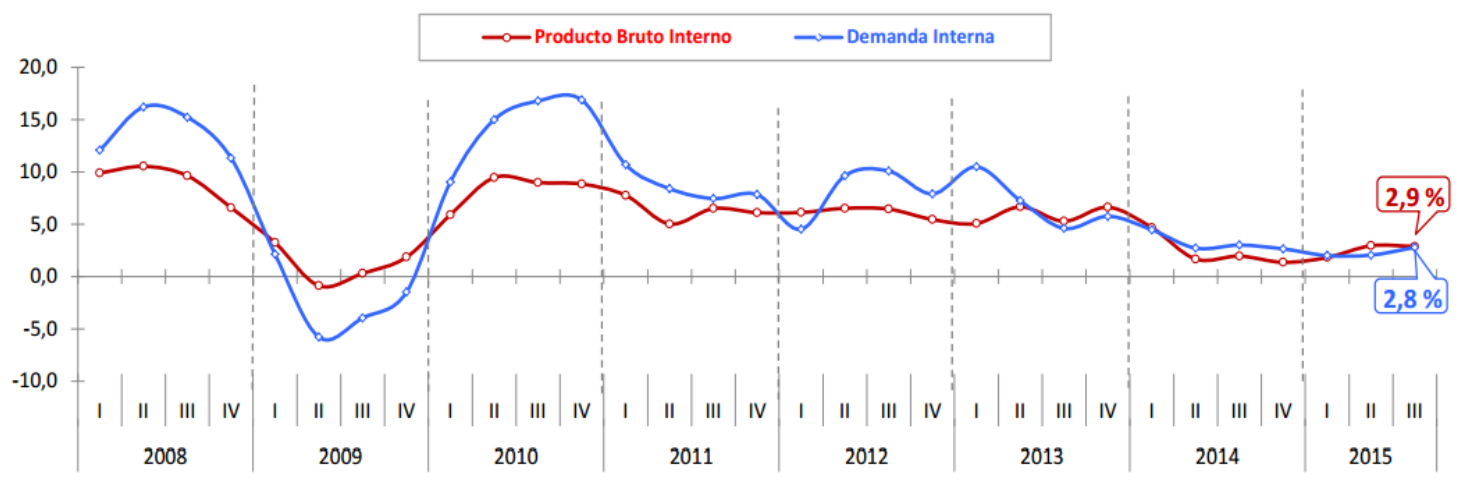

Figura 7. Producto Bruto Interno y Demanda Interna 2008 I - 2015 III.

Fuente: (INEI - Instituto Nacional de Estadística e Informática, 2016)

En el 2016 el sector comercio de Perú registraría una recuperación de $4.1 \%$ tras el ingreso de 10 centros comerciales a nivel nacional, seis en Lima y cuatro en provincias, estimó el Instituto de Economía y Desarrollo Empresarial (IEDEP) de la Cámara de Comercio de Lima (CCL). 
Si bien el sector comercio es considerado la segunda actividad más dinámica, después del sector construcción, se proyecta que su crecimiento de este año será solo de $3.7 \%$; sin embargo, Esperamos que el sector comercio y específicamente el retail evolucione positivamente en el 2016, a pesar de la actual desaceleración económica, por el impulso que inyectaría la inversión realizada y esperada en el sector, y la ligera mejora de la economía estimada para el 2016 (Peñaranda, 2015), director ejecutivo del IEDEP - CCL.

\section{Inflación}

La inflación repuntó durante los últimos meses y registró un incremento de $4.4 \%$ en el 2015, por encima de la expectativa que se tenía del mercado y del rango de inflación (entre $1 \%$ y $3 \%$ ) por segundo año consecutivo.

Se estima que la inflación para este 2016 siga creciendo, según la encuesta de expectativas del Banco Central de Reserva del Perú (BCRP), trasladándose de 3.2\% a 3.4\% en promedio para este año, mientras que por primera vez se sitúan en 3\% (límite superior del rango meta del BCRP) para el 2017. Sin embargo, el Perú en comparación a otros países de la región tiene las expectativas de inflación más bajas (ver Figura 8).

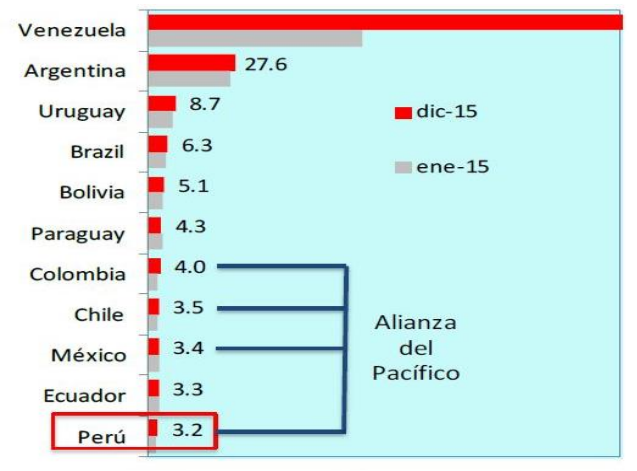

Figura 8. Inflación Esperada 2016 en la Alianza del Pacifico.

Fuente: (Diario Gestión, 2016) 


\section{Volatilidad del Dólar}

Durante los últimos meses, el tipo de cambio ha tenido una tendencia al alza y bordea en promedio S/ 3.446, generando un nuevo máximo de diez años en un contexto de mayor aversión global al riesgo, en medio de la caída del desplome de los precios del petróleo y las preocupaciones sobre el crecimiento económico de China. El dólar terminó el 2015 con un alza del 14.56\%, y hasta la fecha ha acumulado una subida del 0.94\%. (Diario Gestión, 2016).

\subsubsection{Fuerzas Sociales, Culturales y Demográficas (S).}

\section{Tasa de Natalidad}

El Perú en los últimos años ha tenido una tasa de Natalidad decreciente, debido a los programas de planificación familiar fomentados por el Ministerio de Salud y el Ministerio de la Mujer,

En el año 2015 se tuvieron más 578 mil 130 nacimientos, mientras que para el 2021 se prevé que disminuiría el número de nacimientos a 561 mil a nivel nacional según (Radio Nacional, 2015).

\section{Crecimiento de la Clase Media}

La clase media representaría el 65\% de la población urbana para el año 2021, aseguró el presidente de Arellano Marketing, Rolando Arellano. Donde actualmente, el 57\% es parte de ese estrato (ver Figura 9). 


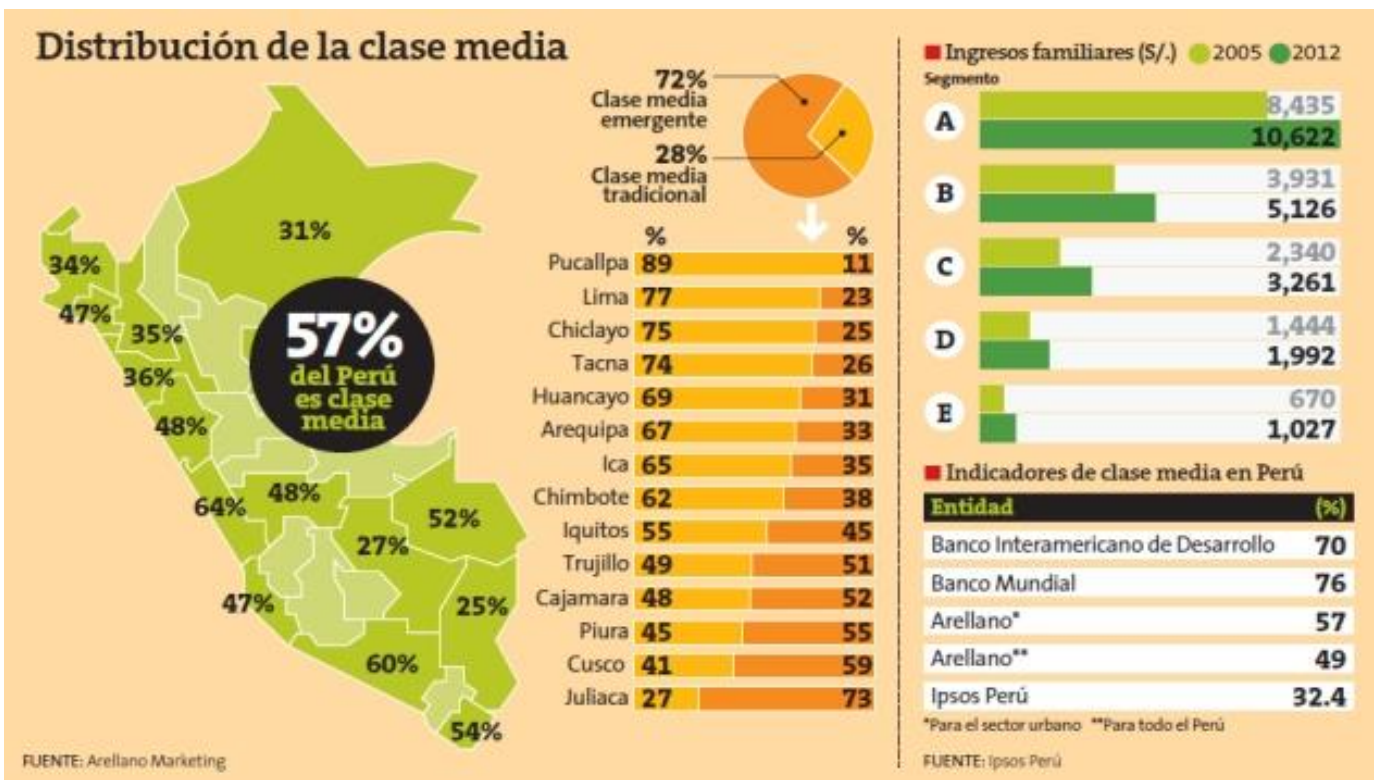

Figura 9. Distribución de la clase media.

Fuente: (Euromoney, 2014)

\section{Rotación del Personal}

El cambio de personal (trabajadores que se van o los retiran), genera grandes

sobrecostos a las empresas, siendo el Perú uno de los países con el más alto nivel de rotación en América Latina. (Othmar Rabitsch), presidente del directorio de Asociación Peruana de Recursos Humanos (Aperhu), explicó que el nivel de rotación laboral en el Perú supera el 18\%, frente al promedio de América Latina, que está entre 5 y $10 \%$.

Refirió que ese nivel de rotación daña a la empresa por los sobrecostos que genera.

Tomando como referencia a Jack Welch (reconocido empresario estadounidense), refirió que el costo de rotar a un gerente equivale a cinco años de sus remuneraciones. (DiarioCorreo, 2014)

\subsubsection{Fuerzas Tecnológicas y Científicas (T).}

Las grandes industrias han identificado las nuevas fuerzas tecnológicas que predominaran el mundo empresarial siendo estas: 


\section{Internet}

La aparición de Internet como herramienta tecnológica ha significado un cambio relevante en el acceso a la información y por lo tanto, en la disponibilidad del conocimiento. El gran desarrollo de lo que conocemos como las Tecnologías de la Información y la Comunicación (TIC), ha provocado transformaciones determinantes en los procesos de producción, en el empleo, la educación, la salud, la administración pública, la comunicación, las relaciones sociales y en definitiva, en casi todas las facetas de la vida cotidiana de las personas.

Esto ha permitido que el Perú, al incrementarse el público internauta, se convierta en un mercado mucho más importante para las empresas y las correspondientes acciones de relaciones públicas.

La tecnología está transformando la forma en que los retailers operan en los mercados en desarrollo. Las expectativas y comportamientos de los compradores están evolucionando impulsados tanto por el clima económico como por el mayor acceso a la información a través de la tecnología. Los consumidores están más conectados que nunca a las marcas, la mercancía y a los compradores. La proliferación de canales y medios de comunicación para la interacción de consumo minorista ha obligado a los retailers a acercarse al mercado internacional desde una perspectiva multicanal, puesto que en los países en desarrollo, la gente está cada vez más dispuesta a comprar en línea.

El crecimiento en el comercio electrónico y el comercio móvil ( on-line) cada vez gana más adeptos y ya coexiste con el comercio tradicional (off-line) en casi todos los mercados, lo que demuestra que Internet es a la vez un complemento viable para las operaciones en las tiendas físicas y la entrada de un juego multicanal en el mercado. 


\section{Las Redes Sociales:}

Se han convertido en una herramienta poderosa para interactuar con otras personas o empresas. Antes los consumidores pedían el libro de reclamaciones para dejar sus quejas, hoy un $47 \%$ de usuarios digitales acude a las redes sociales como Facebook o Twitter, para realizar reclamos o denuncias. Esto refleja que un $70 \%$ de las empresas declara que los clientes son cada vez más exigentes.

Otro resultado del estudio señala que el $65 \%$ de los usuarios mantienen más de tres cuentas de redes sociales, ya sea para interactuar con otras personas, leer noticias, por ocio o publicar y comentar alguna información.

\section{Las Compras Online}

Si bien aún en Perú aun el comercio electrónico no alcanza los niveles de otros países de Latinoamérica debido a la propia idiosincrasia del peruano, según cifras de la Cámara de Comercio de Lima, el comercio electrónico en el país alcanzó los S/. 1000 millones de soles el 2013, lo que representa un incremento del 60\% frente al monto obtenido el 2012 (S/. 611 millones). Se estima que la base de compradores de productos y servicios en portales virtuales llegaría a 3.5 millones de peruanos a fines del 2015.11

Este es un desafío para las empresas, quienes deben plantear nuevas estrategias de venta y marketing y promover la inversión digital para estos compradores.

\section{Uso de Smartphones}

En el Perú, el uso de Smartphones es más creciente en la población. El uso y consumo de información de aplicativos móviles va en aumento y en el Perú va de manera acelerada.

Según el último estudio de IMS y Comscore, el $88 \%$ de los peruanos participantes de la investigación aceden a internet a través de un Smartphone o Table.

Según Daniel Libreros (Country Manager Perú IMS) (LaRepublica, 2015), en la actualidad se siguen 3 tendencias para conectar con el público objetivo: 
- Énfasis en lo social o presencia en las redes sociales.

- Presencia en los entornos móviles que discriminan el lugar y los puntos de contacto en forma fragmentada.

- Definir qué es lo que debemos comunicar, como, en que momento, a quienes y en qué contexto.

\section{Apps}

Las Apps en el Perú han crecido en $170 \%$ en el último año, sin embargo es un mercado pequeño pero con mucho potencial. Este crecimiento va de la mano con el uso de smartphones. Según Javier Álvarez (Gerente de cuenta y estudios multiclientes de IPSOS) al peruano le gusta todo lo que es gratis y no está dispuesto a pagar por descargarse una aplicación móvil cuando existen opciones gratuitas. (El Comercio, 2015)

\subsubsection{Fuerzas Ecológicas y Ambientales (E).}

La protección del medio ambiente es muy importante en el mundo empresarial y encara con el cliente esto da un plus adicional en la toma de decisiones para la compra de un determinado producto.

En el último COP realizado en Francia 2015 se tomó como primer acuerdo en el que tanto naciones desarrolladas como países en desarrollo se comprometen a gestionar la transición hacia una economía baja en carbono. Se estableció como objetivo de lograr que el aumento de las temperaturas se mantenga bastante por debajo de los dos grados centígrados y se comprometió a los firmantes a "realizar esfuerzos" para limitar el aumento de las temperaturas a 1,5 grados en comparación con la era pre-industrial, como lo señala en el texto (BBC Mundo, 2015). 


\subsubsection{Análisis de la Industria.}

El análisis de las condiciones competitivas e industriales es el punto de partida para poder realizar una evaluación de la posición estratégica de la empresa en el sector y en los diferentes mercados.

El potencial crecimiento de ventas que puedan registrar los productos de la marca LEGO, estarán relacionados directamente influenciados por dos sectores. El sector Retail y el sector Juguetes.

\subsubsection{Análisis del Sector Retail.}

Durante la crisis económica que enfrentó Europa en el año 2011, los países en vías de desarrollo se movieron a toda velocidad, aprovechando la mejora de la confianza del consumidor y haciendo que los minoristas continuaran su expansión en estos mercados.

El Perú, gracias a su excelente ubicación geográfica, se ha convertido en un mercado muy atractivo para los retailers: ocupa el puesto número 13 para este tipo de negocio y es el único en Latinoamérica que mantiene un crecimiento sostenido en el sector desde hace más de una década (ver Figura 10).

\section{Análisis del Sector Retail en el Perú.}

Nuestro país ocupa el lugar número 13 como oportunidad para el negocio del Retail, debido a que su economía se mantiene estable, con una inflación controlada de menos del 3\% y en crecimiento, y estos factores permiten que exista confianza en el negocio (ver Tabla 9).

La política fiscal prudente y la disciplina monetaria constituyen los pilares de la economía del Perú, y estos factores animan a los inversionistas bajo un marco de un existente plan nacional para el desarrollo industrial. El foco sigue siendo el cliente de clase media. Los productos de marcas propias siguen teniendo buena acogida y popularidad gracias a su gran calidad y precios asequibles. Lima concentra más de la mitad de los centros comerciales. 
Marcas tales como GAP, Banana Republic, Carolina Herrera, entre otras, han abierto tiendas en

la ciudad.

Tabla 9.

Análisis del Sector Retail en el mundo.

\begin{tabular}{|c|c|c|c|c|c|c|c|}
\hline $\begin{array}{l}2014 \\
\text { RANK }\end{array}$ COUNTRY & $\begin{array}{c}\text { MARKET } \\
\text { ATTRACTIVENNESS }\end{array}$ & $\begin{array}{l}\text { COUNTRY } \\
\text { RISK }\end{array}$ & $\begin{array}{c}\text { MARKET } \\
\text { SATURATION }\end{array}$ & $\begin{array}{c}\text { TIME } \\
\text { PRESSURE }\end{array}$ & $\begin{array}{l}\text { ORDI } \\
\text { SCORE }\end{array}$ & $\begin{array}{c}\text { CHANGE IN RANK } \\
\text { COMPARARED TO } 2013\end{array}$ & CATEGORY \\
\hline 1 CHILE & 100.00 & 100.00 & 13.20 & 47.30 & 65.10 & +1 & \\
\hline 2 CHINA & 60.90 & 52.50 & 44.50 & 100.00 & $64.40^{\prime \prime}$ & +2 & \\
\hline 3 URUGUAY & 93.40 & 57.50 & 70.30 & 32.40 & 63.40 & -- & \\
\hline 4 UNITED ARAB EMIRATES & 98.50 & 82.30 & 17.50 & 43.80 & $60.50^{\prime}$ & +1 & \\
\hline 5 BRAZIL & 99.40 & 59.80 & 48.70 & 33.20 & $60.30^{\prime}$ & -4 & ON THE \\
\hline 6 ARMENIA & 26.40 & 35.30 & 81.50 & 86.70 & $57.50^{\prime}$ & +4 & RADAR \\
\hline 7 GEORGIA & 32.40 & 32.80 & 79.60 & 78.80 & $55.90^{\prime}$ & +1 & \\
\hline 8 KUWAIT & 78.80 & 72.60 & 32.90 & 31.70 & $54.00^{\prime}$ & +1 & \\
\hline 9 MALAYSIA & 66.70 & 68.70 & 32.20 & 43.50 & $52.80^{\prime}$ & +4 & \\
\hline 10 KAZAKHSTAN & 45.40 & 38.50 & 72.70 & 54.30 & $52.70^{\prime}$ & +1 & \\
\hline 11 TURKEY & 83.60 & 50.20 & 46.50 & 30.20 & 52.60 & -5 & \\
\hline 12 RUSSIA & 94.00 & 38.40 & 30.70 & 46.40 & $52.40^{\prime}$ & +11 & \\
\hline 13 PERU & 46.00 & 43.00 & 61.90 & 51.30 & $50.60^{\prime \prime}$ & -1 & \\
\hline 14 PANAMA & 56.20 & 46.90 & 52.70 & 41.30 & $49.30^{\prime}$ & +8 & \\
\hline 15 INDONESIA & 46.20 & 33.40 & 57.70 & 59.60 & $49.20^{\prime}$ & +4 & TO \\
\hline 16 SAUDI ARABIA & 72.30 & 67.30 & 29.50 & 27.40 & 49.10 & -- & CONSIDER \\
\hline 17 OMAN & 75.10 & 79.10 & 27.00 & 11.10 & 48.10 & -- & \\
\hline 18 SRI LANKA & 6.30 & 36.70 & 78.80 & 67.30 & $47.30^{\prime \prime}$ & -3 & \\
\hline 19 NIGERIA & 39.60 & 6.60 & 92.30 & 48.00 & 46.60 & N/A & \\
\hline 20 INDIA & 26.40 & 39.00 & 72.30 & 43.40 & $45.30^{\prime}$ & -6 & \\
\hline 21 COLOMBIA & 50.60 & 43.00 & 53.50 & 29.40 & 44.20 & -3 & \\
\hline 22 JORDAN & 49.80 & 43.70 & 65.60 & 15.20 & $43.60^{\prime}$ & -2 & \\
\hline 23 PHILIPPINES & 33.00 & 33.20 & 55.80 & 50.50 & 43.10 & N/A & \\
\hline 24 COSTA RICA & 62.10 & 45.90 & 40.40 & 21.50 & 42.50 & N/A & \\
\hline 25 MEXICO & 80.00 & 54.40 & 2.90 & 31.80 & $42.30^{\prime}$ & -4 & LOWER \\
\hline 26 BOTSWANA & 26.10 & 60.70 & 34.80 & 44.10 & $41.40^{\prime \prime}$ & -1 & PRIORITY \\
\hline 27 MOROCCO & 24.10 & 35.50 & 69.50 & 35.70 & 41.20 & -- & \\
\hline 28 VIETNAM & 3.80 & 21.90 & 75.00 & 55.70 & 39.10 & $\mathrm{~N} / \mathrm{A}$ & \\
\hline 29 NAMIBIA & 8.60 & 57.90 & 27.20 & 58.80 & $38.10^{\prime \prime}$ & -3 & \\
\hline 30 AZERBAIJAN & 22.00 & 29.50 & 82.30 & 18.60 & $38.10^{\prime}$ & -1 & \\
\hline
\end{tabular}

Fuente: (Euromoney, 2014) 


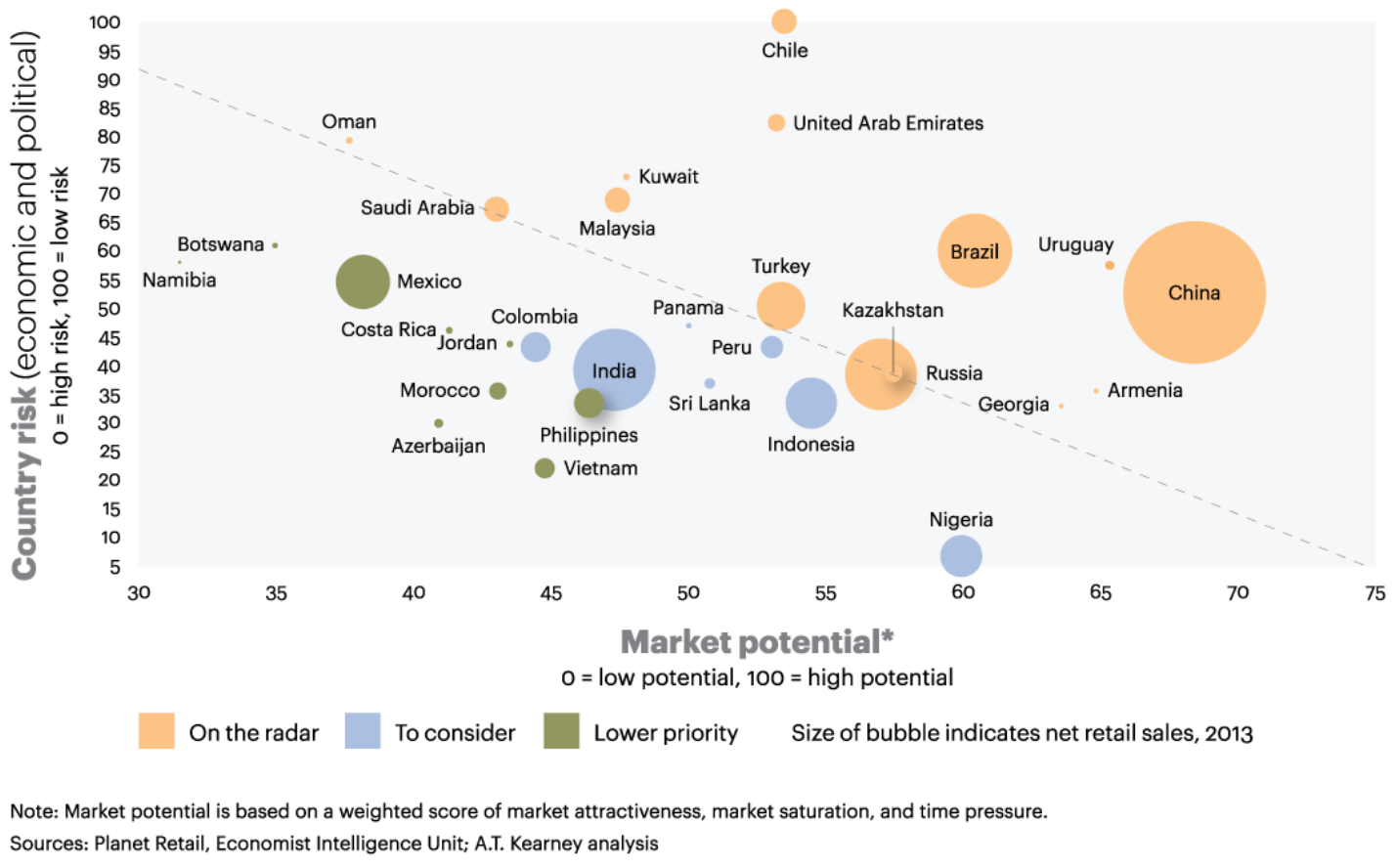

Figura 10. Nivel de atracción por país según Indice global de Desarrollo Retail 2014.

Fuente: (Euromoney, 2014)

\section{Análisis del Sector Juguetes en el Perú.}

Durante el 2015 el mercado de juguetes se mantuvo dinámico y se tuvo un crecimiento de $10 \%$, se espera que el mercado de juguetes en el Perú creciera $15 \%$ en el 2016, siendo los meses de mayor demanda los meses de agosto y diciembre según indica la firma Marcas Inteligentes. (El Comercio, 2015)

El sector juguetes en el Perú está dividido en 4 segmentos (ver Tabla 10), segmento PreEscolar enfocado en los niños de 0 a 3 años, Escolar-Niños enfocado en los niños de 4 a 13 años, Escolar-Niñas enfocado en las niñas y adolescentes enfocado en los jóvenes (hombres y mujeres) de 14 a 16. 
Tabla 10

Segmentos del Sector Juguetes.

\begin{tabular}{lcc}
\hline Segmentos & Tamaño estimado & $\%$ \\
\hline Pre-Escolar & $\mathrm{S} / .80,644,308$ & $23 \%$ \\
Escolar-Niños & $\mathrm{S} / .129,051,541$ & $36 \%$ \\
Adolescentes & $\mathrm{S} / .40,488,630$ & $11 \%$ \\
Escolar-Niñas & $\mathrm{S} / .106,467,521$ & $30 \%$ \\
\hline Total & $\mathrm{S} / .356,652,000$ & $100 \%$ \\
\hline
\end{tabular}

\subsubsection{Modelo de las Cinco Fuerzas de Porter.}

El modelo de las cinco fuerzas de Porter permite ejecutar de forma más adecuada el análisis competitivo, y a su vez, permite determinar la estructura y cuan atractiva es la industria donde la empresa compite. En este modelo se analizan a los proveedores, nuevos participantes, competidores de la industria, sustitutos y compradores. Cabe mencionar, que todas las fuerzas son de suma importancia, pero la rivalidad entre las empresas competidoras es la fuerza que más debe ser evaluada y analizada con detalle, ya que es precisamente la competencia directa o indirecta, la que constantemente está buscando alcanzar una mayor participación de mercado.

\subsubsection{Poder de Negociación de Proveedores.}

La industria de juguetes en el Perú, se caracteriza por la importación de los juguetes de diversas partes del mundo. Por lo que, dependiendo del tipo de marca que se comercializa, el poder de los proveedores podría variar. Las marcas provenientes de China, generalmente no ofrecen una alta diferenciación en el mercado peruano, y ante la elevada oferta de esta, el poder de los proveedores se podría decir que es bajo. Sin embargo, esta situación cambia, cuando hablamos de marcas que tienen un alto grado de diferenciación para el consumidor peruano, tal como el caso de LEGO. Esta marca se comercializa en el Perú, a través de COMEXA, quien a su vez, tiene como socio estratégico o proveedor a ELITE 
BRAND, esta empresa tiene en Latinoamérica la exclusividad en la comercialización de LEGO, y es solo a través de ellos, que COMEXA puede adquirir los productos de la marca.

Al tener ELITE BRAND, la exclusividad de la comercialización de LEGO en Latinoamérica, es necesario que COMEXA, deba rendir cuentas y sustentar los crecimientos que esperan tener con esta marca cada año.

Por lo que, podría existir cierta vulnerabilidad de COMEXA si requiriera cubrir cuotas más altas de mercado. Por ello, para COMEXA, el poder de los proveedores es alto.

\subsubsection{Desarrollo Potencial de Productos Sustitutos.}

Los productos sustitutos, son aquellos que pueden desempeñar una misma función para el mismo grupo de clientes, pero basados en diferentes tecnologías. No existen sustitutos a los juguetes. No obstante, podrían ser considerados los siguientes: los libros infantiles (si bien son considerados elementos de ocio no alcanzan el nivel de satisfacción en los niños como un juguete), los productos tecnológicos (tablets, videojuegos, que tienen un costo mucho mayor a un juguete promedio. Para el caso de la marca LEGO, los productos sustitutos no le generan una alta amenaza, ya que el consumidor busca la marca por su valor diferencial.

\subsubsection{Rivalidad entre Empresas Competidoras.}

Existen tres tipos de competidores en el mercado. El mercado informal vende productos de baja calidad y bajo precio, aprovecha las ventas promocionales del mercado para surtirse de productos y luego especular con la oferta y la demanda. Vende productos de contrabando o de ingreso irregular al país y su ganancia se encuentra en generar liquidez más que en rentabilidad.

El mercado Retail hace compras en volumen, cuenta con espacios de exhibición y concentra mayormente sus ventas en temporada navideña donde ofrecen gran cantidad de ofertas y descuentos. Realizan compras internacionales con elevados márgenes de ganancia 
sobre todo cuando la venta es financiada con tarjetas de crédito. Cuenta con un alto presupuesto para publicidad y mercadeo.

Las tiendas especializadas venden marcas propias a precios más elevados, ofreciendo así productos más exclusivos a nichos más específicos.

El número de competidores en la industria de Juguetes en el Perú, se ha ido incrementando pero de forma bastante reservada, los actores principales siguen siendo los mismos en los últimos 5 años. Sin embargo es un mercado que ha venido expandiéndose a tasas que bordean de $10 \%$ a $15 \%$ aproximadamente. En el Perú, el costo del cliente por cambiar de marcas de Juguetes es bajo, ya que la oferta dada por las grandes cadenas Retail hace que el consumidor pase de una a otra sin mucha fidelización.

En resumen, existe una alta rivalidad entre los competidores de esta industria siendo las tiendas Retail los principales jugadores, porque al tener similares proveedores y productos la competencia termina siendo por el precio. (Ivan Valdez, 2015)

En el caso de los productos de la marca LEGO, estos han conseguido minimizar el impacto que tiene el precio para el comprador, es así, que a pesar que la industria tenga una alta rivalidad y esta se base en el precio, LEGO no requiere entrar, como el resto de participantes en una guerra por precios bajos.

\subsubsection{Ingreso Potencial de Nuevos Competidores.}

Cuando se analiza el ingreso de nuevos competidores en la industria, podemos darnos cuenta que entrar en el mercado local de juguetes tiene cierto grado de complejidad, no solo basta con tener un poco de capital y contactarse con un proveedor en China para traer un contenedor de juguetes y comercializarlo localmente, sino que se requieren muchos certificados y permisos adicionales, los mismos que son a veces complicados y engorrosos, si a ello le sumamos que no podrán competir en cuanto a precios, con las grandes cadenas de Retail, que compran el $80 \%$ de su producción en China, y que, por los altos volúmenes, 
consiguen costos muchos menores que los pequeños comerciantes, asegurándose siempre de colocar sus productos a menores precios, podemos decir que las barreras de entrada son altas.

Dentro de esta industria, la marca LEGO, ha logrado generar una barrera de entrada basada en la diferenciación de su producto e imagen de marca, ya que de por si LEGO genera un alto grado de lealtad entre sus clientes.

\subsubsection{Poder de Negociación de Clientes.}

Existen dos tipos de clientes, personas y empresas. El cliente como persona es el que finalmente realiza la compra guiado por el gusto del consumidor (los niños), cuya decisión, además, se ve determinada por satisfacer su necesidad, por lo cual buscan el menor precio. Otro punto importante de los clientes (personas) es que tienen un alto poder de negociación porque puede influir en el cambio de producto, por el tema del control de calidad, o pedir el Libro de reclamaciones o quejarse en INDECOPI si siente que sus quejas no son resueltas o si no encontró solución a algún problema.

Las empresas son otro tipo de cliente cuya decisión de compra está determinada por la cantidad y el precio de los productos, por ejemplo, en diciembre por las fiestas navideñas. Por lo tanto, al ser el cliente una fuerza que busca buen precio y que cuenta con varias opciones de compra en el mercado, tiene un alto poder de negociación.

Para el caso de la marca LEGO en el Perú, esta fuerza se puede considerar de mediana a baja, ya que, dada la alta diferenciación que tiene la marca, logra reducir el alto poder de los clientes para consumir el producto. Mientras la marca vaya posicionándose mejor en el mercado peruano, lograra seguir aminorando el poder de los clientes.

\subsubsection{Análisis Competitivo.}

Para el análisis competitivo de la industria de Juguetes, hemos basado en la segmentación que tiene la industria, la misma que tiene 4 segmentos. 
- Pre-Escolar (Niños o niñas entre 0 a 3 años de edad)

- Escolar (Niños de 4 a 13 años)

- Adolecentes (de 14 a 16 años)

- Niñas (Niñas de 4 a 13 años)

Para el análisis competitivo nos hemos ayudado de dos matrices, la Matriz Boston Consulting Group (BCG) y la matriz Mc Kinsey.

\subsubsection{Matriz BCG}

Esta matriz clasifica los productos en cuatro categorías según dos variables (ver Figura 11):

1. Posición en cuota relativa de mercado.

Relación entre mi cuota de mercado (valor o volumen) y el líder de mercado o competidor directo.

- $\mathrm{Si}<1$ posiciones interrogante y perro

- $\quad \mathrm{Si}>1$ posiciones estrella y vaca

2. Posiciones de crecimiento de mercado

Relación entre el crecimiento del segmento donde está nuestro producto y el crecimiento medio de la economía, por ejemplo PIB.

- Mayor crecimiento del segmento (posiciones interrogante y estrella)

- Menor crecimiento del segmento (posiciones perro y vaca)

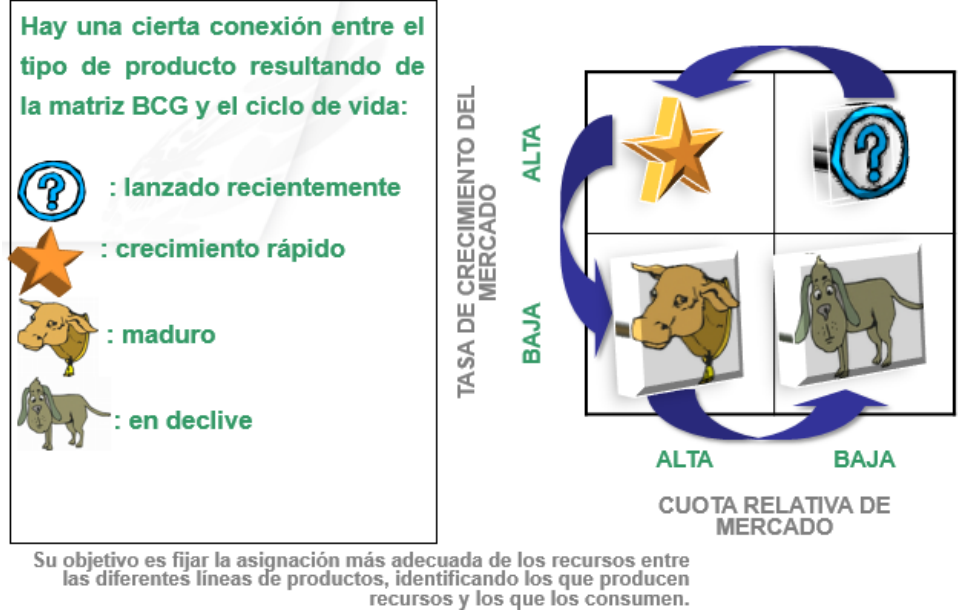

Figura 11. Matriz BCG 
Según los segmentos que existen dentro de la industria de Juguetes en el Perú, se quiere identifica para cada segmento, que cuota relativa y potencial de crecimiento tiene en el mercado para los productos de la marca LEGO (ver Tabla 11).

Tabla 11

Segmentos de los productos LEGO.

\begin{tabular}{|c|c|c|c|c|c|c|c|c|}
\hline \multirow{2}{*}{ Familia } & \multirow{2}{*}{ Segmento } & \multirow{2}{*}{ Crecimiento } & \multirow{2}{*}{ Competidor } & \multirow{2}{*}{ Ventas S/. } & \multirow{2}{*}{ PBI } & \multirow{2}{*}{ Cuota } & \multicolumn{2}{|c|}{ Mercado } \\
\hline & & & & & & & Cuota Rela & $\overline{\text { niento }}$ \\
\hline L Duplo & Pre Escolar-Niños & $3 \%$ & $5 \%$ & 423,245 & $4 \%$ & $8 \%$ & 1.60 & 0.75 \\
\hline L Juniors & Pre Escolar-Niños & $3 \%$ & $5 \%$ & 144,444 & $4 \%$ & $6 \%$ & 1.20 & 0.75 \\
\hline L City & Escolar-Niños & $15 \%$ & $8 \%$ & 634,921 & $4 \%$ & $10 \%$ & 1.25 & 3.75 \\
\hline L Super Heroes & Escolar-Niños & $15 \%$ & $8 \%$ & 603,827 & $4 \%$ & $8 \%$ & 1.03 & 3.75 \\
\hline L Sar Wars & Escolar-Niños & $15 \%$ & $8 \%$ & 553,900 & $4 \%$ & $9 \%$ & 1.13 & 3.75 \\
\hline L Leg of Chima & Escolar-Niños & $15 \%$ & $8 \%$ & 409,312 & $4 \%$ & $1 \%$ & 0.13 & 3.75 \\
\hline L Ninjago & Escolar-Niños & $15 \%$ & $8 \%$ & 345,312 & $4 \%$ & $1 \%$ & 0.13 & 3.75 \\
\hline L Minecraft & Escolar-Niños & $15 \%$ & $8 \%$ & 186,682 & $4 \%$ & $1 \%$ & 0.15 & 3.75 \\
\hline L Ninja Turtles & Escolar-Niños & $15 \%$ & $8 \%$ & 88,568 & $4 \%$ & $1 \%$ & 0.08 & 3.75 \\
\hline L Movie & Escolar-Niños & $15 \%$ & $8 \%$ & 51,270 & $4 \%$ & $0 \%$ & 0.00 & 3.75 \\
\hline L Pirates & Escolar-Niños & $15 \%$ & $8 \%$ & 3,568 & $4 \%$ & $0 \%$ & 0.00 & 3.75 \\
\hline L Toy Story & Escolar-Niños & $15 \%$ & $8 \%$ & 325 & $4 \%$ & $0 \%$ & 0.00 & 3.75 \\
\hline L racers & Escolar-Niños & $15 \%$ & $8 \%$ & 108 & $4 \%$ & $0 \%$ & 0.00 & 3.75 \\
\hline L Castle & Escolar-Niños & $15 \%$ & $8 \%$ & 54 & $4 \%$ & $0 \%$ & 0.00 & 3.75 \\
\hline L Escultura & Adolescentes & $8 \%$ & $30 \%$ & 56,766 & $4 \%$ & $3 \%$ & 0.10 & 2.00 \\
\hline L MindStorms & Adolescentes & $8 \%$ & $30 \%$ & 51,967 & $4 \%$ & $3 \%$ & 0.11 & 2.00 \\
\hline L Creator & Adolescentes & $8 \%$ & $30 \%$ & 183,767 & $4 \%$ & $4 \%$ & 0.14 & 2.00 \\
\hline L Tecnic & Adolescentes & $8 \%$ & $30 \%$ & 49,775 & $4 \%$ & $4 \%$ & 0.14 & 2.00 \\
\hline L Friends & Escolar-Niños & $12 \%$ & $15 \%$ & 452,537 & $4 \%$ & $12 \%$ & 0.80 & 3.00 \\
\hline
\end{tabular}

Nota: Información interna de COMEXA.

Según la puntuación asignada en la Tabla 11, podemos colocar cada Linea dentro la matriz

BCG (ver Figura 12), lo más resaltante es que tenemos 3 productos estrellas (Lego City, Lego

Super Heroe y Lego Star Wars), 1 producto interrogante (Lego Friends) y 2 productos vacas

(Lego Duplo y Lego Junior). 


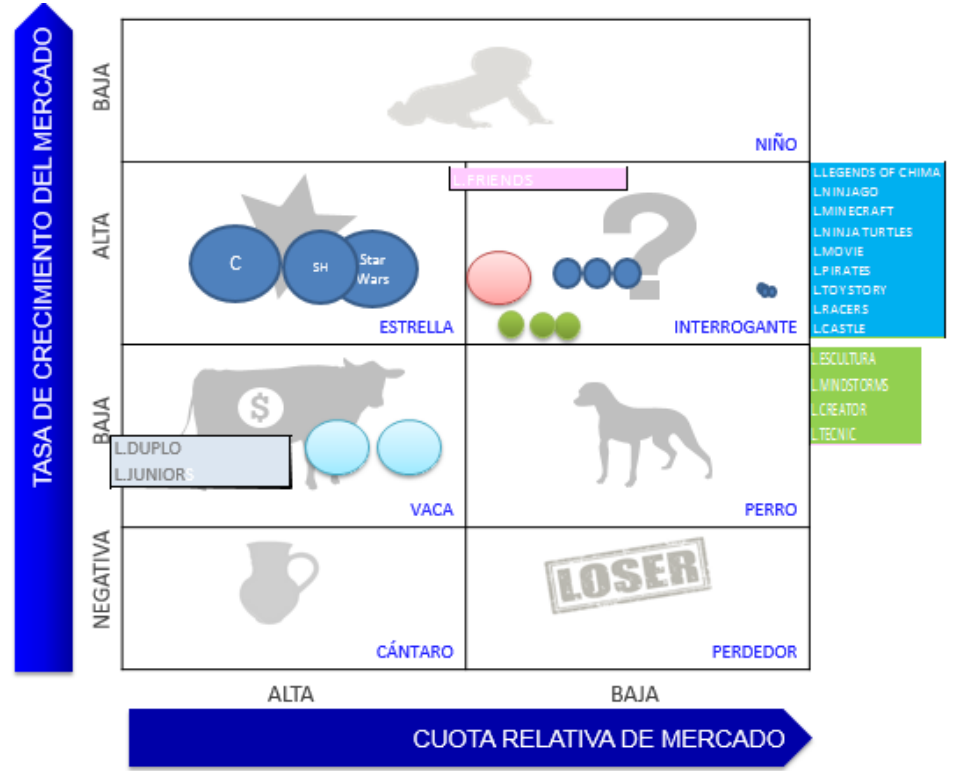

Figura 12.Matriz BCG para los productos de la marca LEGO.

\subsubsection{Matriz MC KINSEY.}

Parte de dos evidencias:

- El atractivo de un mercado no depende solo de la tasa de crecimiento sino de otros factores: accesibilidad, tamaño, existencia de distribución.

- La ventaja competitiva puede derivarse de una imagen de marca, de una organización comercial, adelanto tecnológico, si la cuota de mercado es débil.

Utiliza por tanto un juego de indicadores tanto de atractivo como de competitividad (Evaluaciones subjetivas)

Cada factor elegido se pondera de 0 a 1 . La suma total debe ser 1 . Posteriormente se evalúan de 0 a 100, con lo que la suma de evaluación ponderada (Ponderación por evaluación) estará entre 0 (mínima) y 100 (máxima).

De forma que:

- 0 a 33 : Bajo

- $\quad 34$ a 66: Medio

- $\quad 67$ a 100: Alto 
Para el análisis de LEGO se han usado factores relacionado con el sector juguetes del Perú, tales como tamaño del sector, crecimiento, sensibilidad del precio, rentabilidad media y tecnología y se han analizado las líneas agrupadas por segmentos que se manejan el mercado: Pre escolar, escolar adolescentes y niñas (ver Tabla 12).

La ponderación usada para determinar el atractivo del sector se basó en la importancia que cada factor pueda tener para la compañía. Siendo el crecimiento del mercado el factor que mayor ponderación se le asigno (0.25) debido para las proyecciones de venta de la compañía es fundamental participar en un sector que está creciendo sostenidamente. La sensibilidad del precio tuvo una ponderación más baja (0.15) debido a que los consumidores de LEGO son poco sensibles al precio.

Tabla 12

Matriz Mckinsey/GE - Atractivo del Sector.

\begin{tabular}{|c|c|c|c|c|c|c|c|c|c|}
\hline Factores/Segmentos & Pond. & $\begin{array}{l}\text { Pre Escolar } \\
\text { Evaluación }\end{array}$ & Escolar & Adolescentes & Niñas & $\begin{array}{l}\text { Pre Escolar } \\
\text { Evaluación P }\end{array}$ & $\begin{array}{l}\text { Escolar } \\
\text { Ponderad }\end{array}$ & Adolescentes & Niñas \\
\hline Tamaño del Sector & 0.2 & 60 & 75 & 80 & 80 & 12 & 15 & 16 & 16 \\
\hline Crecimiento & 0.25 & 50 & 80 & 70 & 80 & 12.5 & 20 & 17.5 & 20 \\
\hline Sensibilida al Precio & 0.15 & 70 & 80 & 70 & 80 & 10.5 & 12 & 10.5 & 12 \\
\hline Rentabilidad Media & 0.2 & 60 & 70 & 75 & 80 & 12 & 14 & 15 & 16 \\
\hline Tecnologia & 0.2 & 70 & 70 & 70 & 70 & 14 & 14 & 14 & 14 \\
\hline Total & 1 & & & & & 61 & 75 & 73 & 78 \\
\hline
\end{tabular}

Con respecto a la Posición Competitiva (ver Tabla 13), para el análisis de LEGO uso factores como marca, participación, capacidad tecnológica, lealtad del cliente y poder sobre la distribución, donde la marca fue el factor más relevante con una ponderación de 0.4 debido a que la marca LEGO es sumamente conocida. 
Tabla 13

Matriz Mckinsey/GE Posición Competitiva

\begin{tabular}{|c|c|c|c|c|c|c|c|c|c|}
\hline Factores/ Segmentos & Pond. & $\begin{array}{l}\text { Pre Escolar } \\
\text { Evaluación }\end{array}$ & Escolar & Adolescentes & Niñas & $\begin{array}{l}\text { Pre Escolar } \\
\text { Evaluación }\end{array}$ & $\begin{array}{l}\text { Escolar } \\
\text { onderad }\end{array}$ & Adolescentes & Niñas \\
\hline Marca & 0.4 & 90 & 90 & 90 & 90 & 36 & 36 & 36 & 36 \\
\hline Participación & 0.2 & 60 & 80 & 20 & 90 & 12 & 16 & 4 & 18 \\
\hline Capacidad Tecnologica & 0.1 & 80 & 80 & 80 & 80 & 8 & 8 & 8 & 8 \\
\hline Lealtad del cliente & 0.2 & 80 & 70 & 40 & 80 & 16 & 14 & 8 & 16 \\
\hline Porder de Distribución & 0.1 & 70 & 70 & 70 & 70 & 7 & 7 & 7 & 7 \\
\hline Total & 1 & & & & & 79 & 81 & 63 & 85 \\
\hline
\end{tabular}

Para el caso de los productos Lego, podemos ver en la Figura 13 que los 4 segmentos

que hemos venido analizando se encuentran en diferentes situaciones:

- Línea Pre-escolar.- esta línea se ubica en una posición competitiva media y con un atractivo de la industria también medio, por lo que la decisión de la empresa debe ser la de diversificar en los productos.

- Línea Escolar - Niños.- esta línea se encuentra en una posición competitiva alta, y con un atractivo de la industria alto, por lo que la decisión de la empresa para esta línea debe ser la expansión.

- Línea Adolescente.- esta línea se encuentra en una posición competitiva media, pero con un atractivo del mercado alto, por lo que la empresa debe pensar en la innovación de los productos.

- Línea Escolar - Niñas.- esta línea se encuentra en una posición competitiva alta, y con un atractivo de la industria alto, por lo que la decisión de la empresa para esta línea debe ser la expansión. 


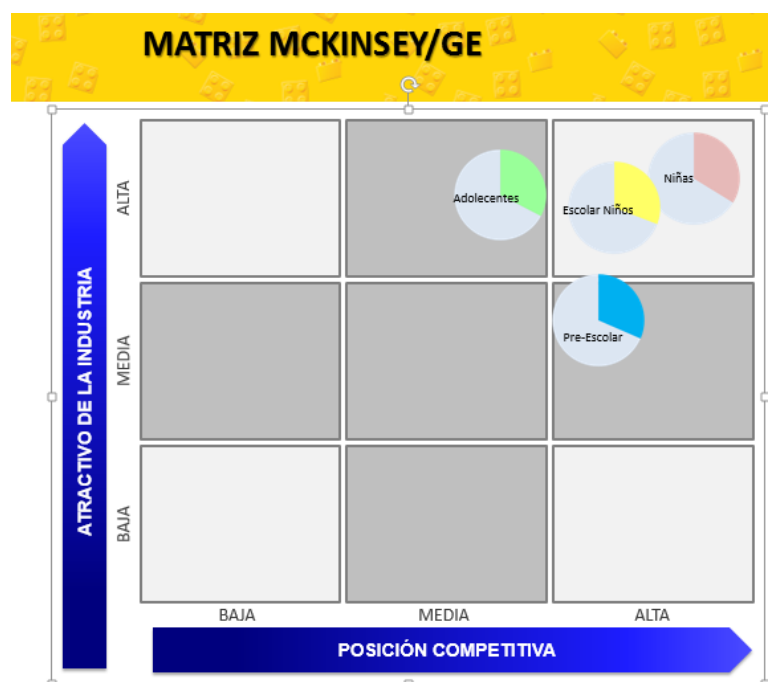

Figura 13. Matriz Mckinsey para los productos de la marca LEGO.

\subsubsection{Análisis de la Competencia.}

1. Competencia Directa

La UEN LEGO compite directamente con una serie de marcas reconocidas a nivel mundial, en el Perú esta situación se replica, siendo asi, podemos decir que los competidores directos de LEGO son:

Hasbro: Es el segundo fabricante mundial de juguetes, con un crecimiento importante en los últimos años, a raíz de su licencia principal, Monopoly y del éxito de su licencia Transformes. Otro factor importante es su alianza con Corporación Disney para la fabricación de los juguetes de licencias como Marvel, Star Wars, Princesas, entre otros

Mattel: Principal fabricante de juguetes en el mundo. A diferencia de Disney, sus licencias parten del juguete y se extienden a los demás medios de entretenimiento infantil. Su principal licencia es Barbie. Además, cuenta con marcas como American Girl, Monster High, Hot Wheels, entre otros.

Fisher-Price: fue fundada en el año 1930 como una filial de la empresa Quaker hasta que en 1991, ésta vendió todo lo relacionado con la marca a Mattel Inc. la mayor empresa fabricante de juguetes del mundo 
Los juguetes de Fisher-Price se clasifican de acuerdo a las edades del consumidor final:

- De 0 a 5 años: Se centran en juguetes para edad pre-escolar. Éstos pueden ser muñecos para bebés, música, diversos artilugios para aprender diferentes cosas como pueden ser las letras, los números o los animales, además de elementos de ayuda para dormir (máquinas de olas, móviles, peluches, etc.

- De 6 a 11 años: Son productos más maduros que permiten el paso a los juguetes que Mattel se encarga de fabricar. De todos modos, éstos presentan versiones más infantiles, resistentes y seguras.

\section{Competencia Indirecta}

LEGO compite indirectamente con cualquier producto de juguetes que provengan de las importaciones o contrabando y que no necesariamente sean de una marca en particular. Un ejemplo de competidores indirectos para LEGO son las marcas blancas de las grandes tiendas por departamento que normalmente importan de China.

\subsubsection{Matriz de Evaluación de Factores Externos (MEFE).}

La matriz MEFE permite tener un resumen y evaluación de la información de las fuerzas políticas, económicas, sociales, tecnológicas, y ecológicas, que se genera a raíz del análisis PESTE; para de esta forma poder cuantificar los resultados en oportunidades y amenazas que tiene el entorno. Esto permitirá crear una lista establecida de las oportunidades que podrían beneficiar a la empresa y las amenazas que deberían evitarse.

Nuestra matriz de evolución de factores externos nos da un resultado de 2.86 (ver Tabla 14), lo cual ubica a nuestra industria en un escenario alentador, sin ser extremadamente favorable. 
Tabla 14

Matriz de Evaluación de Factores Externos - MEFE.

\begin{tabular}{|c|c|c|c|}
\hline & Ponderación & Clasificación & $\begin{array}{l}\text { Puntuación } \\
\text { Ponderada }\end{array}$ \\
\hline \multicolumn{4}{|l|}{ Oportunidades } \\
\hline Mercado de Juguetes en expansión a nivel nacional (15\%) & $10 \%$ & 4 & 0.40 \\
\hline Fortalecimiento en el Perú de la clase media $(2.4 \%)$ & $10 \%$ & 4 & 0.40 \\
\hline Proyecciones de crecimiento en los proximos años del sector reatail en el Peru. & $8 \%$ & 3 & 0.24 \\
\hline Crecimiento del comercio electronico y uso de medios digitales (Mobile, apps, etc). & $6 \%$ & 4 & 0.24 \\
\hline Incremento y apertura de nuevos centros comerciales & $8 \%$ & 4 & 0.32 \\
\hline Desarrollo de la tecnologia de almacenamiento virtual. & $5 \%$ & 3 & 0.15 \\
\hline Marco legal favorable para la inversion extranjera. & $5 \%$ & 4 & 0.20 \\
\hline \multirow{2}{*}{$\begin{array}{l}\text { Mayor formalizacion y exigencia de las autoridades peruanas para la importacion } \\
\text { de Juguetes (control de calidad) }\end{array}$} & $7 \%$ & 3 & 0.21 \\
\hline & $59 \%$ & & \\
\hline \multicolumn{4}{|l|}{ Amenazas } \\
\hline Tasa de natalidad cada vez mas controlada con tendencia a la baja. & $6 \%$ & 2 & 0.12 \\
\hline Volatilidad en los últimos meses del dólar (con tendencia al alza). & $8 \%$ & 2 & 0.16 \\
\hline Indice de rotacion de personal en el Peru es alto $(18 \%)$ & $5 \%$ & 2 & 0.10 \\
\hline Alto poder de negociacion de los proveedores & $6 \%$ & 1 & 0.06 \\
\hline Alto poder de negociacion de los grandes distribuidores (canal moderno) & $6 \%$ & 1 & 0.06 \\
\hline Incetidumbre politica por las elecciones presidenciales (desconfianza de los inversionistas) & $4 \%$ & 2 & 0.08 \\
\hline \multirow{2}{*}{$\begin{array}{l}\text { Fenomeno del Niño podria afectar varios sectores de la economia, reduciendo la } \\
\text { capacidad de compra de un grupo de consumidores }\end{array}$} & $6 \%$ & 2 & 0.12 \\
\hline & $41 \%$ & & \\
\hline Total & $100 \%$ & & 2.86 \\
\hline
\end{tabular}

\subsection{Análisis Interno}

Para la realización del análisis interno utilizaremos como herramienta la cadena de valor y se complementara con la Matriz de Evaluación de Factores Internos (MEFI).

Se ha descrito brevemente la actual situación de la empresa en sus áreas funcionales desde el punto de vista comercial y/o de Marketing.

\subsubsection{Análisis de la Cadena de Valor de COMEXA para la UEN LEGO.}

Para el análisis de cadena de valor, se toman en cuenta diversos factores que intervienen en la creación de valor en un producto. Para COMEXA se separó en actividades de apoyo que son: infraestructura, gestión de recursos humanos, dirección, sistemas y finanzas; y en actividades 
primarias como son: logística, marketing, ventas y servicio post ventas. A continuación pasaremos a describirlas.

\subsubsection{Actividades de Apoyo.}

En la cadena de Valor de Michael Porter las actividades de apoyo son las que sustentan a las actividades primarias y se apoyan entre sí, proporcionando insumos comprados, tecnología, recursos humanos y varias funciones de toda la empresa.

Infraestructura: COMEXA, posee su centro de operaciones en San Isidro, en la calle Libertadores 454. Acá se manejan la mayoría de áreas como Marketing, Ventas, Finanzas, Recursos humanos, Contabilidad, Sistemas. Estas oficinas actualmente tienen más de 50 trabajadores, y dado el crecimiento que ha registrado la compañía en los últimos años, se estima que será necesario una remodelación de sus instalaciones o el desplazarse a un área más grande.

COMEXA, cuenta con otro punto estratégico para la atención de sus clientes que desean algún servicio de post venta, este punto se ubica en el centro de Miraflores, en la avenida Comandante Espinar. Asimismo, COMEXA ha logrado desarrollar su crecimiento mediante la apertura de tiendas propias en distintos puntos de Lima y provincias del Perú. Estas tiendas, se encuentran bajo el nombre de Baby Infanti Store y Lego Store, logrando tener hoy en día, 28 puntos de ventas. Mediante esta estrategia COMEXA, logra acercarse cada vez más a sus consumidores.

Asimismo, COMEXA maneja en el Perú marcas reconocidas a nivel mundial como Infanti, Lego, Chicco, Britax, Bebe Confort, entre otras

Gestión de RRHH: Se encarga del reclutamiento y capacitación de personal que irían a las distintas tiendas y los otros canales de distribución con que opera COMEXA. Debe velar porque el canal propio (tiendas propias), no estén desabastecidas de personal (vendedores) y su posterior entrenamiento. 
Para el caso del personal que se contrata para LEGO, ya sea que este vaya a las grandes cadenas Retail como mercaderistas o promotores, o a su propia red de tiendas (LEGO STORE), se busca un perfil que tenga cierta afinidad con la marca, adicional a las competencias básicas que se solicitan a un vendedor o promotor convencional. Es decir, lo que se busca es que el vendedor hable el mismo idioma del consumidor o cliente, para poder asesorarlo de manera adecuada hasta que se pueda concretar la venta. El área de RRHH, entre otras cosas tiene como funciones:

- Competencias y calificaciones profesionales.

- Selección, capacitación, y desarrollo del personal.

- Disponibilidad y calidad de los vendedores

- Costos laborales en relación a la industria y los competidores.

- Nivel de remuneraciones y beneficios.

- Efectividad de los incentivos al desempeño.

- Nivel de rotación y de ausentismo.

- Calidad del clima laboral.

Actualmente esta área se encuentra en restructuración, dada el alto índice de disconformidad que se pudo encontrar en las últimas encuestas internas de clima laboral, y por los excesivos tiempos que tardan en poder reponer al personal en tienda.

Dirección: La alta dirección de COMEXA actualmente tiene claro el panorama para desarrollar el negocio en el corto plazo, sin embargo, tiene una miopía estratégica para establecer un plan a mediano y largo plazo. Esta falta de planificación a mediano y largo plazo, trae consigo incertidumbre de todas las áreas acerca de que es lo que quiere la empresa. El liderazgo ejercido por la Gerencia general ha sido fundamental para lograr conseguir los objetivos año tras año, sin embargo, es necesario trabajar en un plan más elaborado con objetivos mucho más trascendentales. 
Sistemas: El área de Sistemas, está monitoreando que el flujo de información se maneje de manera adecuada, desde Administración Central hacia tiendas. Asimismo vela para que la interface entre los Key Account de COMEXA y la información proveniente de sus grandes clientes, este actualizada para una correcta toma de decisiones del área de Marketing y Comercial. Asimismo, el área está desarrollando nuevos proyectos, para mejorar el flujo de información que la compañía requiere, ya que actualmente el canal propio (Tiendas propiasLEGO STORE-BABY INFANTI STORE), requiere reportes más avanzados para medir el nivel de rotación de sus inventarios (inmovilización de productos), y el nivel de quiebre de estos.

Finanzas: Se encarga de evaluar a los nuevos clientes, así como establecer las políticas de pagos y créditos. Esta área, evalúa constantemente los mejores mecanismos para mantener un flujo activo de dinero (caja) para no tener problemas de efectivo, así como también que los indicadores financieros estén dentro de los parámetros establecidos por la gerencia general.

Se pudo ver que existía un problema en el ciclo de conversión del efectivo, debida a que se otorgan créditos con más de 60 días, sin embargo la mayoría de pagos se hace a 45 días. Además no existe una política clara para alinear a los proveedores y clientes en sus fechas de pago, generando desorden e incomodidad.

Actualmente el canal de tiendas propias (LEGO y BABY INFANTI STORE), le generan el efectivo diario a la compañía, ya que estas tiendas no trabajan a crédito (salvo el cliente pague con tarjeta de crédito).

Asimismo COMEXA, al ser parte de DOREL GROUP, tiene una sólida espalda financiera, lo que le permite, generar inversiones importantes si se presentasen oportunidades de mercado que ameriten invertir. 


\subsubsection{Actividades Primarias.}

Importaciones: El área de importaciones le hace el seguimiento para que la mercadería llegue a destino dentro de los tiempos planificados. Asimismo, se encarga de las coordinaciones para que se cumplan con todas las normas y requisitos establecidos por Aduanas.

Debemos tomar en cuenta, que para realizar el futuro plan de marketing es necesario estar alineados con los tiempos en que llega la mercadería de determinada línea, para asegurarnos que se tiene la amplitud y profundidad necesaria en caso se planifiquen campañas puntuales de determinada línea de productos.

Almacenamiento y Distribución: Vela porque los productos lleguen a los distintos clientes, ya sea del canal moderno, tradicional y tiendas propias. Asimismo es el responsable del correcto almacenaje y de las mermas que se pueden generar en la gestión de reposición, velando por llevar un correcto sistema de control de inventarios y rotación de estos.

El área de Logística de COMEXA, viene trabajando con un reconocido operador logístico como UNIMAR, quien es el actual socio estratégico de COMEXA en lo que a la cadena de abastecimiento se refiere. UNIMAR tiene muchos años y experiencia en el mercado, agilizando la operación y moldeándola para que esta tenga cada vez menos contratiempos.

La función de logística es vital, ya que con una correcta planificación en los despachos, nos aseguramos que no falte mercadería en el punto de venta. Esta área ha ido mejorando sus ratios en los últimos años, reduciendo los "No despachos" de manera considerable.

Debemos considerar que el consumidor y/o cliente de la marca LEGO, es muy exigente en cuanto a las novedades que la marca tiene, siendo importante para COMEXA, 
tener estas cuanto antes en las tiendas, ya sea propias o las de intermediación, con el fin que lleguen a nuestro consumidor final.

Marketing: Toma las decisiones estratégicas relacionadas a las marcas que maneja COMEXA en su cartera, estas decisiones están relacionas a la colocación de precios con que saldrán al mercado, la comunicación para cada tipo de cliente, los canales de distribución que se utilizaran, y como podremos ingresar a nuevos mercados o mejorar nuestra posición en los mercados actuales.

El área de Marketing de COMEXA, está encargada de la planificación de las compras de mercadería a los proveedores locales y extranjeros, por lo que debe negociar volúmenes, márgenes, y un correcto control de sus inventarios internos para no tener un sobre stock que dificulte la capacidad de compra.

La marca LEGO en el Perú, tiene dentro de marketing una Product Manager que se encarga de todas las decisiones en cuanto al MIX de productos y una correcta distribución a sus distintos canales, ya sea tiendas propias y/o los canales de distribución.

Actualmente Marketing no maneja de manera adecuada sus mediciones o indicadores de gestión, partiendo de la premisa que para saber que algo ha funcionado debe medirse, ya que solo conociendo el impacto real de una campaña o acción táctica, es que podrá ajustarse o mejorar la estrategia.

Algunos puntos en que se debe mejorar son:

- Mix de productos: balance beneficio-costo de los bienes y servicios

- Comunicaciones integradas.

- Planeamiento de los productos.

Ventas: El área de ventas de COMEXA, está a cargo de dos canales de distribución. Canal de tiendas propias y canal de intermediarios. Cada canal debe velar por lograr sus objetivos e indicadores anuales y mensuales. El canal propio o B2C, está compuesto por 
vendedores de tiempo completo, medio tiempo, jefes de tienda, supervisores zonales y un jefe del canal. Los indicadores que se miden en este canal con mayor frecuencia, son proyecciones de ventas diarias por tienda, proyecciones de ventas diarias por familias y unidades estratégicas de negocios, variación en los tickets promedio, número de visitantes a las tiendas y ratios de conversión, este canal no otorga crédito a sus clientes, ya que trabaja con el consumidor directamente. El canal de intermediación o B2C, está compuesto por mercaderistas, supervisores de mercaderistas, Key Account, y un gerente del canal. Deben generar vínculos fuertes con los clientes o compradores y dar el soporte necesario a sus actividades para que se pueda generar el Sell In y el Sell Out de los productos que comercializa COMEXA.

Servicio: COMEXA, se está enfocando recién, en desarrollar un plan de capacitaciones para los vendedores, teniendo hoy en día como una de las prioridades para que el servicio integral que ofrece sea percibido como generador de valor. El servicio integral que quiere desarrollar se dará en todas las aristas, desde el cliente interno (personal), el servicio de atención dentro de cada tienda, y el servicio técnico con reparaciones rápidas y confiables, disponibilidad de los repuestos, etc.

\subsubsection{Competencias Básicas de la Empresa.}

Se entiende como competencias básicas de una empresa, a todas aquellas actividades de la misma, que están orientadas a generar valor, de tal forma que puedan convertirse incluso en una ventaja competitiva para la compañía. De acuerdo a la firma consultora Bain \& Company, la prueba de fuego para una competencia básica es que sea difícil de copiar o desarrollar por los competidores.

Comexa al ser una importadora de productos Lego, tiene como competencias básicas las siguientes: 
- Servicio al Cliente. Las tiendas Lego ofrecen a sus clientes una atención especializada, brindada por un personal capacitado en los productos de la marca, Este personal no solamente está capacitado en los productos, sino también a pasado por una capacitación de servicio al cliente con lo cual no solo ofrece conocimiento del producto que vende (LEGO), sino también calidez, amabilidad, cercanía y manejo de objeciones en el trato con los clientes.

- $\quad$ Flexibilidad. Debido a los rápidos cambios del mercado, originados por la globalización y tendencias mediáticas, Comexa es flexible y se adapta rápidamente a los nuevos requerimientos del mercado, así por ejemplo las líneas de productos y los productos en sí, están constantemente adaptándose a las tendencias del mercado actual. Un ejemplo de ello son las líneas Lego Star Wars, Lego Super Heroe, Lego City, etc.; las cuales se lanzaron de acuerdo a los momentos en que estos iconos mediáticos se pusieron de moda, logrando una gran aceptación de los consumidores.

- Calidad. Los productos Lego son a nivel mundial sinónimo de calidad, lo cual general mente está asociado a los conceptos de fiabilidad y rendimiento. Esto permite gozar de la confianza de nuestros clientes permitiéndonos exigir un mayor precio por el producto que ofrecemos.

- Distribución por medio de canales propios(tiendas propias) a nivel nacional:

- Logística integrada: COMEXA, ha logrado obtener una ventaja competitiva en cuanto al abastecimiento y toda su cadena de suministro, así se logra optimizar recursos en poder tener el producto en los tiempos estimados.

\subsubsection{Capacidades de Marketing de la Empresa.}

Day (1994) define las capacidades de marketing como aquellas habilidades y competencias de la empresa que le ayudan no sólo a entender el comportamiento de los factores que definen sus mercados, sino también aquellas que le permiten operar de manera 
más efectiva en dichos mercados. Este tipo de capacidades de marketing incluye capacidades de comprensión del mercado como la investigación de mercados, capacidades para crear y mantener relaciones de mercado como la gestión de relaciones con los clientes y capacidades cruzadas.

La capacidad Marketing de Comexa son los recursos y aptitudes que tiene para desempeñar una correcta comercialización de los productos LEGO, las cuales son:

Producto: COMEXA a través de los productos de la marca Lego, otorga calidad e innovación a sus clientes.

Precio: COMEXA, ha desarrollado una estrategia de precios basados en el alto valor que proyecta la marca LEGO en el Perú.

Comunicación: COMEXA, se cuelga de la comunicación internacional que la marca ha desarrollado para Latinoamérica, y no ha hecho esfuerzos por desarrollar una estrategia de comunicación integral local.

Distribución: COMEXA, utiliza múltiples canales de distribución para llegar al consumidor final, ya sea a través de su canal propio (tiendas LEGO STORE y Baby Infanti Store) o través de sus canales de intermediación.

Existe una clara debilidad en el área de Marketing por el poco conocimiento que se tiene de los hábitos de compra de los potenciales consumidores de LEGO. Además se es necesario para COMEXA, que el área de Marketing empiecen a trabajar en un plan de marketing estructurado que les permitan aprovechar las ventajas competitivas que se tienen.

\subsubsection{Matriz de Evaluación de Factores Internos (MEFI).}

El puntaje para la organización luego de hacer el análisis MEFI (ver Tabla 15), es de 3.11, ubicándose por encima del promedio, lo que nos permite concluir que COMEXA, es una organización fuerte, posee una consistencia interna interesante como para competir exitosamente en el mercado de juguetes. Para ello debemos poner énfasis en las debilidades, 
desarrollando estrategias internas que nos permitan superarlas, de ser posible convertirlas en fortalezas. Así mismo, aprovechar las fortalezas para seguir creciendo en el mercado.

\section{Tabla 15}

Matriz de Evaluación de Factores Internos

\begin{tabular}{|c|c|c|c|}
\hline & Ponderación & Clasificación & $\begin{array}{l}\text { Puntuación } \\
\text { Ponderada }\end{array}$ \\
\hline \multicolumn{4}{|l|}{ Fortaleza } \\
\hline Se encuentra en una etapa de crecimiento según el ciclo de vida del producto. & $6 \%$ & 4 & 0.24 \\
\hline Maneja un amplio Mix de productos & $8 \%$ & 4 & 0.32 \\
\hline Se encuentra en la mayoria de C.C a traves de cualquiera de sus canales distribucion. & $8 \%$ & 4 & 0.32 \\
\hline La marca LEGO en el Peru, ofrece una amplia variedad de precios. & $6 \%$ & 3 & 0.18 \\
\hline $\begin{array}{l}\text { La selección del personal es sometida a rigurosas pruebas que garanticen la estandarizacion } \\
\text { del servicio a nivel mundial. }\end{array}$ & $8 \%$ & 4 & 0.32 \\
\hline La compañía se encuentra con un buen soporte financiero. & $6 \%$ & 3 & 0.18 \\
\hline Tiene un alto poder de negociacion para con los clientes de los centros comerciales. & $6 \%$ & 4 & 0.24 \\
\hline Cuenta con la garantía de la marca LEGO, reconocida a nivel mundial. & $8 \%$ & 4 & 0.32 \\
\hline Altos estandares en cuanto a calidad del producto. & $8 \%$ & 4 & 0.32 \\
\hline \multirow[t]{2}{*}{ Las tiendas LEGO STORE en Lima, cuentan con una infraestructura moderna. } & $6 \%$ & 3 & 0.18 \\
\hline & $70 \%$ & & \\
\hline \multicolumn{4}{|l|}{ Debilidades } \\
\hline Las importaciones muchas veces presentan retrasos, lo que genera incomodidad & $4 \%$ & 1 & 0.04 \\
\hline Reduccion de espacios en el canal moderno por falta de gestion del area comercial. & $4 \%$ & 2 & 0.08 \\
\hline Falta de un sistema integrado para administrar los datos de los clientes & $2 \%$ & 2 & 0.04 \\
\hline Falta de eventos y activaciones en coordinacion con los centros comerciales. & $4 \%$ & 2 & 0.08 \\
\hline $\begin{array}{l}\text { Falta de planificación para las promociones del mes, lo que se traduce en una mala } \\
\text { distribución a las tiendas. }\end{array}$ & $5 \%$ & 2 & 0.10 \\
\hline Falta presencia en la redes sociales. & $4 \%$ & 2 & 0.08 \\
\hline Falta de un programa de capacitacion continua a la fuerza de ventas & $3 \%$ & 1 & 0.03 \\
\hline \multirow[t]{2}{*}{ Falta de convenios y/o alianzas estrategicas } & $4 \%$ & 1 & 0.04 \\
\hline & $30 \%$ & & \\
\hline Total & $100 \%$ & & 3.11 \\
\hline
\end{tabular}

\subsubsection{Gama de Productos LEGO}

Si bien es cierto, las líneas de productos la marca LEGO es sumamente amplia y variada, en el Perú, por el poco tiempo que se tiene en el mercado tenemos aún una oferta limitada (ver Figura 14).

Dado que se pudieron identificar sectores muy puntuales, estos se agruparon para poder diferenciarlos y tener un mejor enfoque en el momento de desarrollar los objetivos y estrategias.

Básicamente se encontraron 4 segmentos, entre los cuales figuran:

- Prescolar-Bebes 
- Escolar-Niños

- Escolar-Niñas

- Adolescentes.

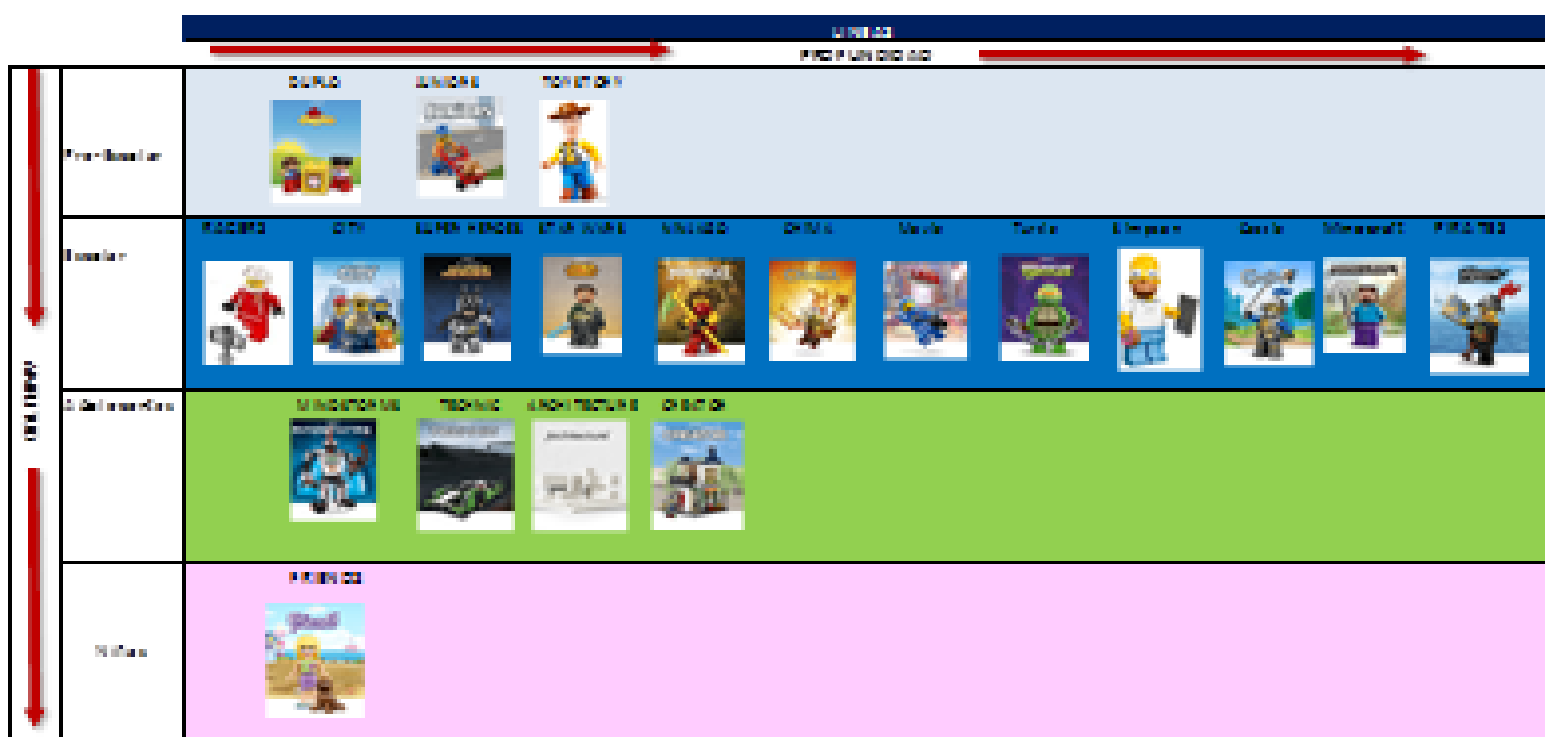

Figura 14. Matriz amplitud y Profundidad de los productos de la marca LEGO.

\subsubsection{Ciclo de Vida de los Productos}

Los productos de la marca Lego en el Perú, se encuentran en una etapa de crecimiento (ver Figura 15). Esta fase se caracteriza por un crecimiento en las ventas a un ritmo acelerado. Lo que se busca es que tengamos usuarios satisfechos y que se transforme en consumidores que repiten sus compras, e influyen en otros usuarios potenciales por una comunicación de boca a boca, lo que mejora la tasa de participación del mercado.

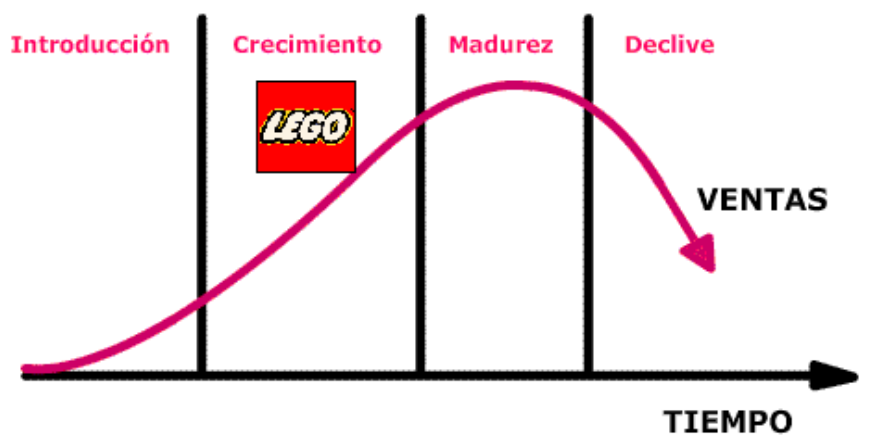

Figura 15. Ciclo de Vida de la marca LEGO. 


\subsubsection{Canales de Distribución.}

Los productos de la marca LEGO llegan al consumidor final a través de dos canales: B2B, B2C. Donde el canal B2B es el que se encarga de comercializar los productos a través de intermediarios, sub-distribuidores, mayoristas (canal moderno). Y el canal B2C es el que se encarga de vender el producto directamente al consumidor final a través de las tiendas LEGO y Baby Infanti Store (ver Figura 16).

\begin{tabular}{|c|c|c|c|c|}
\hline \multicolumn{2}{|c|}{ COMEXA B2B } & \multicolumn{2}{c|}{ COMEXA-B2C } \\
\hline TRADICIONAL & \multicolumn{2}{|c|}{ MODERNo } & \\
\hline LIMA & Tiendas por Dptos & Supermercados & Tienda Virtual-Web \\
\hline Lima Centro/Otros comercios & Saga/Ripley/Oeshle/Paris & Wong/Metro/Tottus/Vivanda \\
\hline
\end{tabular}

Figura 16. Canales de Distribución de la marca LEGO.

Baby Infanti Store: Tiendas dedicadas a la venta exclusiva de artículos para Bebes y accesorios, en estas tiendas se comercializa la marca INFANTI pero tienen espacios exclusivos donde también se comercializa la marca LEGO. Actualmente se cuenta con 25 tiendas BABY INFANTI a nivel nacional.

Actualmente cuenta con 3 tiendas en Lima y aún no ha incursionado en las provincias. Las Tiendas Baby Infanti Store sirven también de plataforma para la distribución de los productos LEGO.

Baby Infanti cuenta con una página Web a través de la cual realizan las ventas de sus productos donde presenta la relación de colecciones que ofrece. Es usando este canal que también se comercializan los productos de la marca LEGO

Se necesita desarrollar una página web más moderna, dinámica, responsiva y con plataforma de pagos a fin de informar de nuevos lanzamientos, promocionar productos, y 
generar nuevos clientes, además de generar una plataforma exclusiva para LEGO, y que no esté vinculada a Baby Infanti.

La distribución de los productos LEGO se hace a través de toda la cadena de tiendas de COMEXA, es decir a través de las tiendas BABY INFANTI y LEGO STORE, tal como se puede apreciar en la Figura 17, estas se encuentran estratégicamente ubicadas en las principales ciudades del Perú.

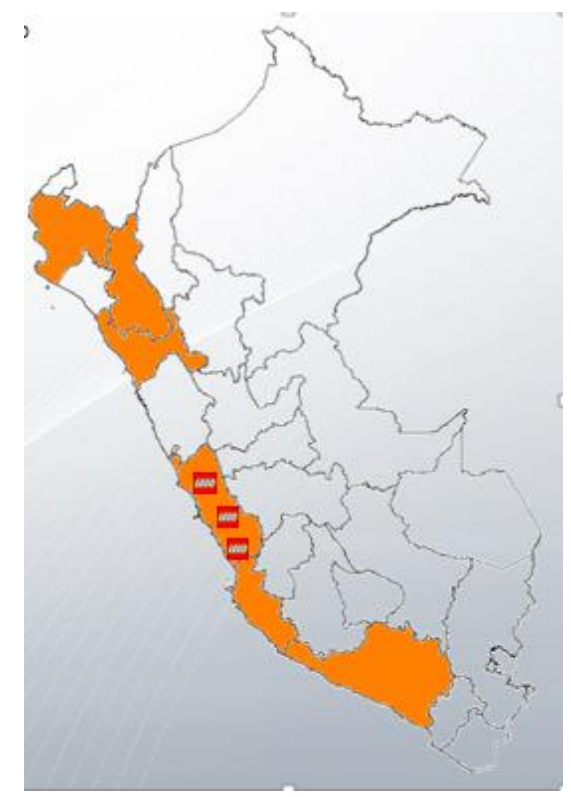

Figura 17. Ubicación de COMEXA en el Perú.

\subsubsection{Precio}

Los productos de la marca LEGO según el análisis de precios que se pudo hacer dentro de la compañía, son inelásticos (ver Tabla 16), lo que equivale decir que ante un incremento del precio, la cantidad demandada se reduce en menor proporción. La estrategia actual de precio de la UEN de LEGO está basada en el alto valor percibido por los clientes hacia la marca. Por ello esta unidad maneja un margen alto sobre el costo de los productos teniendo precios promedios que oscilan entre S/.169 y S/.229. 
Actualmente el margen de la UEN de LEGO oscila entre $50 \%$ y $50.5 \%$. Es en el canal de tiendas propias o B2C donde se logra obtener un mayor margen (ver Tabla 17).

Tabla 16

Precio Promedio y Margen por Segmentos.

\begin{tabular}{lccccc}
\hline Segmentos & $\begin{array}{c}\text { Precio } \\
\text { Promedio }\end{array}$ & Share & Venta & Margen & $\begin{array}{c}\text { Analisis } \\
\text { Elasticidad }\end{array}$ \\
\hline Pre-Escolar & S/. 229 & $25 \%$ & S/.6,240,131 & $50.00 \%$ & Inelastica \\
Escolar & S/. 229 & $43 \%$ & S/. 11,011,996 & $50.00 \%$ & Inelastica \\
Adolecente: & S/. 199 & $13 \%$ & S/. 3,303,599 & $50.00 \%$ & Inelastica \\
Niñas & S/. 169 & $19 \%$ & S/.4,771,865 & $50.00 \%$ & Inelastica \\
\hline Total & $100.00 \%$ & S/.25,327,591 & $50.00 \%$ & \\
\hline
\end{tabular}

Nota: Información interna de COMEXA.

Tabla 17

Margen por Canal.

\begin{tabular}{lccc}
\hline \multicolumn{1}{c}{ Canal } & 2015 & $\begin{array}{c}\text { Margen } \\
\text { Actual }\end{array}$ & S/. \\
\hline B2B & $\mathrm{S} / .8,472,459$ & $40 \%$ & $\mathrm{~S} / .3,388,983$ \\
B2C & $\mathrm{S} / .16,855,132$ & $55 \%$ & $\mathrm{~S} / .9,270,323$ \\
\hline Total & $\mathrm{S} / .25,327,591$ & $50 \%$ & $\mathrm{~S} / .12,659,306$ \\
\hline
\end{tabular}

Nota: Información interna de COMEXA.

\subsubsection{Comunicación}

Actualmente la estrategia de comunicación de los productos de la marca LEGO se basa en publicitarse en la televisión por cable aprovechando la estrategia regional de LEGO para Latinoamérica. En el Perú, LEGO no se anuncia a través de la radio o los medios escritos (ver Figura 18). 


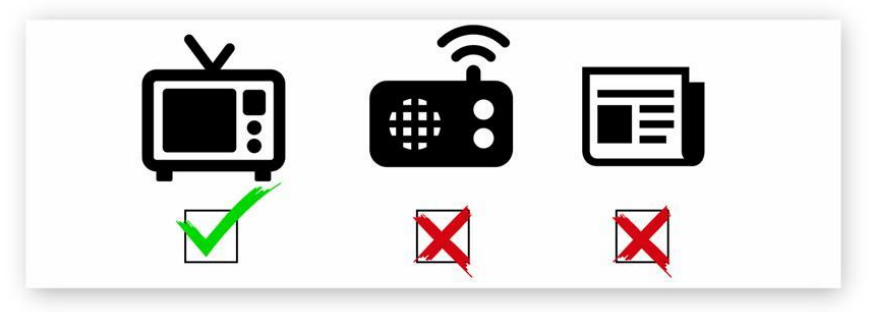

Figura 18.Comunicación Tradicional.

Aprovechando la penetración y el desarrollo exponencial de las redes sociales, a partir del 2014, LEGO implemento un Fan Page en Facebook. Sin embargo el manejo de esta comunicación no se explota en su real dimensión, no tiene una página web para LEGO Perú, no participa en pinterest, Youtube, instagram y finalmente la administración de la comunicación no recae en un community manager (ver Figura 19).

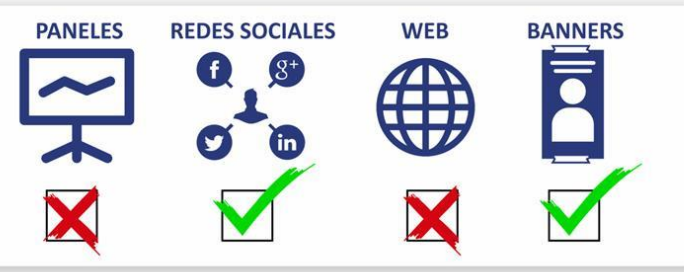

Figura 19. Comunicación No Tradicional.

\subsection{Matriz FODA.}

Tanto las variables analizadas en el entorno externo como interno, que se mostraron en los puntos anteriores, contribuyeron para hacer un análisis FODA, enfocado en la UEN LEGO. La matriz FODA la podemos ver en las Tablas 18,19,20 y 21. 
Tabla 18

Matriz FODA - Fortalezas

Nro.

Fortalezas

1 Se cuenta con productos estrellas dentro de la cartera

2 Maneja un amplio Mix de productos.

3 Se encuentra en la mayoria de C.C a traves de cualquiera de sus canales distribucion.

$4 \quad$ Ofrece una amplia variedad de precios.

$5 \quad$ La selección del personal es sometida a rigurosas pruebas que garanticen la estandarizacion del servicio a nivel mundial.

6 La compañía se encuentra con un buen soporte financiero, lo que les permite tener capital disponible para continuar expandiéndose.

$7 \quad$ La marca LEGO, le genera a COMEXA un alto poder de negociacion para con los clientes de los centros comerciales.

8 Contar con la garantía de la marca LEGO, reconocida a nivel mundial.

9 Altos estandares en cuanto a calidad del producto.

10 Las tiendas LEGO STORE en Lima, cuentan con una infraestructura moderna.

Tabla 19

Matriz FODA - Oportunidades

Nro.

Oportunidades

$1 \quad$ Mercado de Juguetes en expansión a nivel nacional (15\%)

2 Fortalecimiento en el Perú de la clase media (2.4\%)

3 Proyecciones de crecimiento en los proximos años del sector reatail en el Peru.

4 Crecimiento del uso de internet y de medios digitales (Mobile, apps, etc).

5 Incremento y apertura de nuevos centros comerciales

6 Desarrollo de la tecnologia de almacenamiento virtual.

$7 \quad$ Marco legal favorable para la inversion extranjera.

8 Mayor formalizacion y exigencia de las autoridades peruanas para la importacion de Juguetes (control de calidad) 
Tabla 20

Matriz FODA - Debilidades

Nro.

Debilidades

1 Las importaciones de la marca LEGO, muchas veces presentan retrasos, lo que genera incomodidad en los clientes y/o consumidores

2 Reduccion de espacios en el canal moderno por falta de gestion del area comercial.

$3 \quad$ No se cuenta con un sistema de captura de datos

$4 \quad$ Poca profundidad en el portafolio de productos LEGO en el Perú

$5 \quad$ Falta de eventos y activaciones en coordinacion con los centros comerciales.

$6 \quad$ Falta de planificación para las promociones del mes, lo que se traduce en una mala distribución a las tiendas.

$7 \quad$ No se ha desarrollado un plan para medios digitales

$8 \quad$ Falta de un programa de capacitacion continua a la fuerza de ventas

$9 \quad$ Falta de convenios y/o alianzas estrategicas para generarle trafico a nuestros canales de distribucion.

Tabla 21

Matriz FODA - Amenazas

\begin{tabular}{cl}
\hline Nro. & \multicolumn{1}{c}{ Amenazas } \\
\hline 1 & Tasa de natalidad cada vez mas controlada con tendencia a la baja. \\
2 & Volatilidad en los últimos meses del dólar (con tendencia al alza). \\
3 & Indice de rotacion de personal en el Perú es alto (18\%) \\
4 & Alto poder de negociacion de los proveedores \\
5 & Alto poder de negociacion de los grandes distribuidores (canal moderno) \\
6 & Incetidumbre politica por las elecciones presidenciales (Desconfianza \\
& de los inversionistas) \\
7 & Fenomeno del Niño podria afectar varios sectores de la economia, reduciendo la \\
& capacidad de compra de un grupo de consumidores \\
\hline
\end{tabular}




\section{Capítulo IV. Estudio de Mercado}

\subsection{Problema de investigación}

Como se ha visto en el punto 1.2 "Definición del problema u oportunidad", en este caso, es claro que nos enfrentamos a un problema de decisión administrativa que se orienta a la posibilidad de invertir en la expansión de la marca LEGO en el Perú, teniendo como respaldo el crecimiento de ventas de la marca desde que ingreso al mercado peruano en el año 2012.

Este contexto y la rentabilidad obtenida en los últimos años, hacen que el tomador de decisiones defina el problema de decisión administrativa:

¿Debería COMEXA invertir en la expansión de la marca LEGO en el Perú?

Para poder responder esta pregunta, el investigador debe responder a la pregunta ¿Cómo es el comportamiento del consumidor peruano de juguetes y productos de la marca LEGO?

Esta investigación para determinar si existe una demanda insatisfecha, nos lleva a plantear las siguientes preguntas específicas:

1 ¿Quiénes son nuestros clientes? ¿Cuáles son sus características socioeconómicas, psicográficas y de comportamiento de compra?

2 ¿Cómo perciben los clientes la marca LEGO? ¿A todos los atrae lo mismo?

3 ¿Existen compradores potenciales del mercado objetivo insatisfecho?

Hipótesis:

H1: Existe relación en comprar juguetes en tiendas especializadas con tener hijos.

H2: Existe relación en comprar juguetes de la marca LEGO con producto educativo.

H3: Existe relación en comprar juguetes de la marca LEGO con producto de calidad.

H4: Existe relación en comprar juguetes de la marca LEGO con el precio. 


\subsection{Necesidades de Información}

El objetivo de la investigación entonces parte de la necesidad de validar estas hipótesis anteriormente planteadas y para ello buscó y analizó la información relevante a este mercado. Esta información se divide en componentes de información de la siguiente manera:

Componente 1: Características Socio Demográficas, Psicográficas y Comportamiento de compra.

Socio Demográfica: Ingreso, ocupación, educación, nivel socio económico.

Psicográficas: Personalidad, estilos de vida, intereses, gustos, inquietudes, opiniones, valores

Comportamiento de compra: Lealtad de marca beneficios buscados (precio, calidad, servicio), tipo de usuario, nivel de uso (heavy / ligth users), hábitos de consumo y de compra (lugar de compra, frecuencia de compra, volumen de compra)

Componente 2: Atributos de la marca

Atributos de la marca: Calidad, Creatividad, Aprendizaje, Innovación.

Componente 3: Demanda Insatisfecha

No es necesario obtener información adicional.

\subsection{Método de investigación cualitativo}

Para el desarrollo de esta investigación cualitativa usamos el grupo de enfoque o "focus group" como herramienta que ayudó a encontrar la información que se necesitaba.

\subsubsection{Proceso de muestreo.}

1. Definición de la población.

Para este estudio nos enfocamos en hombres y mujeres entre los 25 y 45 años de edad, que sean padres de familia con hijos menores a los 16 años que hayan comprado al menos una vez la marca LEGO.

2. Tamaño de la muestra 
Para ello, se desarrollaron dos sesiones grupales ocho personas, siendo un grupo de hombres y otro de mujeres.

3. Selección de los elementos de la muestra

Se seleccionó a los participantes de los dos focus, usando los siguientes criterios:

Grupo 1 Un grupo de hombres, padres de familia entre los 25 y 45 años de edad.

Un grupo de mujeres, madres de familia entre los 25 y 45 años de edad.

En total participaron 16 personas dentro del segmento objetivo.

\subsubsection{Obtención de datos}

La obtención de datos fue desarrollada en dos partes. Por un lado, se diseñó una guía de pautas que tuvo como objetivo, obtener información exploratoria sobre las características psicográficas, sociodemográficas y el comportamiento de compra de las personas que participaron en las sesiones grupales. Por otro lado, se llevó a cabo la aplicación de la guía de pautas a través de dos "Focus Group" como trabajo de campo, lo que permitió obtener información relevante para la investigación.

\subsubsection{Diseño de la guía de pautas:}

El punto de partida para el diseño de la guía de pauta se inició con el análisis de los componentes uno y dos de las necesidades de información (características sociodemográficas, psicográficas, comportamiento de compra y los atributos de marca), los cuales nos llevaron a estructurar la guía de pautas. Asimismo, las preguntas que se plantearon tuvieron como objetivo responder a las interrogantes previamente planteadas a través de las necesidades de información.

La guía de pautas se dividió en cuatro segmentos. En primer lugar, la introducción, la cual tuvo como finalidad conocer de forma general a las personas, "romper el hielo" y crear una atmósfera de confianza entre los participantes y el entrevistador. En segundo lugar, se plantearon preguntas que hacían referencia a las características sociodemográficas, 
psicográficas y el comportamiento de compra de los participantes. Asimismo, a través de las preguntas relacionadas con la percepción de la marca se buscó conocer la preferencia, específicamente por la marca LEGO. Finalmente, en el cierre se les pidió hacer comentarios adicionales con referencia al tema tratado y se les agradeció por su participación y apoyo brindado.

La guía de pautas consto de 26 preguntas, las cuales pueden ser revisadas en el apéndice 1.

\subsubsection{Aplicación y trabajo de campo.}

Las sesiones grupales se realizaron en las instalaciones de los Laboratorios HERSIL S.A. ubicadas en la Avenida Los Frutales 220 en el distrito de Ate.

La primera sesión grupal se realizó el martes 2 de febrero del 2016 a las 7:30 de la noche, con una duración de 60 minutos con la participación de 6 mujeres de la población objetivo. La segunda sesión grupal se realizó el lunes 15 de febrero del 2016, a las 7:00 de la noche, con una duración promedio de 65 minutos con la participación de 8 hombres de la población objetivo.

\subsubsection{Procesamiento y Análisis de datos.}

Para llevar a cabo el procesamiento y análisis de los grupos de enfoque se tuvieron que realizar, en primer lugar, las transcripciones de los 2 Focus Group, las mismas que se pueden revisar en el apéndice 2. Estas transcripciones se procesaron y analizaron mediante una ficha individual y luego una ficha resumen, la cual se puede revisar en el apéndice 4 y 5.

En la transcripción del primer focus group pudimos notar que el audio no era bueno, lo cual dificultaba el trabajo de transcribir lo que los panelistas decían, es por ello que para el segundo focus se mejoró la grabación del audio, lo cual facilito la recopilación de información. 
Tanto en el primer como en el segundo focus, el conductor de la dinámica, fue bastante efectivo a la hora de indagar por la información relevante, dirigió bien la discusión para obtener la mejor información posible de los panelistas.

\subsubsection{Resultado del Estudio Cualitativo.}

A través de la ficha resumen, se encontraron algunos datos relevantes como:

De los participantes del focus group la mayoría compra en centros comerciales y ya saben que marca van a comprar, Siendo las favoritas NERF y LEGO. La compra es influenciada por los gustos de los hijos pero es de igual importancia el precio del juguete, el consumidor en base a las marcas y a los gustos de los hijos busca ofertas y/o descuentos donde una opción de compra cada vez más fuerte es el internet. Las ocasiones de mayor compra son las fechas de cumpleaños y navidad, teniendo cada vez más rotación el "día del niño”. La compra de los juguetes también es guiada por la durabilidad y creatividad, donde Lego es conocida por los participantes como un producto de calidad y que es muy difícil que sea cambiado por otro producto similar. La mayoría de los participantes conocen la marca LEGO, así como las tiendas LEGO Store.

\subsection{Método de investigación Cuantitativo.}

\subsubsection{Proceso de Muestreo.}

El siguiente estudio se realizó en base un muestreo no probabilístico, para el cual se aplicaron encuestas de tipo personal en centros comerciales de Lima.

Se escogió aplicar las encuestas en centros comerciales porque son un espacio donde se concentra por lo general tiendas por departamentos y tiendas independientes que generan un habitual tráfico de personas, que se ajustan al perfil bajo estudio. Los centros comerciales seleccionados fueron: C.C. Lima Sur, C.C. Lima Norte, C.C. La Rambla, C.C. Jockey Plaza y C.C. San Miguel, debido a que son los más representativos en la ciudad de Lima. 
1. Definición de Población.

Hombres y mujeres entre 25 y 45 años residentes de la ciudad de Lima, que hayan comprado alguna vez un juguete y que pertenezcan al nivel socioeconómico A, B y C.

2. Tamaño de la muestra.

Se dividió la muestra en 5 grupos donde cada centro comercial era un grupo. Se asignaron 50 encuestas por C.C. Para tener un total de 250 encuestas.

El tamaño de la muestra fue de 250 encuestas para poder abarcar el mayor número de personas dispersas en la ciudad de Lima.

3. Selección de los elementos de la muestra.

Se seleccionaron personas que visitan centros comerciales de Lima (C.C. Lima Sur, C.C. Lima Norte, C.C. La Rambla, C.C. Jockey Plaza y C.C. San Miguel) con las características de la población objetivo.

\subsubsection{Obtención de Datos.}

Para la obtención de los datos estuvo divida en dos fases. Por un lado, se diseñó un cuestionario a partir de las respuestas obtenidas en los "Focus Groups" (ver apéndice 5), y por otro lado, se aplicó dicho cuestionario en los 5 grupos que representan los centros comerciales con una cuota de 50 encuestas por C.C., donde se finalizó recogiendo información a 243 personas, faltando 7 encuestas en el C.C Jockey Plaza debido a la complejidad de la población que frecuenta dicho C.C.

Todo esto permitió obtener información de suma importancia para la investigación del mercado de juguetes, características del público objetivo y necesidades de la demanda insatisfecha.

1. Diseño del cuestionario.

El cuestionario tuvo una pregunta filtro, diseñada para descartar a todas aquellas personas que estaban fuera de nuestro segmento objetivo. 
El cuestionario consto de 3 partes. La primera parte, se enfocó en el consumo general de juguetes, y tuvo 9 preguntas. La segunda parte, se enfocó en la marca LEGO, teniendo 8 preguntas. Por último, la tercera parte se enfocó en obtener datos demográficos y estuvo compuesta por 6 preguntas.

2. Aplicación.

Se trabajó con un cuestionario, el cual tenía 27 preguntas y era de manera presencial, es decir se necesitaba un encuestador y un encuestado para poder realizar la encuesta. Antes de comenzar el cuestionario, el encuestador se presentó muy amablemente y le pidió permiso para acceder a 5 minutos del tiempo del encuestado, las preguntas eran leídas por el encuestador de manera pausa para poder obtener la respuesta. El encuestador realizo la pregunta filtro para poder seguir con la aplicación del cuestionario.

Fue necesario contar con material adicional que ayudara a realizar la encuesta, como son tableros, lapiceros y cartillas.

3. Trabajo de Campo.

El Trabajo de campo estuvo a cargo de los 3 integrantes del grupo de la maestría más un compañero. Los 4 encargados de recolectar la información estuvimos capacitados y preparados bajo un check list, el cual tenía los siguientes puntos:

- Conocer el Cuestionario.

- Hacerlas preguntas según el orden establecido.

- Utilizar los términos precisos o un lenguaje sencillo para el encuestado.

- Leer despacio.

- Repetir las preguntas según las veces que sea necesario.

- Seguir las instrucciones según los saltos establecidos en el cuestionario.

El cuestionario inicio con una pregunta filtro, la misma que permitió descartar, si las personas a las que se les aplico el cuestionario, compraban o no juguetes. Esta pregunta era 
relevante para la investigación ya que todo el desarrollo se basaba en los hábitos de compra de juguetes.

Para controlar la calidad del recojo de información, fue necesario armar grupos de 2 el cual uno encuestaba y el otro supervisaba y daba apoyo logístico y/o ayudaba en resolver dudas con respecto al recojo de la información. Al finalizar cada turno se realizaba una revisión rápido de las encuestas recolectadas para identificar posibles fallas y proponer mejoras en el transcurso del próximo turno.

Las personas que se seleccionaron fueron aquellos que visitaron los centros comerciales Jockey Plaza, Lima Norte, Plaza Lima Sur, Plaza San Miguel, La Rambla San Borja, entre el Domingo 21 de Febrero y el lunes 22 de Febrero en tres turnos distintos, entre las 11 am y 1 pm, entre las $3 \mathrm{pm}$ y $5 \mathrm{pm}$ y entre las $7 \mathrm{pm}$ y $9 \mathrm{pm}$.

A las personas se les abordo con un intervalo de tiempo de cinco minutos.

\subsubsection{Procesamiento y Análisis de datos.}

Para el procesamiento de información, las encuestas fueron revisadas según el orden de llegada con la finalidad de no encontrar cuestionarios con respuestas incompletas. Un caso particular fueron las encuestas procesadas en el centro comercial Jockey Plaza, donde se encontraron 7 encuestas donde no se recolecto de la manera idónea, las cuales fueron eliminadas para el análisis. El siguiente paso fue enumerar y tabular las encuestas para poder ser ingresadas en el software SPSS versión 20. El 10\% de las encuestas digitadas se volvieron a revisar para detectar posibles errores de digitación, la depuración de la información se realizó haciendo cruce de variables o preguntas para ver la consistencia de las encuestas.

Una vez recolectada la información en una base de datos, se comenzó con el análisis exploratorio, análisis descriptivo, distribución de frecuencias, tablas simples, tablas cruzadas o de contingencia, tablas de respuestas múltiples y pruebas de hipótesis Chi Cuadrado. Es 
muy importante señalar que debido a que es una encuesta No Probabilística no puede ser inferida a la población y solo se obtiene información porcentual de la muestra encuestada.

\subsubsection{Resultados}

A continuación mostraremos los resultados de nuestra investigación:

1. Datos Básicos.

Se realizaron 243 encuestas, el $42 \%$ son del género masculino y $58 \%$ son del género femenino como se muestra en la Figura 20, concentrándose las personas encuestadas en los grupos de 30 a 44 años con $67 \%$ como indica la Figura 21.

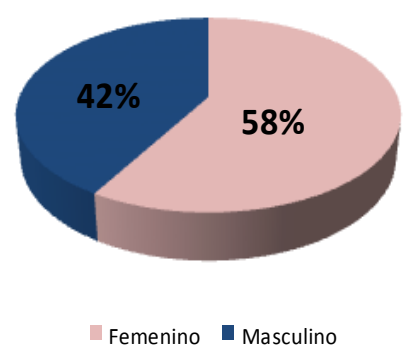

Figura 20. Genero del Encuestado.

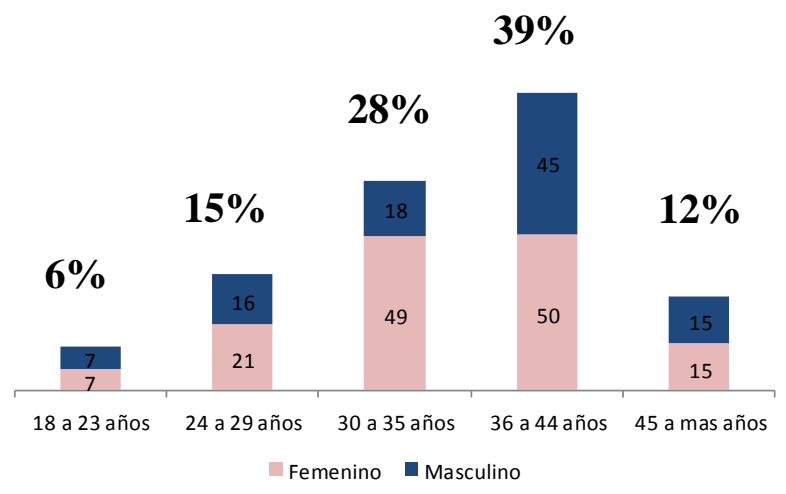

Figura 21. Distribución por rango de Edad.

Del total de los encuestados el 64\% manifiesta tener hijos (ver Figura 22) y la actividad que mayormente se realiza en tiempos libres es estar con la familia (65\%), el $40 \%$ realiza actividades sociales (ver Figura 23). 


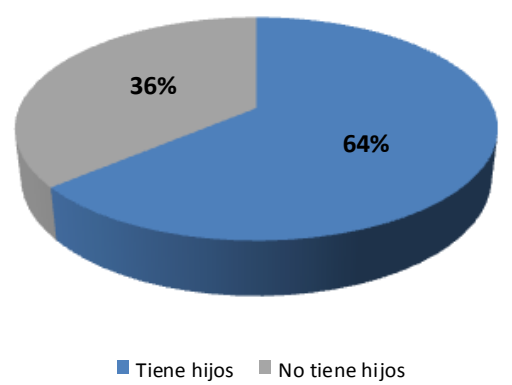

Figura 22.Porcentaje de encuestados con hijos.

En la Figura 24, se puede observar las actividades que realizan los encuestados, en relación a si tienen hijos o no, siendo el estar con la familia (74\%) la actividad más realizada por los que tienen hijos, mientras las actividades artística (55\%) son las más realizadas por los que no tienen hijos.

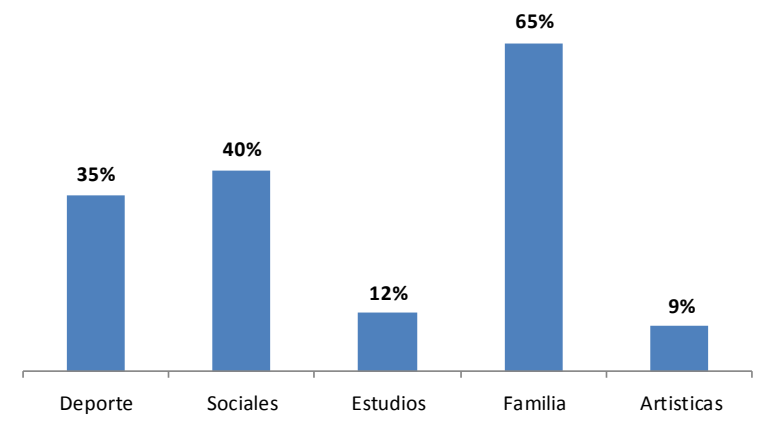

Figura 23.Actividades que realiza en sus ratos libres.

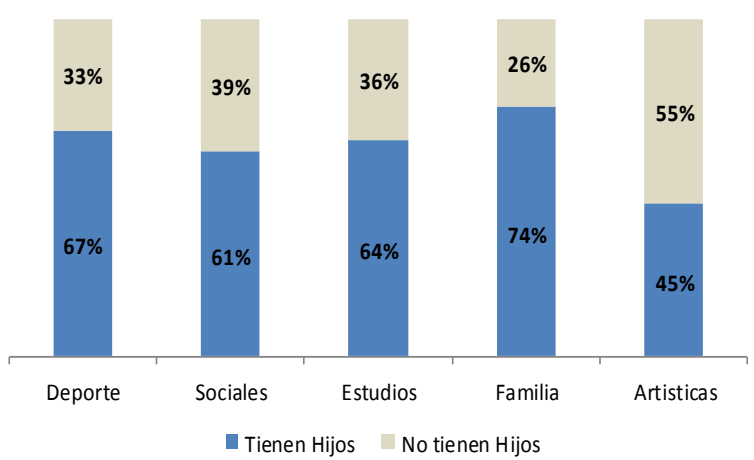

Figura 24. Actividades que realiza vs. Tienen hijos. 
2. Componente 1: Comportamiento de compra.

De los encuestados, el 99\% (242 encuestados), ha comprado alguna vez juguetes. El $50 \%$ de los encuestados, tiene una frecuencia de compra, de más de tres veces al año (ver Figura 25), siendo las fechas de mayor compra en Navidad 86\%, Cumpleaños 84\%, día del niño 30\% (ver Figura 26).

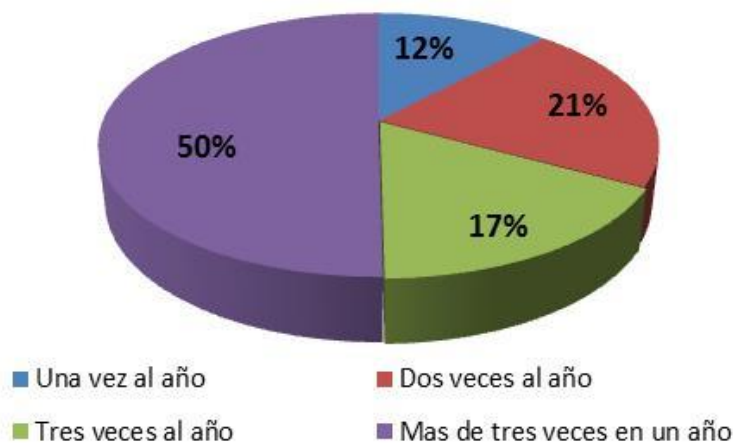

Figura 25. Frecuencia de compras.

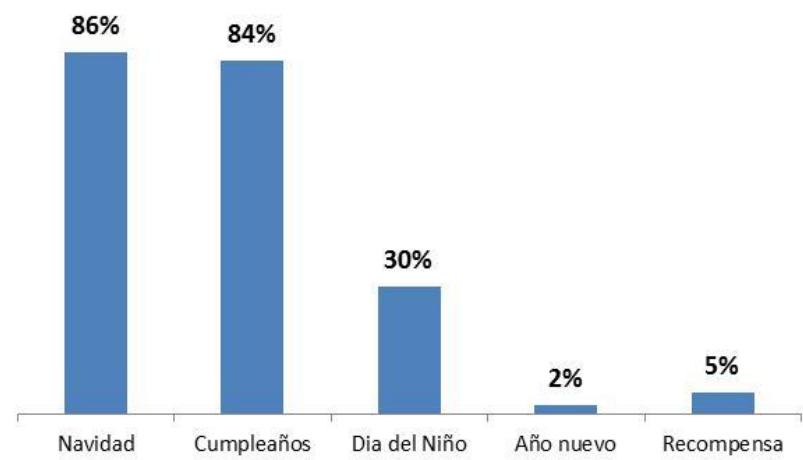

Figura 26.Fechas de Compras.

Sobre los lugares de compra, el 74\% de los encuestados compra los juguetes en una tienda por departamento, $44 \%$ compra en supermercados, mientras que el $11 \%$ lo hace a través de tiendas especializadas (ver Figura 27). Un dato importante es que las compras On line, actualmente equivalen al $9 \%$ de los encuestados. 


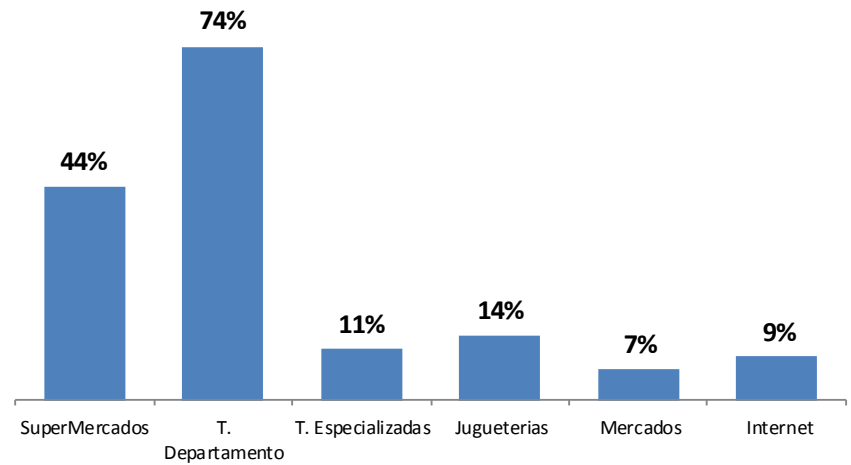

Figura 27. Lugar de Compra.

La marca de Juguetes que más suelen comprar es Fisher Price 50\%, seguida por Hasbro $49 \%$, mientras que Lego y Nerf tienen $44 \%$ y $37 \%$ (ver Figura 28), pero si se compara con cual considera la mejor marca de juguete, Fisher Price lidera con un 59\%, mientras que el 50\% indica que Lego. Hasbro ocupa la tercera posición con 39\%.

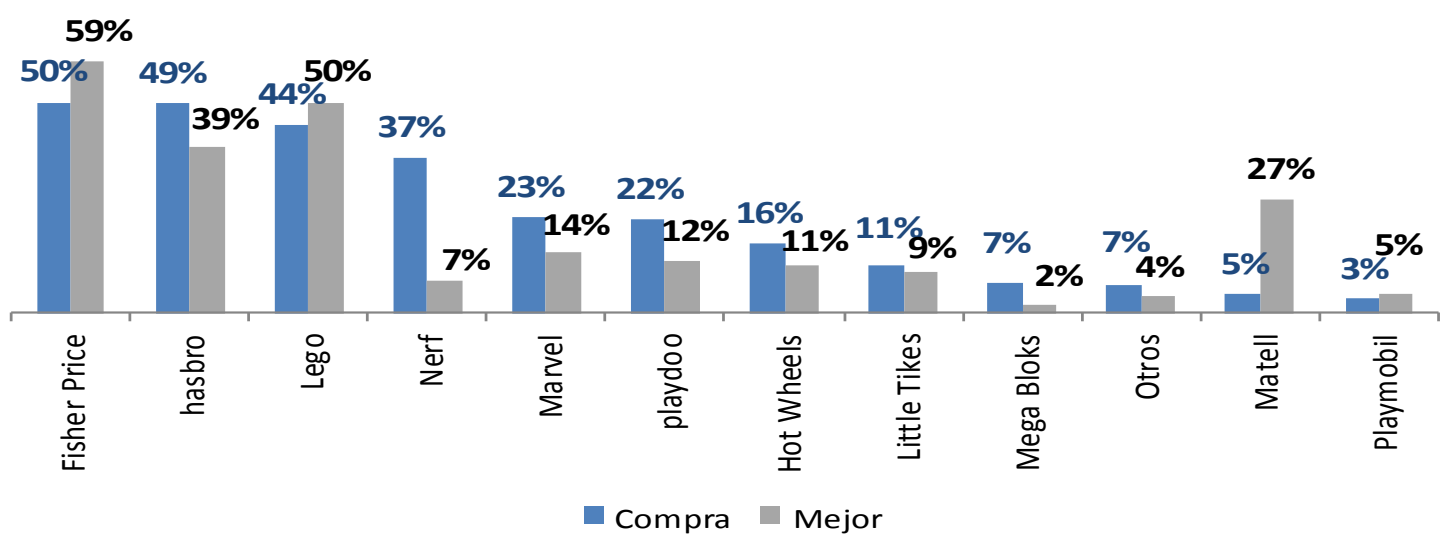

Figura 28. Marca de Juguetes preferidas.

E1 36\% de los encuestados gasta entre S/.50 y S/.100 soles por la adquisición de un juguete, de los cuales el 57\% tiene hijos. Un dato interesante puede ser que, los encuestados sin hijos gastan menos en la compra de juguetes (ver Figura 29 y 30). 


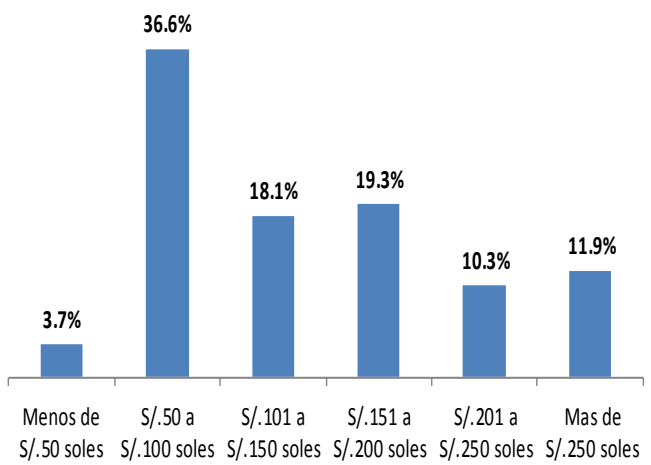

Figura 29.Gastos de compra.

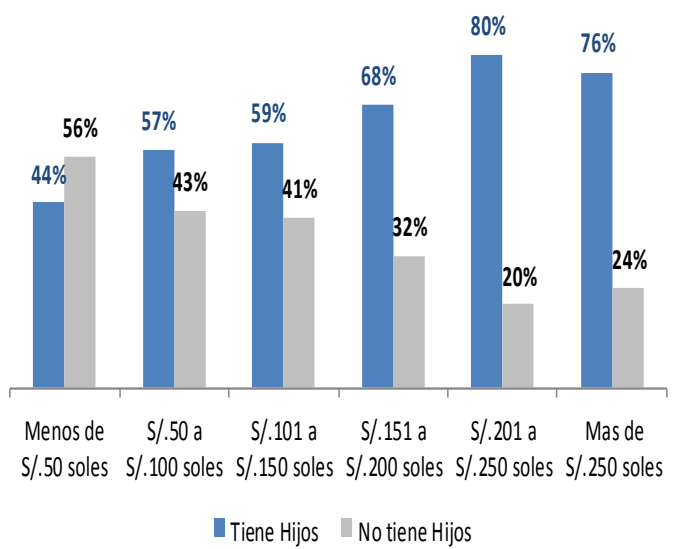

Figura 30. Gastos de compra vs tienen hijos.

Con respecto al perfil de los consumidores de juguetes el 58\% (ver Figura 31) conoce la marca LEGO, donde el $27 \%$ compro los productos de la marca Lego al menos una en su vida (ver Figura 32).

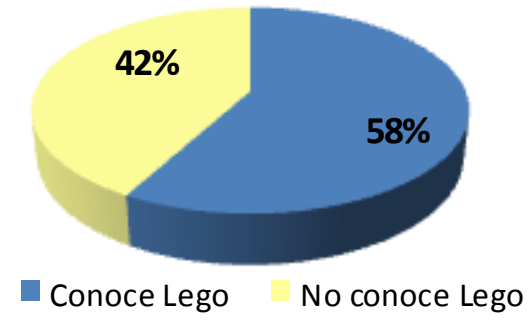

Figura 31. Conoce los productos de la marca LEGO. 


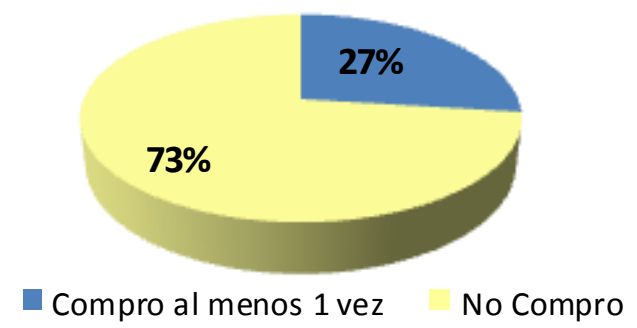

Figura 32. Compro los productos de la marca LEGO.

De los encuestados que manifestaron que conocen los productos de la marca Lego, el 96\% que tienen hijos compra en tiendas especializadas, un $80 \%$ compra en jugueterías (ver Figuras 33 y 34).

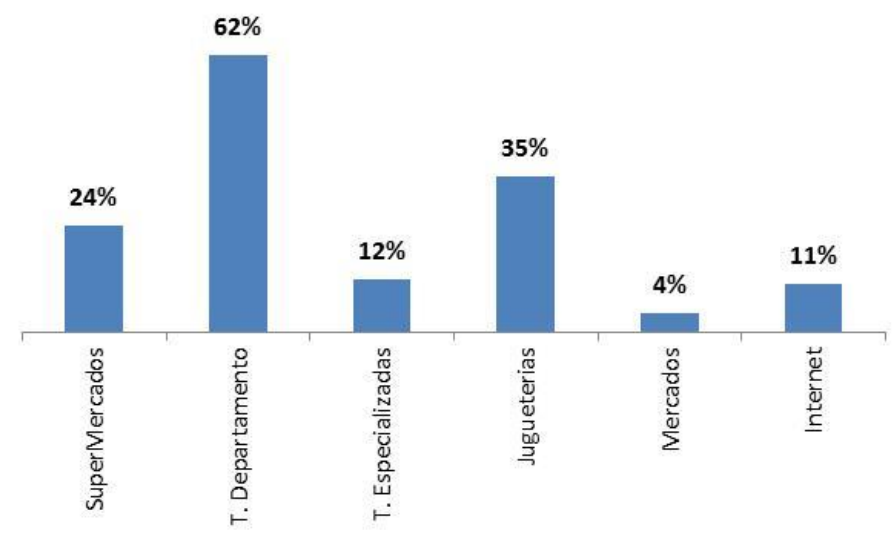

Figura 33. Lugar de compra de los productos de la marca LEGO.

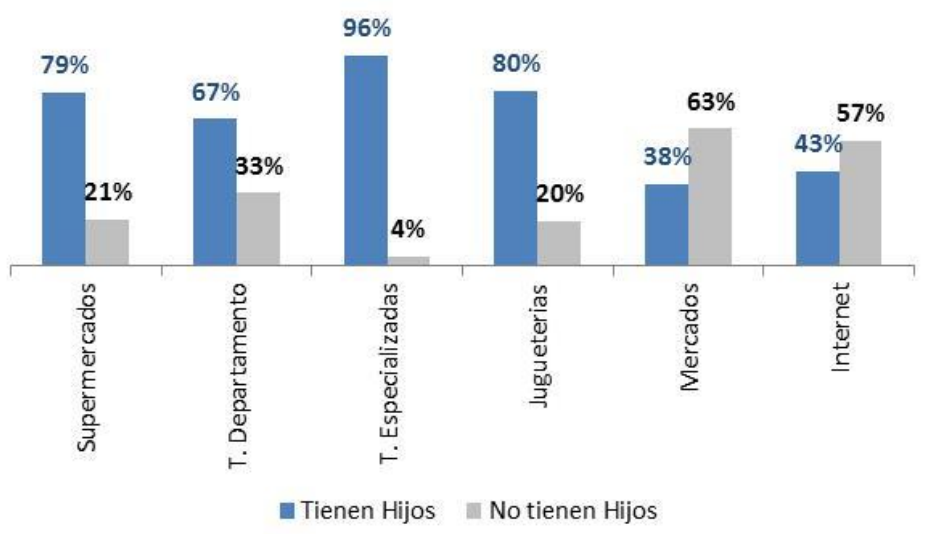

Figura 34. Lugar de compra con tener hijos. 
3. Componente 2: Atributos de la marca.

Para la compra de un juguete, los encuestados manifestaron que un atributo muy importante es la Calidad 70\%, siendo el precio el segundo atributo importante 53\% (ver Figura $35)$.

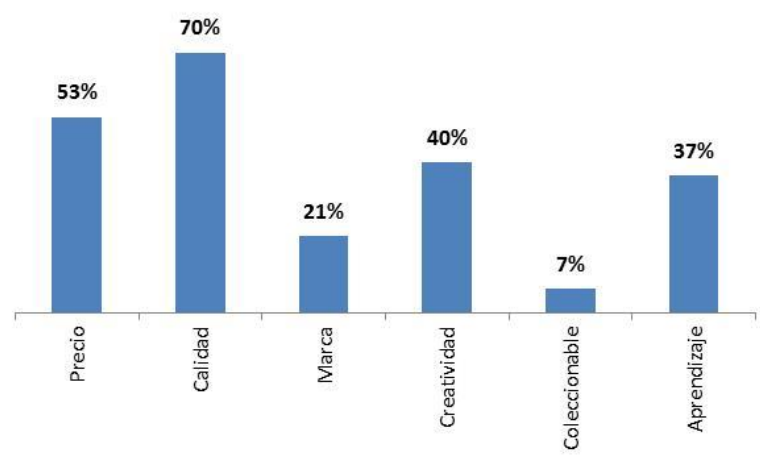

Figura 35. Atributos importantes de los juguetes.

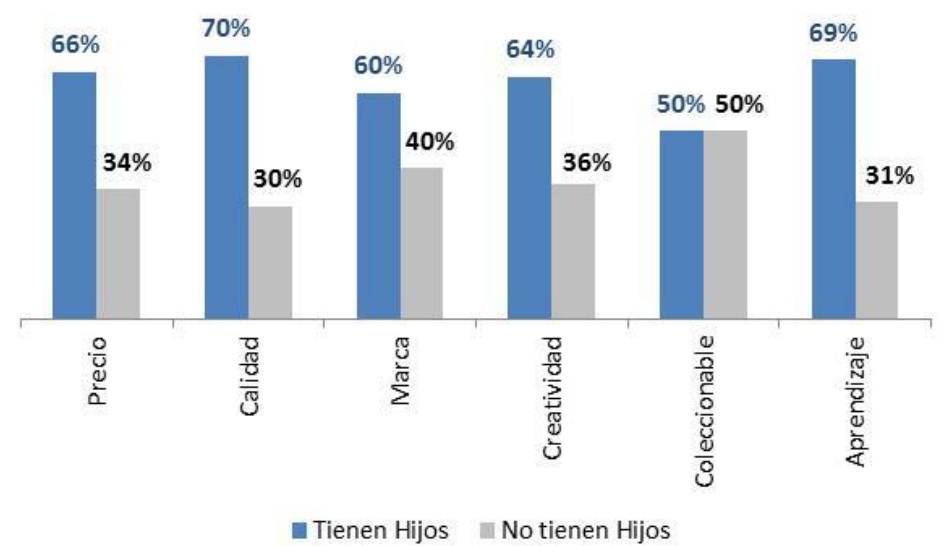

Figura 36. Atributos vs tener hijos.

En la Figura 36, se puede apreciar que la calidad es el atributo más importante para los encuestados con hijos con un 70\%, seguido por Aprendizaje con un 69\%. Para los encuestados padres o no padres de familia el atributo de coleccionable es igual con un 50\%, mientras que el atributo de la marca del juguete es el segundo de importancia para los encuestados que manifiestan no tener hijos.

Con respecto a la importancia de algunos atributos y decisiones de compra de juguetes, observamos en la Figura 37 que la Calidad 73\% es de gran importancia, seguido por 
el tipo de juguete $71 \%$ (denominando tipo de juguete a los juguetes de corte deportivo, guerra, educativo, etc.), mientras que el tema de coleccionable solo alcanza un $25 \%$ de importancia. Con esta podemos afirmar que la calidad es el atributo más importante a la hora de comprar un juguete según nuestros encuestados.

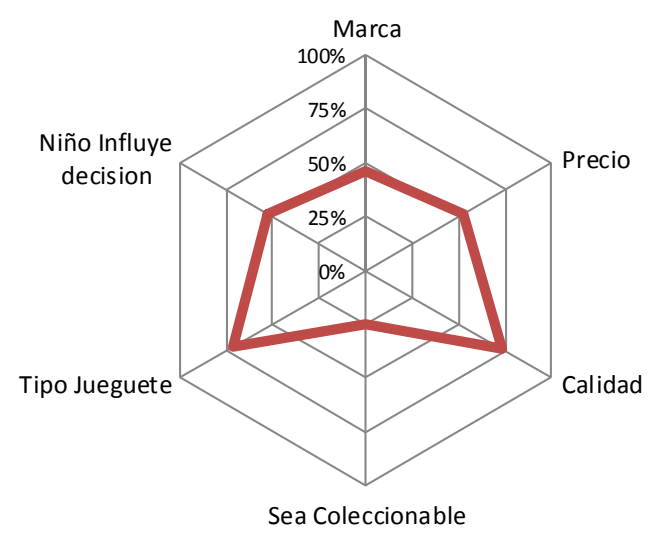

Figura 37. Atributos de un juguete.

Con respecto a los productos de la marca Lego, de los encuestados el atributo más importante es que es un producto educativo 52\%, seguido por calidad 35\% (ver Figura 38), mientras de los encuestados que manifestaron tener hijos también consideran que Lego es un producto educativo $75 \%$ y de alta calidad $70 \%$ (ver Figura 39). 


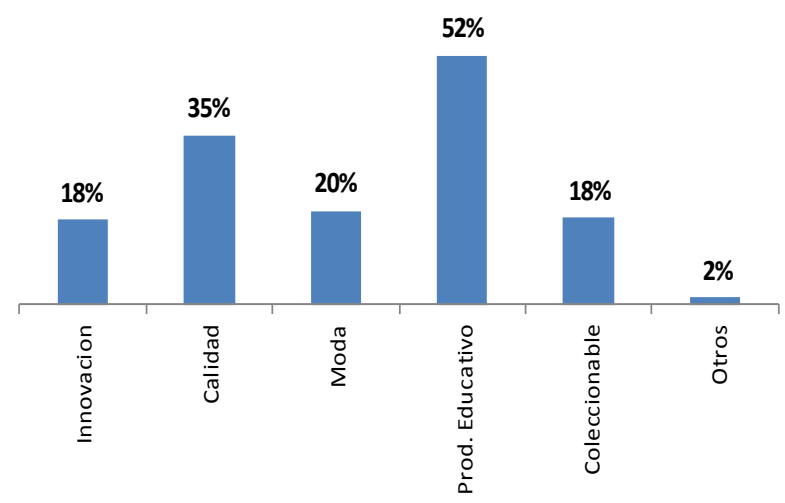

Figura 38. Atributos de los juguetes de la marca LEGO.

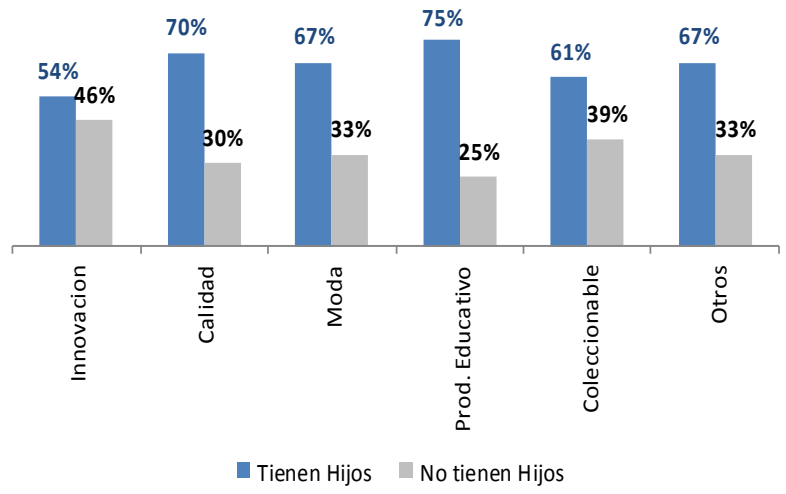

Figura 39. Atributos de los productos de la marca LEGO vs. tener hijos.

\section{Componente 3: Demanda Insatisfecha}

Del 58\% que conoce la marca LEGO, el 73\% no ha comprado nunca (ver Figura 32).

Dentro de los motivos por la cual no compro los productos de la marca Lego, el $67 \%$ no compraría nunca por los precios y por atractividad del producto, mientras que un $33 \%$ si lo compraría (ver Figura 40).

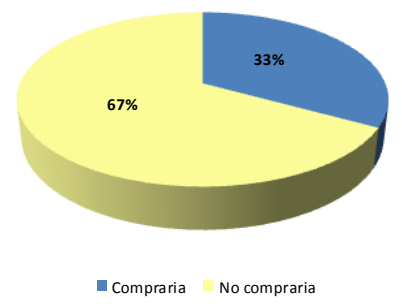

Figura 40. Intensión de compra de los productos de la marca LEGO. 


\subsubsection{Validación de Hipótesis.}

De las necesidades de información planteada en el capítulo anterior y con las encuestas realizadas podemos despejar las siguientes hipótesis a través del test Chi Cuadrado con $\mathrm{n}$ grado de libertad.

Se plantearon las siguientes hipótesis para ver el comportamiento de compra en función a tener hijos.

Hipótesis 1:

Ho: Existe relación en comprar juguetes en tiendas especializadas con tener hijos.

H1: No existe relación en comprar juguetes en tiendas especializadas con tener hijos.

Con un alfa de 0.05 , el valor esperado es de 3.84 y dado que la probabilidad de $\mathrm{x}^{2}>$ 1.09 es mayor que alfa, se acepta la hipótesis nula. Entonces podemos concluir que existe relación en comprar juguete en tiendas especializadas con tener hijos.

\section{Hipótesis 2:}

Ho: Existe relación en comprar juguetes de la marca LEGO con producto educativo.

H1: No existe relación en comprar juguetes de la marca LEGO con producto educativo.

Con un alfa de 0.05 , el valor esperado es de 3.84 y dado que la probabilidad de $x^{2}>$ 0.74 es mayor que alfa, se acepta la hipótesis nula. Por lo tanto existe relación comprar juguetes de la marca LEGO con producto educativo.

\section{Hipótesis 3:}

Ho: Existe relación en comprar juguetes de la marca LEGO con producto de calidad. H1: No existe relación en comprar juguetes de la marca LEGO con producto de calidad. 
Con un alfa de 0.05 , el valor esperado es de 3.84 y dado que la probabilidad de $x^{2}>$ 2.13 es mayor que alfa, se acepta la hipótesis nula. Lo que equivale a decir existe relación en comprar juguetes de la marca LEGO con productos de calidad.

\section{Hipótesis 4:}

Ho: Existe relación en No comprar juguetes de la marca LEGO con el precio

H1: No existe relación en No comprar juguetes de la marca LEGO con el precio.

Con un alfa de 0.05 , el valor esperado es de 3.84 y dado que la probabilidad de $\mathrm{x}^{2}>$ 1.89 es mayor que alfa, se acepta la hipótesis nula. Lo que equivale a decir existe relación en comprar juguetes de la marca LEGO con el precio.

\subsection{Análisis del Producto}

De acuerdo a lo encontrado en la investigación de mercado, tanto cualitativa como cuantitativa, podemos indicar que los productos de la marca LEGO, son percibidos como productos educativos (52\%) y de alta calidad (35\%) ver Figura 41, y tienen un componente de creatividad relevante para los consumidores. La edad (a mayor edad) influye para que los compradores consideren que sea un producto educativo (ver Figura 42).

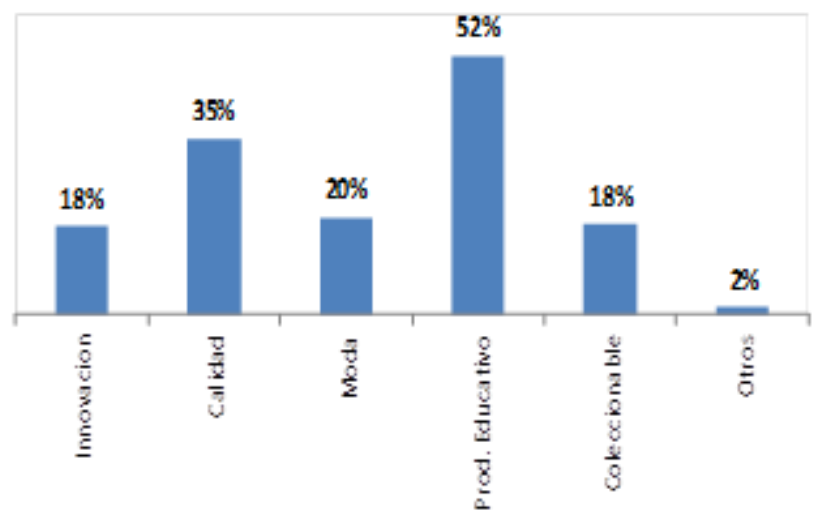

Figura 41. Atributos de los productos de la marca LEGO. 


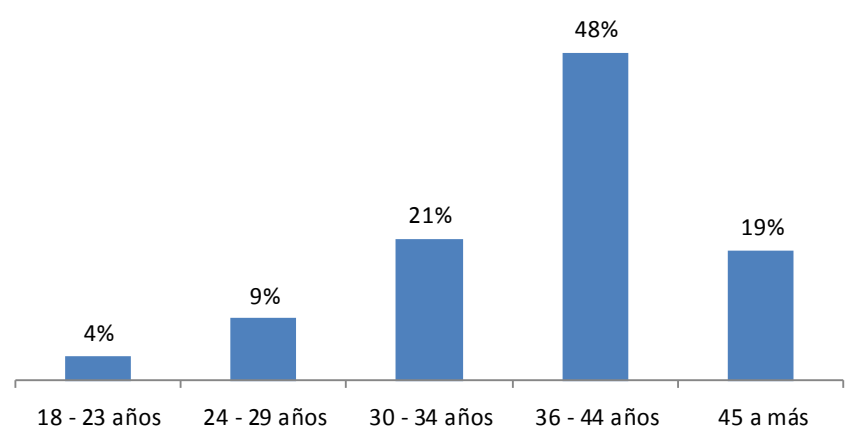

Figura 42. Distribución de edad de los encuestados que lo consideran que LEGO es un producto educativo.

Otros motivos de compra de los productos de la marca LEGO son que son coleccionables, innovadores y la moda $(18.5 \%, 17.5 \%, 16 \%$ respectivamente), LEGO siempre lanza productos relacionados con las tendencias más populares de los medios de comunicación masiva, como cine, videojuegos, series animadas, como por ejemplo: The Bing bang Theory, The Simpson, Star Wars, Harry Potter, Minercraft, entre otras.

Estos opinan que LEGO es una marca para todas las edades y para cada etapa del crecimiento del niño, desde los 2 a los 16 años, asimismo que desarrolla la creatividad de quienes lo usan, Otro punto importante es que los compradores de los productos LEGO, asocian la calidad del producto con la garantía del mismo.

Los Compradores de los productos de la marca LEGO, en un 34\% (ver Figura 43) de los encuestados considera irremplazables por otra marca, vale decir, que de no encontrar el producto en las góndolas de algún supermercado o tiendas especializada no comprarían otra marca. 


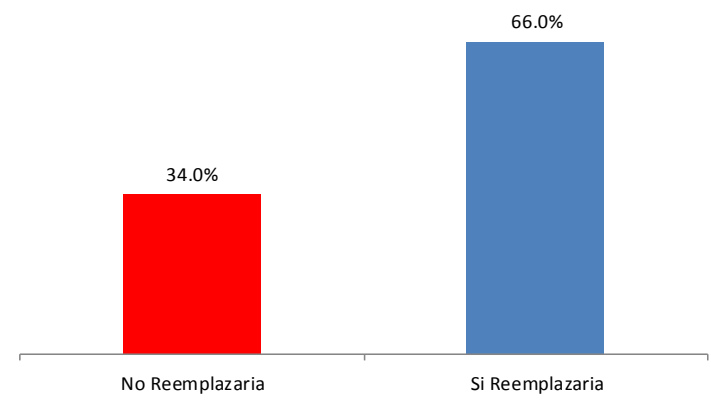

Figura 43. Reemplazo de los productos de la marca LEGO.

Los productos de la marca LEGO, para muchos de los compradores puede transmitir sensaciones, emociones y sentimientos, esto básicamente por la relación que la marca ha logrado a través de los años con sus consumidores habituales, muchos de los cuales, lo asocian con sus recuerdos de infancia.

\subsection{Tendencias del Producto:}

Según los estudios realizados, los consumidores y clientes peruanos, buscan mayor variedad de productos para niñas, por lo que sería una buena apuesta el ampliar, para el mercado peruano, los productos LEGO para este tipo de consumidor. En la Figura 44 se puede apreciar de los consumidores que no compran LEGO (67\%) por precio y atractividad.

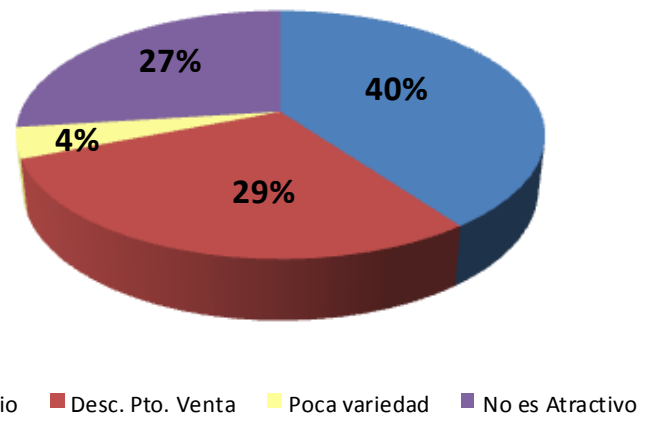

Figura 44. Razones por que no compro productos de la marca LEGO.

Esto coincide con la información encontrada en el estudio de "Consumer Truth", donde señala que algunas marcas de Juguetes, se ven forzadas a lanzar líneas de personajes femeninos no tradicionales (científicas, paleontólogas, arquitectas, etc.) 
Otro hallazgo encontrado, fue que un grupo importante de los clientes, sobre todo los que compran en el canal moderno, busca packs de productos más pequeños para poder regalar en alguna ocasión especial.

Se pudo apreciar, en la investigación de mercados, que una de las tendencias de los clientes de LEGO del Perú, es la de consumidores adultos solteros, que valoran los productos clásicos y coleccionables, o de armado complejo, se encontraron muchos fanáticos de las series Star Wars que compran la línea Lego Star Wars como también un grupo amante de la robótica y que buscan la línea Lego Mindstorm.

Esta información coincide con los hallazgos encontrados por estudios realizados por la empresa Consumer Truth, donde señala que existen nuevas formas de ser y consumir, que las familias típicas, padres madres e hijos, se añaden nuevas formas familiares como familias monoparentales, multigeneracionales, mixtas, familias con Amos de Casa, parejas sin hijos (y con mascotas), mujeres que no desean ser madres (NOMO - No Mother) y otras tipologías como PANKS (mujeres profesionales sin hijos que engríen sobrinos) Single/DINK Market" (adultos solteros y/o sin hijos) (Takehara, 2014).

\subsection{Análisis de Ventas:}

Según la información encontrada en las distintas fuentes de la investigación, las ventas de LEGO se desaceleran con respecto al crecimiento que se tuvo en los últimos años (ver Tabla 7), Según ello se proyecta un crecimiento 7\% en promedio para los próximos 3 años. Considerando que la empresa crecerá a tasas menores al crecimiento del mercado de juguetes, podemos preveer que se perderá participación de mercado, sin embargo el estudio de mercado nos permitió identificar que existe un mercado potencial para continuar el desarrollo de la marca (ver Tabla 22). 
Tabla 22

Potencial del Mercado para los productos de la marca LEGO.

\begin{tabular}{lccrcr}
\hline & & & & Tamano del & Potencial \\
Conocen & Compraron & Comprarian & & Mercado & \\
\hline $\mathrm{Si}$ & $58 \% \mathrm{Si}$ & $27 \% \mathrm{Si}$ & $94 \%$ & & \\
& & $\mathrm{No}$ & $6 \%$ & & $64,229,491$ \\
\cline { 2 - 6 } & $\mathrm{No}$ & $73 \% \mathrm{Si}$ & $33 \%$ & & \\
& & $\mathrm{No}$ & $67 \%$ & $237,887,005$ & $57,306,979$ \\
\hline No & $42 \%$ & $\mathrm{Si}$ & $33 \%$ & & \\
& & $\mathrm{No}$ & $67 \%$ & $172,263,003$ & $56,846,791$ \\
\hline Total & & & & $410,150,008$ & $178,383,261$ \\
\hline
\end{tabular}

En la Tabla 22 podemos ver un ejercicio que se ha realizado cruzando el resultado de la investigación cuantitativa con las ventas del mercado de juguetes. Si bien, este análisis no es exacto, nos sirve para establecer algún parámetro que nos permita estimar el potencial del mercado. Si consideramos que del 58\% que conocen la marca, un $27 \%$ ha comprado y el $94 \%$ volvería a comprar y lo sumamos al $33 \%$ del $73 \%$ que conoce la marca y no ha comprado pero estaría dispuesto a comprar, tenemos que hay aproximadamente más de 121 millones de soles en potencialidad de mercado. Si consideramos que ahora tenemos una venta estimada anual de 27 millones, y existe un potencial de 121 millones, nos deja un buen margen para el crecimiento por lo menos de hasta 50 millones de soles para los próximos 5 años. Esto sin considerar los 56 millones que equivalen al 33\% del $42 \%$ que no conoce nuestro producto, pero que estaría dispuesto a comprarlo si lo conociera. 


\subsection{Tendencias del Comportamiento del Consumidor:}

Según lo encontrado en distintas fuentes las tendencias que se esperan:

Los consumidores de la marca Lego, tienden a comprar juguetes, por lo menos tres veces al año. Habiendo encontrado que uno de los nuevos hábitos de compra, se centra hoy, en el día del niño como uno de los ejes centrales de compra. Esta información la pudimos ver en una primera instancia en la investigación cualitativa, validándose luego con la investigación cuantitativa.

El comportamiento del comprador de LEGO, es para algunos casos planificado, se han encontrado que existe hoy en día, un nuevo segmento de consumidores, compuesto por adultos maduros que compran para sí mismos. Se pudo encontrar además, que el nuevo consumidor de LEGO, usa los medios digitales para realizar sus compras, buscar información de los nuevos lanzamientos, comparar los precios y expresar sus experiencias con la marca. Se ha encontrado que los nuevos consumidores de LEGO, empiezan, en la mayoría de casos, su primera experiencia de compra en el canal moderno(grandes cadenas Retail-supermercados), para luego, una vez enganchados con el producto, pasar a comprarlo en tiendas especializadas(LEGO STORE), elevando su ticket promedio de compra. Esto básicamente se da, porque en los canales modernos el flujo de gente es mayor, y las cajas que se encuentran son de menor precio.

\subsection{Tendencias de Medios, Distribución y Precios:}

El uso de medios digitales gratuitos para comunicarse es, cada día es más una de las tendencias que resaltan en el consumidor de LEGO. En la investigación de mercado, se encontró que la gran mayoría, usa Facebook, Twitter, Instagram y YouTube tanto para expresar sus experiencias, como para consumir información. Este tipo de medios, suele ser bastante dinámico e interactivo y cada día más, es uno de los más poderosos para conquistar públicos específicos. 
Los medios tradicionales (TV, Radio, Cine, Revistas y Diarios), si bien han mantenido su influencia, están siendo reemplazados por nuevas formas de experiencia (Netflix, Spotify, Blogs, Twiter, etc).

Sobre el tema de distribución, hemos encontrado que el canal tradicional, ha ido perdiendo terreno, no solo en la percepción del consumidor, sino también en el volumen de ventas en las que participa. Los consumidores actuales están migrando al canal moderno (retail) a través de los grandes centros comerciales, tiendas por departamento y supermercados, siendo estos la tendencia en el crecimiento de ventas. Uno de los canales que mayor desarrollo está consiguiendo, es el canal representado por las tiendas especializadas, como LEGO STORE, la cual no solo permite encontrar productos en mayor variedad, sino que implica toda una experiencia de compra para el consumidor.

Sin embargo, se pudo descubrir que el comprador de LEGO, considera que estos productos deberían tener mayor cobertura geográfica en Lima.

Los compradores, si bien no consideran los productos de la marca LEGO como económicos o baratos, si creen que este alto precio se compensa con el alto valor que les ofrece la marca Muchos compradores desconocen que los productos de la marca LEGO, tenga una amplia variedad de precios dentro de su portafolio de productos. Asimismo, los compradores de LEGO, están constantemente en la búsqueda de descuentos, ya que consideran que es una buena oportunidad de comprar estos productos e incrementar la brecha entre el precio y el valor que reciben.Dentro de los segmentos del mercado que compran el producto, a través de las investigaciones pudimos encontrar varios segmentos a desarrollar:

- Niños Pre Escolar (menores a 4 años).

- Niños Escolares (5 a 14 años).

- Adolescentes (15 a 18 años).

- Niñas 


\section{Capítulo V. Formular Objetivos de Marketing}

\subsection{Objetivos Estratégicos de COMEXA}

- Incrementar la facturación de la compañía de 76 millones de soles (2015) a 115 millones de soles en el 2019.

- Mejorar el resultado operativo de $18 \%$ sobre las ventas a 22\% en el 2019.

- Incrementar la participación de mercado en la UEN de LEGO, de 7\% a 8.2\% para el año 2019.

- Incrementar la facturación de la UEN de Juguetes Lego, de 25 millones de soles a 51 millones de soles para el 2019, con ello la marca tendrá el 44\% de la facturación total de COMEXA, teniendo por llegar el primer año 2017 a 33 millones de soles.

\subsection{Objetivos Generales de Marketing}

El principal objetivo que se quiere alcanzar con este plan de marketing es vender S/. 33 millones de soles en el 2017, que significan un incremento en 23\% de la venta del año 2016.

1. Objetivos de Producto.

- Vender S/.3.5 millones de soles en productos de la marca LEGO para niñas en el 2017.

- Vender en una nueva línea para niños, 770 mil soles, en en el 2017

- Vender s/ 9.6 millones de soles en dos de nuestros productos estrellas

2. Objetivos de Distribución.

- Vender 1.5 millones de soles, con una nueva tienda LEGO STORE en el 2017.

- Vender mediante nuevos canales de distribución, S/850 mil soles, en el 2017. 
3. Objetivos de Comunicación.

- Incrementar los mecanismos para dar a conocer nuestro MIX y promociones a nuestros clientes.

4. Objetivos de Precios

- Recuperar 2 puntos porcentuales más en el margen, para el año 2017, es decir pasar de $50 \%$ a $52 \%$. 


\section{Capítulo VI. Formular las Estrategias de Marketing}

\subsection{Seleccionar el Mercado Objetivo}

Segmento 1 Compradores Planeados: Estos compradores por lo general son padres de familia que saben exactamente qué es lo que quieren, y que hará todo lo posible para conseguirlo sin dudarlo.

Segmento 2 Compradores Semi-Planeados: Estos compradores pueden tener una idea aproximada en el regalo, pero necesitan bastante ayuda y seguridad para la compra.

Segmento 3 Compradores por impulso: Estos compradores no han considerado comprar un set LEGO, que necesitan para ser activados por la inspiración para una compra.

Segmento 4 Consumidores: El consumidor puede tanto influenciar o tomar la decisión. Sus deseos son el último camino a la compra.

Para la estrategia de segmentación, se ha elegido el segmento 1 compradores planeados (padres) y segmento 4 consumidores (hijos) por ser estos los segmentos de mayor tamaño y oportunidad de consumir nuestros productos.

\subsection{Desarrollar el Posicionamiento del Producto}

Para desarrollar el posicionamiento de los productos de la marca LEGO, debemos determinar una proposición de valor, es decir, de qué manera se creara un valor diferenciado para el segmento que hemos elegido. Según Renvoise en su libro Neuromarketing, El posicionamiento de un producto, servicio o marca empieza a crearse a través de mecanismos de percepción y se va transformando en un proceso cerebral donde intervienen diversos estímulos (Renvoise, 2006). Siguiendo el modelo que propone el autor, es que se establecieron los pasos para determinar un adecuado posicionamiento para los productos de la marca LEGO 
1. Insight.

Valores y motivaciones del consumidor LEGO ESCOLAR:

- "Me gusta que mis hijos jueguen y aprendan"

- "Mis hijos solo quieren juguetes relacionados a sus personajes favoritos"

- "No me gusta que estén pegados al Play Station y a esto es guerra"

2. Propuesta de Valor.

Mas Precio $/$ Mas Calidad $=$ Creatividad para los niños

3. Promesa.

LEGO es una marca relacionada al desarrollo de la creatividad en los niños. Esta es una oferta de valor que los padres modernos, con poco tiempo para compartir con sus hijos, buscan constantemente y aprecian en este tipo de productos.

4. Diferenciación.

LEGO se diferencia con otros productos del mercado debido a su asociación con la calidad y creatividad. Estos son puntos importantes para la generación de la diferenciación en el mercado y para crear nuestra imagen de marca.

5. Unique Selling Proposition.

Entre nuestra ventaja diferencial, tenemos las siguientes:

- Beneficio ser el único producto en constante innovación. "Sólo lo mejor es suficiente".

- Altos estándares de calidad en los niveles de producción.

- Películas que ayudan a fortalecer la marca.

- Incentivo de creatividad para cada segmento de nuestro target.

- Frecuencia de engagement con nuestros consumidores.

- Tiendas propias con FF.VV directa de la empresa.

- Modelo de negocio basado en relación calidad - precio. 
Para ello en base a fuentes primarias y secundarias, fue posible desarrollar un mapa de atributos de LEGO respecto a la competencia (ver Tabla 23).

Tabla 23

Mapa de Atributos de los productos de la marca LEGO.

\begin{tabular}{lcccc}
\hline \multicolumn{1}{c}{ Atributos } & Lego & Matell & Marcas Chinas & Hasbro \\
\hline & & & & \\
Calidad & 10 & 9 & 2 & 9 \\
Precio & 5 & 5 & 10 & 7 \\
Surtido & 6 & 7 & 9 & 6 \\
Valor de la Marca & 10 & 9 & 3 & 9 \\
Distribución & 6 & 7 & 8 & 6 \\
Servicio al cliente & 8 & 8 & 2 & 7 \\
Equipos de ventas & 8 & 5 & 2 & 4 \\
Creatividad & 10 & 6 & 3 & 8 \\
Comunicación & 8 & 8 & 3 & 8 \\
Activaciones & 8 & 5 & 1 & 5 \\
Satisfacción & 10 & 9 & 4 & 6 \\
\hline
\end{tabular}

Como pueden ver en la Figura 45, los atributos que mayor puntaje obtuvieron para el análisis de la marca LEGO, fueron calidad, creatividad, satisfacción y valor de marca.

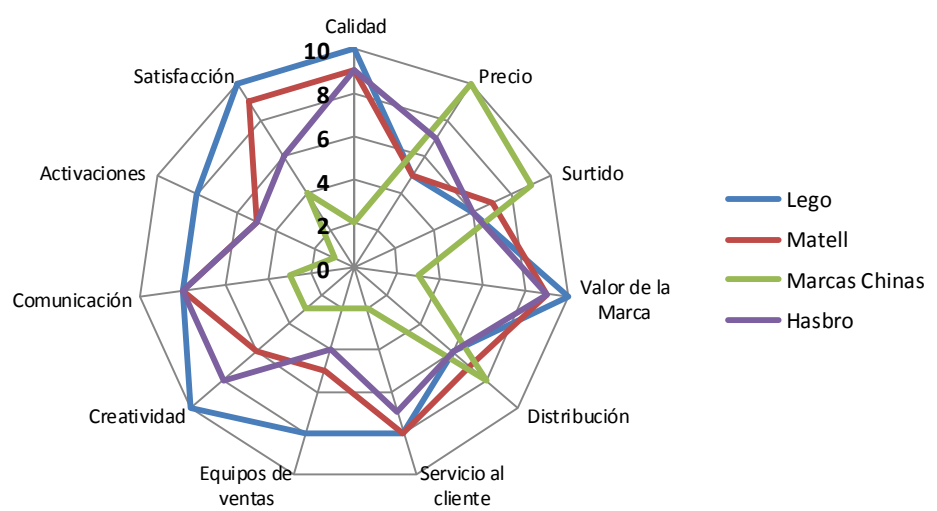

Figura 45. Mapa de atributos de los productos de la marca LEGO.

6. Mapa Perceptual.

Teniendo en cuenta que una de las principales formas de valorar un producto es el análisis de calidad precio, estas 2 características se convierten en ejes para realizar un mapa porcentual de la marca y su competencia (ver Figura 46). En este análisis se puede apreciar 
claramente que LEGO es percibida como una marca de alto precio pero de alta calidad, por lo cual la gente está dispuesta a pagar. Si comparamos la posición de sus principales competidores como Hasbro y Mattel, LEGO tiene una ligera ventaja con respecto a la calidad.

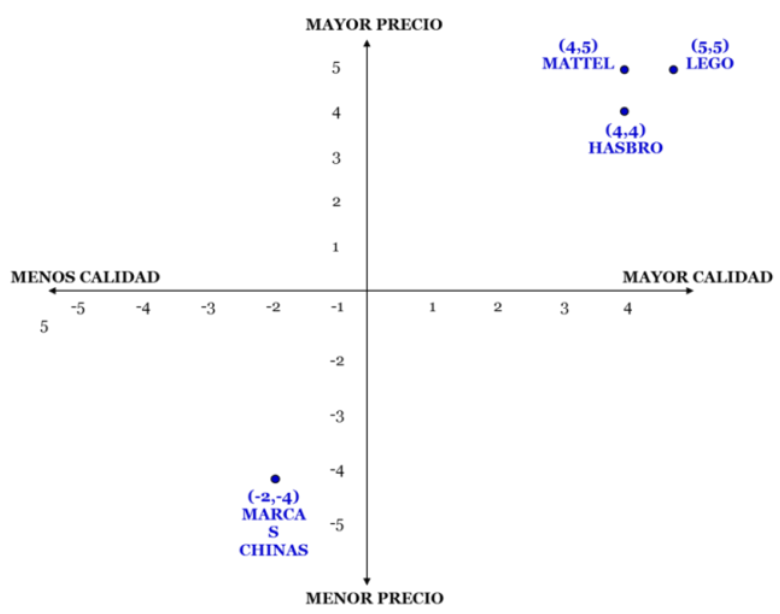

Figura 46. Mapa perceptual de los productos de la marca LEGO.

\subsection{Formular las Estrategias de Marketing}

La formulación de estrategias será en función a los objetivos trazados en el capítulo IV y esto a través de los objetivos de producto, distribución, comunicación y precio.

1. Producto

Objetivos Especifico 1: Vender S/.3.5 millones de soles en productos de la marca LEGO para niñas en el 2017.

Estrategia: Ampliar el Mix de Productos para niñas, reforzando sus líneas principales.

Objetivo Especifico 2: Vender en una nueva linea para niños, 770 mil soles en el 2017.

Estrategia: Ampliar el portafolio de productos para niños

Objetivo Especifico 3: Vender s/ 9.6 millones de soles en dos de nuestros productos estrellas.

Estrategia 1: Incrementar las actividades de marketing para la línea LEGO STAR WARS. 
Estrategia 2: Incrementar las actividades de marketing para la línea LEGO City.

\section{Distribución}

Objetivo Específico 1: Vender S/. 1.5 millones de soles, con una nueva tienda LEGO STORE en el 2017.

Estrategia: Aperturar una tienda nueva LEGO STORE en LIMA-Centro comercial Salaverry

Objetivo Específico 2: Vender mediante nuevos canales de distribución, S/850 mil soles, en el 2017.

Estrategia: Desarrollar un canal de distribución on Line.

3. Comunicación.

Objetivo Específico 1: Incrementar los mecanismos para dar a conocer nuestros MIX y promociones a nuestros cliente.

Estrategia 1: Desarrollar un Show Room para cerrar acuerdos comerciales con nuestros clientes B2B.

Estrategia 2: Desarrollar un plan de medios digital integral.

Estrategia 3: Desarrollar un sistema de centralización de información - CRM.

Estrategia 4: Implementar un plan de capacitación para las fuerzas de ventas.

\section{Precio}

Objetivo Específico: Recuperar 2 puntos porcentuales más en el margen en el 2017, es decir, pasar de $50 \%$ a $52 \%$.

Estrategia: Realizar un incremento en los precios 5\% en todos los productos de LEGO. 


\section{Capítulo VII. Ejecución de las Estrategias}

Nuestro principal objetivo es poder lograr en el 2017, incrementar la facturación en $23 \%$ respecto al 2016, para ello se han elaborado diversas estrategias de marketing, que parten del análisis de los factores internos y externos que encontramos a lo largo de la elaboración del presente proyecto.

Es con la matriz FODA que se desprenden los objetivos específicos de producto, precio, comunicación y distribución. Para cada uno de estos objetivos específicos, se han desarrollado diversas estrategias que a su vez, conllevan a implementar las distintas actividades, las mismas que se complementaron en muchos casos con el estudio de mercado que elaboramos (Focus Group y entrevistas de profundidad).

Por ello, cada actividad parte de objetivos, los mismos que a su vez parten del FODA (Ver Tabla 24).

\subsection{Planes de Acción}

Los planes de acciones se dividirán por las $4 \mathrm{P}$ de marketing.

\section{Producto.}

Objetivo Especifico 1: Vender S/. 3.5 millones de soles en el 2017 en productos Lego para niñas.

Estrategia: Ampliar el Mix de Productos para niñas, reforzando sus líneas principales Actividad: Lanzamientos la línea LEGO Girls y reforzar la línea LEGO Friends. Evento: Activación promocional para la línea LEGO Girls y LEGO Friends. Descripción del Evento: Con este evento se espera generar un vínculo de los productos Lego para niñas, mediante Stand con los principales personajes de LEGO Girls. Para desarrollar esta activación, es necesario captar la atención de las niñas y sus padres, por ello es vital que se realicen las activaciones en puntos estratégicos del centro comercial, para que 


\section{Tabla 24}

\section{Resumen de Objetivos, Estrategias y Acciones}

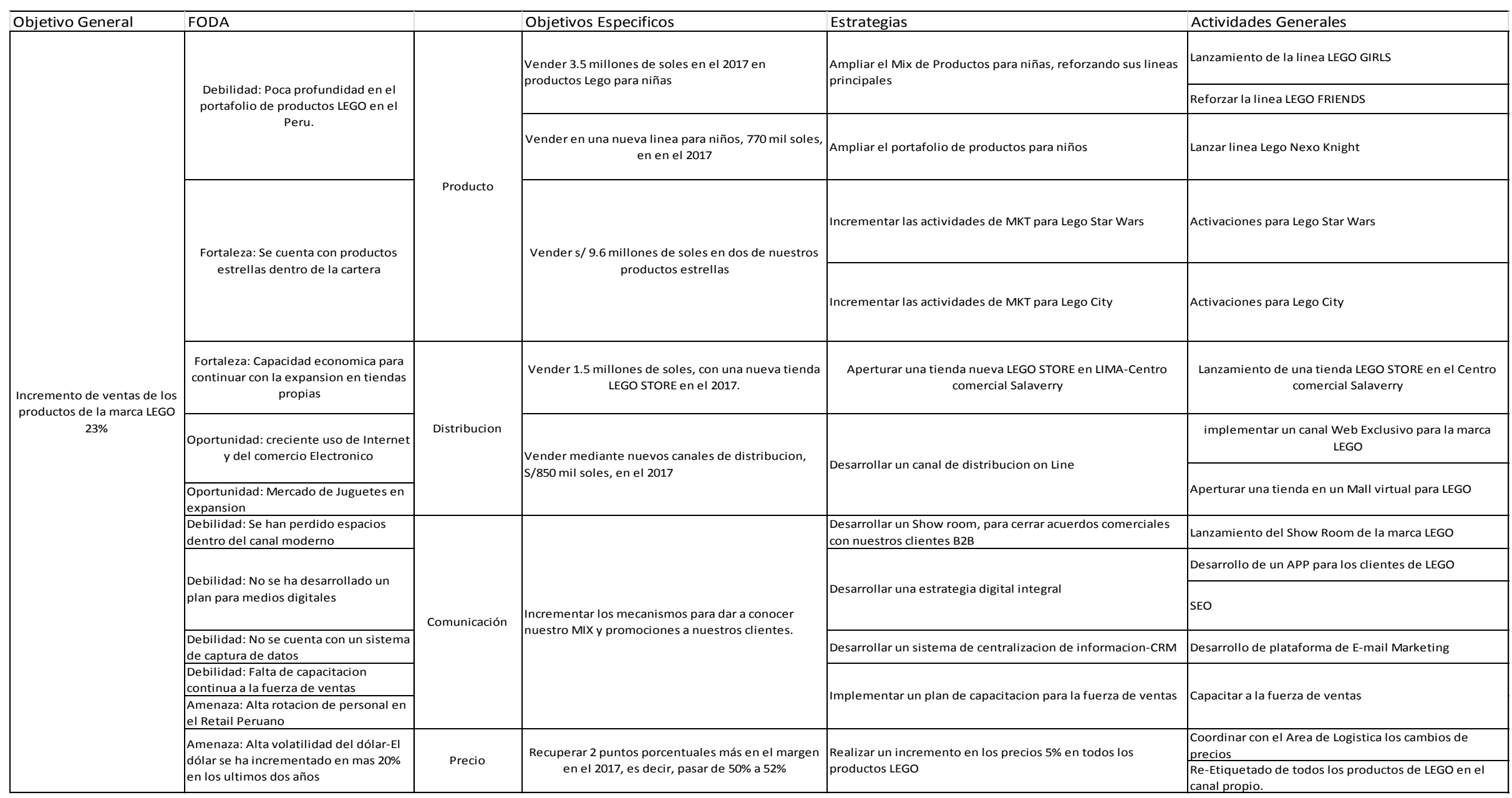


así se acerquen y quieran llevarse un recuerdo del momento a casa. Se entregara una fotografía enmarcada (ver Figura 47), la cual no tendrá costo alguno.

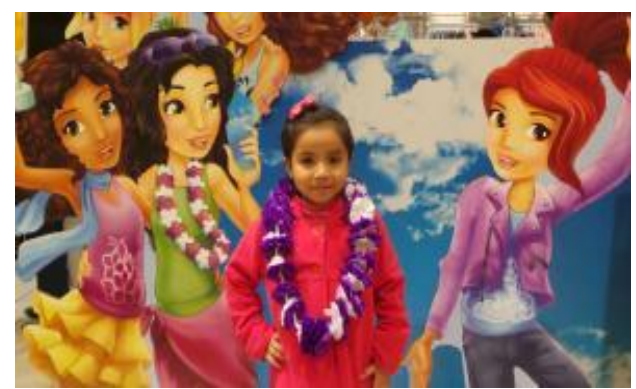

Figura 47. Fotografía enmarcada con su personaje favorito.

Los lugares donde se realizaran estas activaciones serán los centros comerciales Plaza San Miguel, Jockey Plaza y Plaza Lima Norte que se caracterizan por generar un mayor número de visitas al día. El evento se desarrollara el tercer y cuarto sábado y domingo de enero del 2017 y tendrá una duración de 3 horas cada día.

El nombre del evento será "Tomate una foto con tu personaje favorito de LEGO Girls y LEGO Friends".

Comunicación del Evento: La comunicación será a través de redes sociales como Facebook, Instagram, Twiter, envío de mailling de la base de datos proporcionada por el área de Inteligencia Comercial y Banners dentro de las tiendas LEGO y Baby Infanti Store. Área responsable: Marketing.

Inversión: S/.123 mil soles.

Calendarización: Enero y Setiembre 2017

Objetivo Especifico 2: Vender en una nueva línea de niños S/. 770 mil soles en el 2017.

Estrategia: Ampliar el portafolio de productos para niños.

Actividad: Lanzamiento de la Línea LEGO NEXO KNIGHT

Evento: Acercamiento con el Apps de Nexo Knights 
Descripción del evento: Consiste en visitar las tiendas Lego-Plaza Norte, tómate La Mejor foto con los Nexo Knights y subirla a tu muro y etiquétanos con LEGO StorePeru. Muéstrale a cualquier personal de la tienda y te ganas un escudo de energía como recompensa para tu juego en casa.

Los poderes Nexo Knights tienen forma de escudo y cada uno de ellos posee un icono diferente. Cada vez que veas un escudo, podrás usar la app Merlok 2.0 para escanearlo y agregarlo a tu colección de poderes. Abre el escáner de poderes, sujeta el dispositivo de forma que el escudo sea claramente visible en el espacio asignado y el escáner de poderes se ocupará del resto.

El lanzamiento se realizara en los centros comerciales Plaza San Miguel, Jockey Plaza, Plaza Lima Norte y Open Plaza Salaverry. La actividad se realizara el segundo viernes de Febrero 2017 y tendrá una duración de 3 horas.

Nombre del Evento: “Adquiere tus súper poderes con LEGO NEXO KNIGHT” Comunicación del Evento: La comunicación será a través de redes sociales como Facebook, Instagram, Twiter, maling de la base de datos proporcionada por el área de Inteligencia Comercial, Banners dentro de las tiendas LEGO y Baby Infanti Store., Vitrinas: viniles en todas las tiendas LEGO y Baby Infanti Store y Material POP dentro del canal moderno. Área responsable: Marketing, Sistemas, canal B2B y canal B2C.

Inversión: S/.125 mil soles.

Calendarización: Febrero del 2017

Objetivo Especifico 3: Vender S/.9.6 millones de soles en dos de nuestros productos estrellas.

Estrategia 1: Incrementar las actividades de marketing para LEGO Star Wars. Actividad: Activaciones para Lego Star Wars. 
Evento 1: Activación de LEGO Star Wars.

Descripción del Evento 1: Se convocara a la LEGION 501 para que participe de un evento masivo que se desarrollara en los principales centros comerciales de Lima, este evento se programara en 1 centro comercial por semana a partir del mes de Octubre, y se buscara asociar los personajes de Star Wars con los productos de la marca LEGO Star Wars.

Cada niño que compre un producto en la tienda LEGO o en las grandes cadenas Retail, podrá acceder a participar de una sesión de fotos con toda la LEGION 501 de Star Wars Perú. Las activaciones se realizara en los centros comerciales Plaza San Miguel, el primer viernes, sábado y domingo de octubre, y en el centro comercial Jockey Plaza, el tercer viernes, sábado y domingo de octubre. Estas activaciones tendrán una duración de 5 horas diarias.

Evento 2: Armado y exhibición de piezas LEGO Star Wars.

Descripción del Evento 2: Armado y exhibición de piezas LEGO Star Wars en los centros comerciales para lo cual se convocara el grupo LEGO LUG, que realizara el armado masivo de todas las naves y personajes LEGO de Star Wars. Esta exhibición se realizara en 2 centros comerciales en el mes de Marzo.

Las activaciones se realizara en los centros comerciales Plaza San Miguel, el primer viernes, sábado y domingo de marzo, y en el centro comercial Jockey Plaza, el tercer viernes, sábado y domingo de marzo. Estas activaciones tendrán una duración de 5 horas diarias.

Comunicación del Evento: La comunicación será a través de redes sociales como Facebook, Instagram, Twiter, envío de mailling de la base de datos proporcionada por el área de Inteligencia Comercial y Banners dentro de las tiendas LEGO y Baby Infanti Store. Responsable: Marketing. Inversión: S/.137.5 mil soles. 
Calendarización: Marzo y Abril del 2017.

Estrategia 2: Incrementar las actividades de marketing LEGO CITY.

Actividad: Activaciones para LEGO CITY.

Evento: Arma un camión de Bomberos y obtén tu certificado como constructor oficial de LEGO.

Descripción del Evento: El evento se debe realizar en un espacio de 50 metros cuadrados. Cada niño que quiera participar deberá dejar sus datos y un correo electrónico. Se colocaran 4 mesas de armado con capacidad para 5 niños. Cada mesa contara con las instrucciones de la pieza que se deben construir. El evento estará a cargo de 6 personas que participaran de la siguiente manera, un líder o maestro constructor, un apoyo por cada mesa (4) y un anfitrión o animador. Cuando el niño logre concluir la pieza asignada por el maestro constructor, se le invitara a acercarse a la "Gran construcción del camión de Bomberos de LEGO CITY” y colocara esa pieza en el camión. Para ello se le dará a cada niño, un casco y un chaleco de bomberos. Una vez colocada la pieza, al participante se le toma una foto, se le da un diploma como constructor y un regalo de nuestra línea LEGO CITY.

Se realizara en los centros comerciales Plaza San Miguel, el primer viernes, sábado y domingo de abril, y en el centro comercial Jockey Plaza, el tercer viernes, sábado y domingo de abril. Estas activaciones tendrán una duración de 5 horas diarias.

Comunicación del Evento: La comunicación será a través de redes sociales como Facebook, Instagram, Twiter, envío de maling de la base de datos proporcionada por el área de Inteligencia Comercial y Banners dentro de las tiendas LEGO y Baby Infanti Store. Área responsable: Marketing, Canal B2B y Canal B2C.

Inversión: S/.84 mil soles.

Calendarización: Mayo del 2017 


\section{Distribución.}

Objetivo Especifico 1: Vender S/. 1.5 millones de soles con una nueva tienda LEGO STORE en el 2017.

Estrategia: Aperturar una tienda nueva LEGO STORE en Lima - Centro comercial Salaverry. Actividad: Lanzamiento de una tienda LEGO Store en cencto comercial Salaverry.

Evento: Realizar un evento en el centro comercial.

Descripción del Evento: Iniciar la comunicación en el mes de Marzo del 2017 con los ejecutivos del centro comercial de nuestro interés de tener una tienda con 100 metros cuadrados para nuestra futura tienda LEGO, hacer las negociaciones con el centro comercial el detalle del acuerdo contractual y comunicar a ELITE BRAND, la decisión de expansión en Lima y hacerle llegar toda la información requerida por LEGO EE.UU. para luego cerrar el acuerdo contractual con el Centro comercial.

Comunicación del Evento: La comunicación de la apertura de la nueva tienda será a través de redes sociales como Facebook, Instagram, Twiter, envió de maling de la base de datos proporcionada por el área de Inteligencia Comercial.

Área responsable: Marketing, Canal B2C, Logistica, Recursos Humanos. Inversión: S/.301 mil soles.

Calendarización: Enero, Febrero y Marzo del 2017

Objetivo Especifico 2: Vender mediante nuevos canales de distribución S/. 850 mil soles en el 2017.

Estrategia: Desarrollar un canal de distribución On Line.

Actividad 1: Implementar un canal Web Exclusivo para la marca LEGO.

Evento: Lanzamiento de la página Web 
Descripción del Evento: La página se lanzara en los primeros días de abril 2017, para lo cual se tercerizará el diseño y mantenimiento.

Comunicación del Evento: Promocionar nuestra página Web a través de redes sociales como Facebook, Instagram, Twiter, envió de maling de la base de datos proporcionada por el área de Inteligencia Comercial y Banners dentro de las tiendas LEGO y Baby Infanti Store. Área responsable: Marketing y Sistemas.

Inversión: S/.70 mil soles.

Calendarización: Enero, Febrero, Marzo y Abril del 2017.

Actividad 2: Aperturar una tienda en el nuevo concepto Mall virtual para LEGO.

Evento: Dar a conocer la presencia de LEGO en el Mall Virtual

Descripción del Evento: La página se lanzara en los primeros días de Julio 2017, para lo cual se tercerizará el servicio.

Comunicación del Evento: Promocionar nuestra presencia de LEGO en el Mall Virtual a través de redes sociales como Facebook, Instagram, Twiter.

Área responsable: Marketing y Sistemas.

Inversión: S/.12.4 mil soles.

Calendarización: Mayo y Junio del 2017.

\section{Comunicación.}

Objetivo Específico: Dar a conocer nuestro mix de productos y promociones a los clientes B2B.

Estrategia 1: Desarrollar un Show Room para cerrar acuerdos comerciales con nuestros clientes.

Actividad: Desarrollar un Show Room, para cerrar acuerdos comerciales con nuestros clientes de los canales modernos 
Evento: Desarrollar un Show Room.

Descripción del Evento: Desarrollar un Show Room para los principales clientes B2B dando a conocer toda nuestra gama de productos LEGO así como las promociones y lanzamientos para el año 2017.

Comunicación del Evento: La comunicación se realizara de manera personalizada a nuestros clientes B2B.

Área responsable: Marketing.

Inversión: S/.23.5 mil soles.

Calendarización: Enero a Diciembre del 2017.

Estrategia 2: Desarrollar un plan de medios digital integral.

Actividad 1: Desarrollo de un APP para los clientes de LEGO.

Descripción del Actividad: Se tercerizará el desarrollo de una aplicación móvil para la marca LEGO.

Comunicación del Evento: La comunicación será a través de redes sociales como Facebook, Instagram, Twiter, envío de maling de la base de datos proporcionada por el área de Inteligencia Comercial y Banners dentro de las tiendas LEGO y Baby Infanti Store. Área responsable: Marketing y Sistemas.

Inversión: S/.20.8 mil soles.

Calendarización: Mayo a Agosto del 2017.

Actividad 2: Posicionamiento en buscadores (SEO).

Descripción del Actividad: Se contratara los servicios de un posicionador web para mejorar los resultados de búsqueda y posicionamiento de la marca LEGO.

Área responsable: Marketing y Sistemas.

Inversión: S/.6.6 mil soles. 
Calendarización: Enero a Diciembre del 2017.

Estrategia 3: Desarrollar un sistema de centralización de información - CRM.

Actividad: Desarrollo de una plataforma de E-mail Marketing

Descripción del Actividad: tercerizar un servicio de una plataforma Email para poder automatizar él envió de mailing y analizar la tasas de aceptación, incremento de ventas de las promociones enviadas a través de este medio, así como también administrar y actualizar una mejor base de datos de nuestros clientes.

Área responsable: Marketing y Sistemas.

Inversión: S/.75.4 mil soles.

Calendarización: Junio, Julio y Agosto del 2017.

Estrategia 4: Implementar un plan de capacitación para las fuerzas de ventas.

Actividad: Capacitar a las fuerza de ventas.

Evento: Charlas para la mejora en atención al servicio al cliente.

Descripción del Evento: se realizaran charlas motivacionales para el manejo de situaciones, calidad de servicio y conocimiento del producto a toda la fuerza de ventas tanto del canal directo (B2C), como del canal moderno (B2B).

Comunicación del Evento: La comunicación será a través de los correos internos del personal, asimismo de su supervisor encargado.

Área responsable: Recursos Humanos, canal B2B y canal B2C.

Inversión: S/.131 mil soles.

Calendarización: Enero, Febrero, Marzo, Noviembre y Diciembre del 2017. 


\section{Precio.}

Objetivo: Recuperar 2 puntos porcentuales más en el margen 2017, es decir, pasar de 50\% a $52 \%$.

Estrategia: Realizar un incremento en los precios $5 \%$ en todos los productos de la marca LEGO.

Actividades:

- Coordinar con logística de COMEXA, el cambio de precios.

- Coordinar con el área comercial de COMEXA los nuevos precios y la fecha en que estos comenzaran a regir.

- Comunicación con los clientes del canal moderno de COMEXA, por el incremento de precios.

- Re-Etiquetado de todos los productos de LEGO en el canal propio.

Área responsable: Finanzas, Logística, Canal B2C y Marketing.

Inversión: S/.30 mil soles.

Calendarización: Enero del 2017.

\subsection{Presupuesto de Marketing}

Comexa para los productos de la marca LEGO diseño el presupuesto 2017 dividió en 4 partes según las estrategias que se llevaran a cabo:

En la Tabla 25 se puede apreciar el presupuesto detallado por estrategias y fechas de realización de los eventos o actividades. 
Tabla 25

Calendario y Presupuesto.

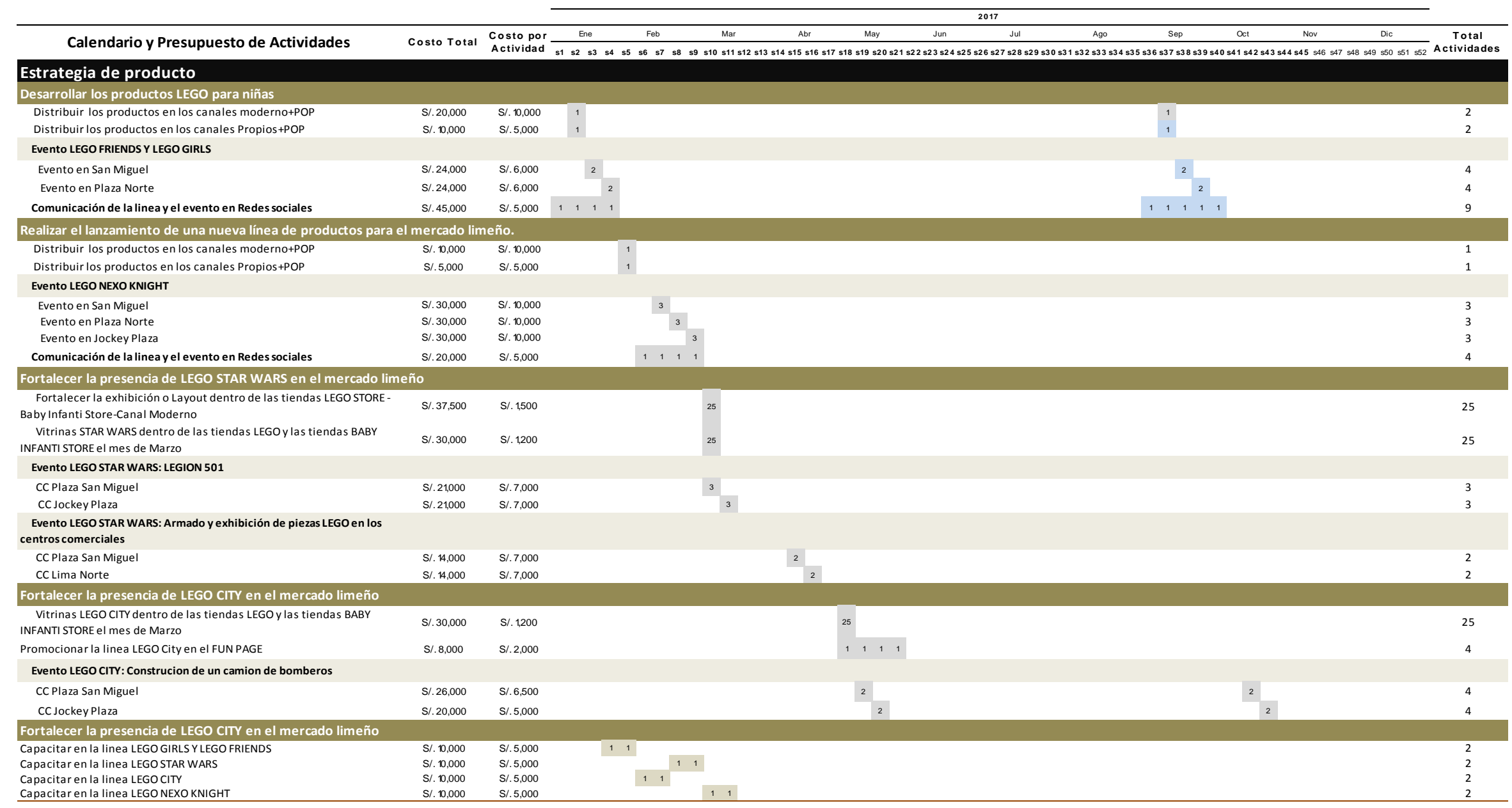




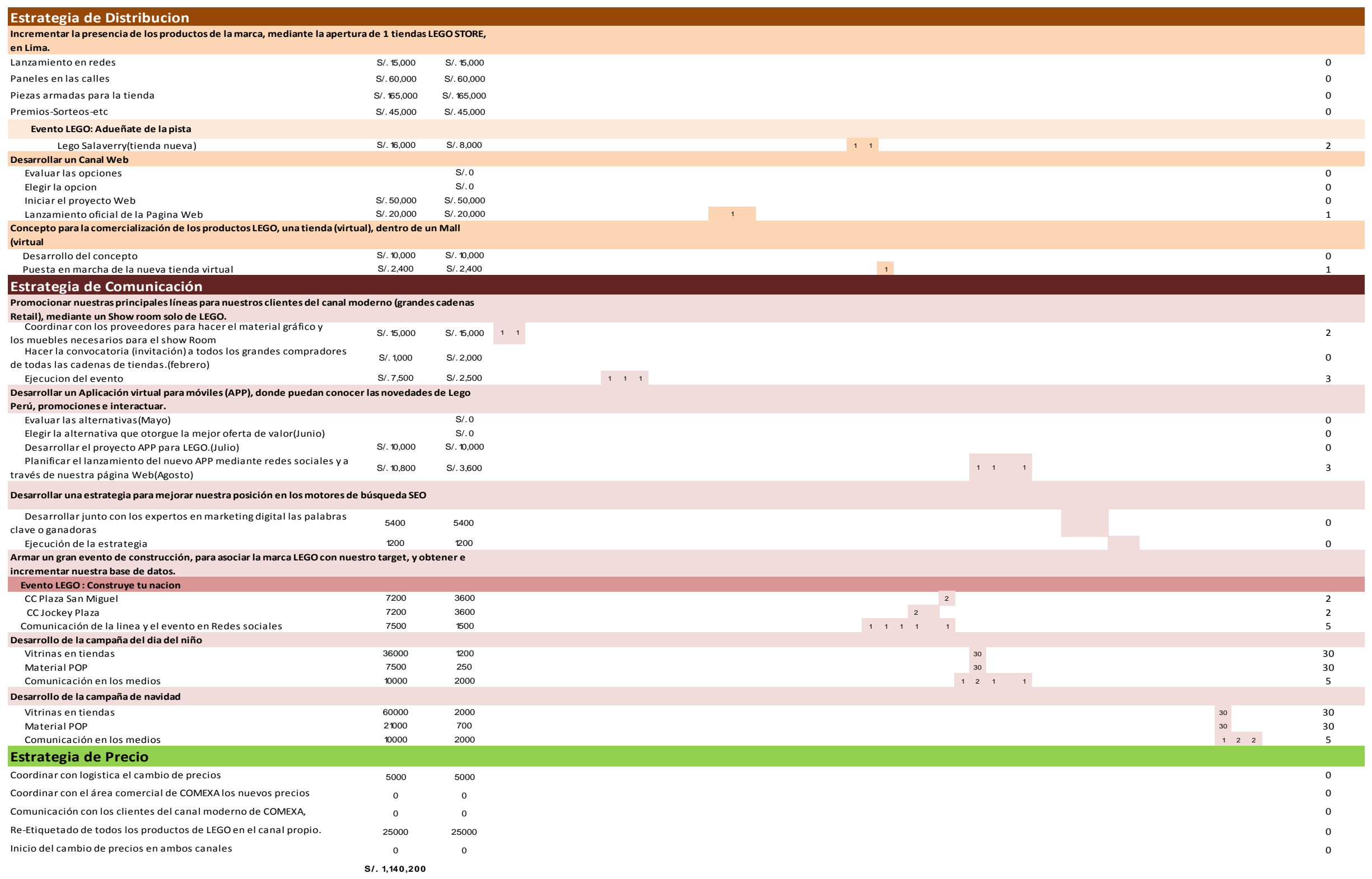




\subsection{Estado de Resultados}

Para el presente proyecto, y poder determinar el impacto de Plan de marketing en las ventas y en el resultado operativo de la unidad de negocios, fue necesario partir del análisis de 4 escenarios posibles.

En el primer escenario, se muestran las ventas del año 2017 sin un plan de marketing estructurado, con una mínima inversión (ver Tabla 26), equivalente al 2\% de las ventas proyectadas.

Para la proyección de dichas ventas, se consideró la desaceleración que la unidad de negocios (LEGO Perú), registrara en el 2016, debido entre otras cosas, a una falta de un Plan de Marketing estructurado con una baja inversión. En este resultado, podemos ver que las ventas en el 2017, se proyectan con un crecimiento de 7\% con respecto al cierre del 2016 , que equivale a un ingreso de S/ 29, 330, 582 soles, con un Resultado operativo de S/. 7, 141,127 soles, esto nos arroja un retorno de $24.3 \%$ sobre las ventas.

Por otra parte, tenemos tres escenarios más, donde se aplica un plan de marketing estructurado, donde la inversión de inversión se incrementa entre 3\% y 4\% de las ventas (dependiendo del escenario; pesimista, esperado y optimista)

En un escenario pesimista, se puede apreciar que las ventas, aplicando el plan de Marketing, llegan a S/.30, 701,170 soles (ver Tabla 27), lo cual significa un incremento a las ventas respecto al cierre del 2016 de $12 \%$. Se proyectó un gasto de marketing de S/1, 140,200 soles, que equivalen a $3.7 \%$ de las ventas esperadas y un resultado operacional de S/7, 504,672 soles lo que nos da un retorno de $24.4 \%$ sobre las ventas. Estos resultados, son mejores, que los esperados obtener sin un plan de marketing. 
Tabla 26

Estado de Resultados Escenario sin Plan de Marketing.

$107 \%$

Ventas Esperadas en el marca LEGO 29,330,582

Costo de Venta (50\%) 14,665,291

Utilidad Bruta $\quad 14,665,291$

Gasto de personal 1,759,835

Gasto de Tarjeta de Credito 879,917

Gasto de movilizacion 261,042

Fletes y combustibles $\quad 126,122$

Gasto de MKT 456,080

Gasto de ventas 3,482,996

Reclutamiento $\quad 56,608$

Abastecimiento Logistica $\quad 486,888$

Mantenimientos $\quad 58,661$

Energia,agua, gas $\quad 199,448$

Comunicaciones 63,061

Gasto de Oficina $\quad 105,590$

Insumos 137,854

Alquileres 2,933,058

Gasto de Administracion $\quad 4,041,168$

Gasto Operativo 7,524,164

Resultado Operacional 7,141,127

Tabla 27

Estado de Resultados Escenario Pesimista

$112 \%$

\begin{tabular}{lr}
\hline Ventas Esperadas en el marca LEGO & $30,701,170$ \\
Costo de Venta (48\%) & $14,736,561$ \\
Utilidad Bruta & $15,964,608$ \\
Gasto de personal & $1,842,070$ \\
Gasto de Tarjeta de Credito & 921,035 \\
Gasto de movilizacion & 266,263 \\
Fletes y combustibles & 132,015 \\
Gasto de MKT & $1,140,200$ \\
Gasto de ventas & $4,301,583$ \\
Reclutamiento & 56,608 \\
Abastecimiento Logistica & 509,639 \\
Mantenimientos & 58,661 \\
Energia,agua, gas & 199,448 \\
Comunicaciones & 63,061 \\
Gasto de Oficina & 105,590 \\
Insumos & 144,295 \\
Alquileres & $3,021,050$ \\
Gasto de Administracion & $4,158,353$ \\
Gasto Operativo & $8,459,936$ \\
Resultado Operacional & $7,504,672$ \\
\hline
\end{tabular}


En un escenario esperado, se puede apreciar que las ventas, aplicando el plan de Marketing, llegan a S/.33, 793,678 soles (ver Tabla 28), lo cual significa un incremento a las ventas respecto al cierre del 2016 de 23\%. Se proyectó un gasto de marketing de S/1, 140,200 soles, que equivalen a $3.4 \%$ de las ventas esperadas y un resultado operacional de $\mathrm{S} / 8,664,651$ soles lo que nos da un retorno de $25.6 \%$ sobre las ventas.

Tabla 28

Estado de Resultados Escenario Esperado.

\begin{tabular}{lr} 
& $123 \%$ \\
\hline Ventas Esperadas en el marca LEGO & $33,793,678$ \\
Costo de Venta (48\%) & $16,220,965$ \\
Utilidad Bruta & $17,572,712$ \\
Gasto de personal & $2,027,621$ \\
Gasto de Tarjeta de Credito & $1,013,810$ \\
Gasto de movilizacion & 266,263 \\
Fletes y combustibles & 145,313 \\
Gasto de MKT & $1,140,200$ \\
Gasto de ventas & $4,593,207$ \\
Reclutamiento & 56,608 \\
Abastecimiento Logistica & 560,975 \\
Mantenimientos & 58,661 \\
Energia,agua, gas & 199,448 \\
Comunicaciones & 63,061 \\
Gasto de Oficina & 105,590 \\
Insumos & 158,830 \\
Alquileres & $3,111,681$ \\
Gasto de Administracion & $4,314,855$ \\
Gasto Operativo & $8,908,062$ \\
Resultado Operacional & $8,664,651$ \\
\hline
\end{tabular}

En un escenario optimista, se puede apreciar que las ventas, aplicando el plan de Marketing, llegan a S/.35, 483,362 soles (ver Tabla 29), lo cual significa un incremento a las ventas respecto al cierre del 2016 de $29 \%$. Se proyectó un gasto de marketing de S/1, 140,200 soles, que equivalen a 3.2\% de las ventas esperadas y un resultado operacional de $\mathrm{S} / 9,254,609$ soles lo que nos da un retorno de $26.1 \%$ sobre las ventas. 
Estos resultados, nos muestran que aplicar un plan de marketing estructurado, siempre será una mejor opción que no hacerlo, ya que lo que se gasta en dicho plan, incrementaría notoriamente las ventas esperadas, aun en el escenario más conservador(pesimista).

Tabla 29

Estado de Resultados Escenario Optimista.

$129 \%$

\begin{tabular}{lr}
\hline Ventas Esperadas en el marca LEGO & $35,483,362$ \\
Costo de Venta (48\%) & $17,032,014$ \\
Utilidad Bruta & $18,451,348$ \\
Gasto de personal & $2,129,002$ \\
Gasto de Tarjeta de Credito & $1,064,501$ \\
Gasto de movilizacion & 266,263 \\
Fletes y combustibles & 152,578 \\
Gasto de MKT & $1,140,200$ \\
Gasto de ventas & $4,752,544$ \\
Reclutamiento & 56,608 \\
Abastecimiento Logistica & 589,024 \\
Mantenimientos & 58,661 \\
Energia, agua, gas & 199,448 \\
Comunicaciones & 63,061 \\
Gasto de Oficina & 105,590 \\
Insumos & 166,772 \\
Alquileres & $3,205,032$ \\
Gasto de Administracion & $4,444,195$ \\
Gasto Operativo & $9,196,739$ \\
Resultado Operacional & $9,254,609$ \\
\hline
\end{tabular}




\section{Capítulo VIII. Evaluación de Estrategia}

\subsection{Sistemas de Información}

Hoy en día los negocios gastan millones de dólares en hardware, software, consultorías y servicios, la cual tienen que ver con los sistemas de información. Un Sistema de información se puede definir como un conjunto de componentes interrelacionados que recolectan, procesan, almacenan y distribuyen información para apoyar la toma de decisiones y el control de la organización. Además, los sistemas de información ayudan a los gerentes y los trabajadores a vigilar tendencias que afecte a los productos y oportunidades de ventas, apoyen el planeamiento y vigilen el desempeño de sus colaboradores y competencias, vigilaran las campañas publicitarias y promociones, decisión de fijación de precios y desempeño de ventas, ayudar en la localización y contacto de clientes potenciales, el seguimiento de ventas, el procesamiento de pedidos y apoyo en el servicio al cliente.

Laudon J. y Laudon K. (2012) en su libro Los Sistemas de Información Gerencial, se define claramente que los sistemas de información y control en función de ventas y marketing es vender los productos o servicios de la organización. A marketing le corresponde identificar los clientes para los productos o servicios de la empresa, determinar que necesitan o desean, planear productos y servicios para satisfacer sus necesidades, así como anunciar y promover estos productos y servicios. A ventas le corresponde contactar clientes, vender productos y servicios, tomar pedidos y llevar el registro de ventas. (K., 2007)

\subsection{Tablero de Control y Plan de contingencia}

Comexa para cada objetivo de marketing tiene diferentes tableros de control, los cuales monitorean los estimados de ventas, visitas y otros indicadores permitiendo tomar 
acciones según los resultados. Dependiendo de estos resultados se podrán activar los distintos planes de contingencia.

A continuación se mostrara y detallara los tableros de control y sus planes de contingencia:

1. Objetivo: Vender S/. 3.5 millones de soles en el 2017 en nuestros productos de la marca LEGO para la niñas.

La medición de este objetivo se realizara de manera mensual, por ello, es que los 3.5 millones de soles están repartidos entre los meses de Enero a Diciembre, tomando en cuenta la estacionalidad que tienen los juguetes en el mercado peruano y las actividades que se desarrollaran para estas líneas específicas (ver Tabla 30).

De presentarse desviaciones sobre la venta esperada, se activara el plan de contingencia, este se moverá según dos variables; cuando la venta sea menor al $20 \%$ y cuando sea mayor al 20\%. Cuando sea menor al 20\% el semáforo del KPI se mostrara en rojo, lo cual activara el plan de contingencia para déficit, para este caso se incrementaran las promociones con descuentos y se deberá mejorar las exhibiciones en el canal propio. Cuando tenga un Exceso Mayor de $20 \%$ se programara compras al proveedor y se desactivaran los descuentos en estas líneas en el canal web, ya que lo que queremos es vender en la medida de lo posible los productos con precio blanco (sin descuento), de esta manera mejoramos el margen y cubrimos la creciente oferta hasta que nos vuelva a llegar productos. 
Tabla 30

Tablero de Control - LEGO Friends/LEGO Girls.

\begin{tabular}{|c|c|c|c|c|c|}
\hline \multirow{2}{*}{ Objetivo } & \multirow{2}{*}{$\frac{\text { Venta }}{\text { Mes }}$} & \multirow{2}{*}{$\begin{array}{l}\text { L. Friends/L Girls } \\
\text { Venta Esperada } 2017\end{array}$} & \multicolumn{2}{|c|}{ Plan Contingencia } & \multirow{2}{*}{ KPI } \\
\hline & & & Exceso $>20 \%$ & Debajo del $20 \%$ & \\
\hline \multirow{13}{*}{$\begin{array}{l}\text { Vender } 3.5 \text { millones de soles en el } \\
2017 \text { en productos Lego para niñas }\end{array}$} & January & $S / .101,790$ & & & \\
\hline & February & S/. 127,022 & & & \\
\hline & March & $S / .238,868$ & Programar & & \\
\hline & April & $S / .234,005$ & Compra y & Activar & \\
\hline & May & $S / .237,795$ & desactivar & promociones & \\
\hline & June & $S / .221,226$ & los & con descuentos & \\
\hline & July & $S / .310,886$ & descuentos & y mejorar las & \\
\hline & August & S/. 262,196 & en estas & exhibiciones en & \\
\hline & September & $S / .197,728$ & lineas en el & el canal propio & \\
\hline & Octuber & $S / .343,863$ & canal Web & & \\
\hline & November & $S / .528,149$ & & & \\
\hline & December & $S / .696,471$ & & & \\
\hline & Total & S/. 3,500,000 & & & 0 \\
\hline
\end{tabular}

2. Objetivo: Vender en una nueva línea para niños, 770 mil soles en en el 2017

Para la gama de productos para niños, Comexa ampliara la línea trayendo el producto LEGO NEXO KNIGHT, esto nos permitirá incrementar las ventas en S/. 770,000. Estas ventas se tendrán que alcanzar repartida entre los meses de Enero a Diciembre, tomando en cuenta la estacionalidad que tienen los juguetes en el mercado peruano y las actividades que se desarrollaran para estas líneas específicas. El plan de contingencia se activara cuando en el esperado del mes, se tenga un déficit mayor al $20 \%$, en este caso se activaran las promociones con descuentos y se mejorara las exhibiciones en el canal propio, esto ayudara a que la línea LEGO NEXO KNIGHT sea más conocida y atractiva. Cuando se tenga un exceso mayor al $20 \%$ se programara comprar al proveedor para incrementar el stock y evitar quiebres y se desactivaran los descuentos en estas líneas en el canal web, con el fin de prever el stock en el canal propio y en el canal moderno (ver Tabla 31). 
Tabla 31

Tablero de Control - LEGO Nexo Knight.

\begin{tabular}{|c|c|c|c|c|c|}
\hline \multirow{2}{*}{ Objetivo } & \multicolumn{2}{|l|}{ Venta } & \multicolumn{2}{|c|}{ Plan Contingencia } & \multirow{2}{*}{ KP } \\
\hline & Mes & Venta Esperada 2017 & Exceso $>20 \%$ & Debajo del $20 \%$ & \\
\hline \multirow{13}{*}{$\begin{array}{l}\text { Vender en una nueva linea para } \\
\text { niños, } 770 \text { mil soles, en en el } 2017\end{array}$} & January & $S / .22,394$ & & & \\
\hline & February & S/. 27,945 & & & \\
\hline & March & $S / .52,551$ & Programar & & \\
\hline & April & $S / .51,481$ & Compra y & Activar & \\
\hline & May & S/. 52,315 & desactivar & promociones & \\
\hline & June & $S / .48,670$ & los & con descuentos & \\
\hline & July & S/. 68,395 & descuentos & y mejorar las & \\
\hline & August & S/. 57,683 & en estas & exhibiciones en & 0 \\
\hline & September & $S / .43,500$ & lineas en el & el canal propio & O \\
\hline & Octuber & $S / .75,650$ & canal Web & & \\
\hline & November & $S / .116,193$ & & & 0 \\
\hline & December & $S / .153,224$ & & & O \\
\hline & Total & $S / .770,000$ & & & O \\
\hline
\end{tabular}

3. Objetivo: Vender s/ 9.6 millones de soles en dos de nuestros productos estrellas

Los productos estrellas Lego Star Wars y Lego City se medirán en conjunto y de manera mensual. Las metas planteadas se tendrán que alcanzar repartidas entre los meses de Enero a Diciembre, tomando en cuenta la estacionalidad que tienen los juguetes en el mercado peruano y las actividades que se desarrollaran para estas líneas específicas. La meta para fin de año de estos productos es de S/. 9.6 millones de soles (ver Tabla 32).

Tabla 32

Plan de Contingencia-Productos Estrellas

\begin{tabular}{|c|c|c|c|c|c|}
\hline \multirow{2}{*}{ Objetivo } & Venta & \multirow{2}{*}{$\frac{\text { L. Star Wars/ L. City }}{\text { Venta Esperada } 2017}$} & \multicolumn{2}{|c|}{ Plan Contingencia } & \multirow{2}{*}{ KPI } \\
\hline & Mes & & Exceso $>20 \%$ & Debajo del $20 \%$ & \\
\hline \multirow{13}{*}{$\begin{array}{l}\text { Vender s/ } 9.6 \text { millones de soles en } \\
\text { dos de nuestros productos estrellas }\end{array}$} & January & S/. 279,196.45 & & & \\
\hline & February & S/. 348,404.10 & & Activar & \\
\hline & March & S/. 655,180.16 & Programar & promociones & \\
\hline & April & $S / .641,842.15$ & Compra y & con descuentos & \\
\hline & May & S/. 652,236.81 & desactivar & y mejorar las & \\
\hline & June & S/. 606,791.59 & los & exhibiciones en & \\
\hline & July & S/. 852,716.00 & descuentos & el canal propio. & \\
\hline & August & S/. 719,167.37 & en estas & Desarrollar & \\
\hline & September & S/. 542,340.93 & lineas en el & eventos con los & $\mathrm{C}$ \\
\hline & Octuber & $S / .943,167.46$ & canal Web & centros & $\mathrm{C}$ \\
\hline & November & $S / .1,448,636.21$ & & comerciales & C \\
\hline & December & S/. 1,910,320.77 & & & C \\
\hline & Total & $S / .9,600,000.00$ & & & $\mathrm{C}$ \\
\hline
\end{tabular}


El plan de contingencia se activara cuando las ventas del mes tengan un déficit mayor al $20 \%$ frente al proyectado. En ese caso se tomarían las medidas correctivas de activar las promociones con descuentos y mejorar las exhibiciones en el canal propio, también se desarrollara eventos con los centros comerciales más representativos de Lima. Cuando se tenga un exceso mayor al $20 \%$ se programara comprar al proveedor a fin de no tener quiebres de stock y desactivar los descuentos en estas líneas en el canal web, con el fin de prever el stock en el canal propio y en el canal moderno.

4. Objetivo: Vender 1.5 millones de soles, con una nueva tienda LEGO STORE en el 2017.

Comexa en su plan de expansión, planea la apertura de una nueva tienda Lego Store la cual contribuirá en un gran porcentaje a alcanzar el objetivo de vender en esta nueva tienda 1.5 millones de soles.

El plan de contingencia se activara cuando en las ventas del mes se tenga un déficit mayor al 10\%, siendo las acciones correctivas el incremento de promociones y la publicidad en redes sociales como Facebook, Youtube, twiter, etc. Para dar a conocer la nueva tienda LEGO STORE. En caso las ventas muestren un exceso mayor de 20\%, se corregirá y sincerara el Forecast de lo que queda del año (ver Tabla 33). 
Tabla 33

Plan de Contingencia - Nueva Tienda LEGO STORE.

\begin{tabular}{|c|c|c|c|c|c|}
\hline \multirow{2}{*}{ Objetivo } & \multirow[b]{2}{*}{ Mes } & Apertura Lego Store & \multicolumn{2}{|c|}{ Plan Contingencia } & \multirow{2}{*}{ KPI } \\
\hline & & Ventas & Exceso $>\mathbf{2 0 \%}$ & Deficit $<10 \%$ & \\
\hline \multirow{13}{*}{$\begin{array}{l}\text { Vender } 1.5 \text { millones de soles, con } \\
\text { una nueva tienda LEGO STORE en el } \\
2017 .\end{array}$} & January & $S / .43,624$ & \multirow{12}{*}{$\begin{array}{l}\text { Reestructur } \\
\text { ar el }\end{array}$} & & \\
\hline & February & $S / .54,438$ & & & \\
\hline & March & S/. 102,372 & & & \\
\hline & April & $S / .100,288$ & & Incrementar las & \\
\hline & May & S/. 101,912 & & publicidad on & \\
\hline & June & S/. 94,811 & & pupliciaad en & \\
\hline & July & S/. 133,237 & & Teues suciales, & \\
\hline & August & S/. 112,370 & & conecer la nueva & \\
\hline & September & $S / .84,741$ & & conocer la nueva & \\
\hline & Octuber & S/. 147,370 & & & \\
\hline & November & S/. 226,349 & & & \\
\hline & December & S/. 298,488 & & & \\
\hline & Total & S/. 1,500,000 & & & $\bar{P}$ \\
\hline
\end{tabular}

5. Objetivo: Vender mediante nuevos canales de distribución S/850 mil soles, en el 2017.

Para este objetivo, se planteó hacer 2 acciones de controles y acciones de contingencia, las cuales cada una es independiente de la otra.

\subsection{Desarrollo de un nuevo canal Mall Virtual}

El nuevo canal virtual se medirá de manera mensual, para lo cual se tendrá que alcanzar las metas repartidas en los periodos de Enero a Diciembre, tomando en cuenta la estacionalidad que tienen los juguetes en el mercado peruano y las actividades como los Ciber days u otros desarrollados por la cámara de comercio y el área de marketing que ayudaran a la ventas online. La meta para fin de año de estos productos son de S/. 350,000.

El plan de contingencia se activara cuando en las ventas del mes se tenga un déficit mayor al 10\%, entonces se renegociarán las tarifas con el proveedor (Mall Virtual) y cuando se tenga un exceso mayor al $20 \%$, se tendrá que controlar el stock y solicitar las reposición para no incumplir con los requerimientos de este canal (ver Tabla 34). 
Tabla 34

Plan de Contingencia - Mall Virtual

\begin{tabular}{|c|c|c|c|c|c|}
\hline \multirow{2}{*}{ Objetivo } & \multirow[b]{2}{*}{ Mes } & \multirow[b]{2}{*}{ Venta Esperada } & \multicolumn{2}{|c|}{ Plan Contingencia } & \multirow{2}{*}{ KPI } \\
\hline & & & Exceso $>20 \%$ & Deficit $<10 \%$ & \\
\hline \multirow{13}{*}{$\begin{array}{l}\text { Vender mediante nuevos canales } \\
\text { de distribucion, } \mathrm{S} / 850 \mathrm{mil} \text { soles, en } \\
\text { el } 2017\end{array}$} & January & S/. 10,179 & \multirow{12}{*}{$\begin{array}{l}\text { Controlar el } \\
\text { Stock y } \\
\text { reposicion }\end{array}$} & \multirow{12}{*}{$\begin{array}{c}\text { Renegociar } \\
\text { tarifas con el } \\
\text { proveedor(Mall } \\
\text { Virtual) }\end{array}$} & \\
\hline & February & S/. 12,702 & & & \\
\hline & March & $S / .23,887$ & & & \\
\hline & April & $S / .23,400$ & & & \\
\hline & May & S/. 23,779 & & & \\
\hline & June & $S / .22,123$ & & & \\
\hline & July & S/. 31,089 & & & \\
\hline & August & $S / .26,220$ & & & \\
\hline & September & S/. 19,773 & & & \\
\hline & Octuber & S/. 34,386 & & & \\
\hline & November & S/. 52,815 & & & \\
\hline & December & $\mathrm{S} / .69,647$ & & & 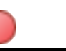 \\
\hline & Total & S/. 350,000 & & & \\
\hline
\end{tabular}

5.2. Desarrollo de un canal Web

Comexa en su plan de expansión, desarrollara en el 2017 y a través de un servicio tercerizado un canal web para LEGO. Este será canal será medido con los indicadores tradicionales como ventas, visitas y likes. Se espera que este canal contribuya en un gran porcentaje a alcanzar el objetivo general de la línea y logre vender S/.500,000.00 soles de soles en el primer año. Este canal será medido de manera mensual, también por el número de likes $(100,000)$ y visitas $(250,000)$ según la estacionalidad y las actividades como los ciber days que realiza la cámara de comercio (ver Tabla 35). 
Tabla 35

Plan de Contingencia - Canal Web.

\begin{tabular}{|c|c|c|c|c|c|c|c|c|}
\hline \multirow{2}{*}{ Objetivo } & \multirow[b]{2}{*}{ Mes } & \multicolumn{4}{|c|}{ Canal Web } & \multicolumn{2}{|c|}{ Plan Contingencia } & \multirow{2}{*}{ KPI } \\
\hline & & Ventas & Visitas & Likes & Ratio & Exceso $>20 \%$ & Deficit $<10 \%$ & \\
\hline \multirow{13}{*}{$\begin{array}{l}\text { Vender mediante nuevos canales } \\
\text { de distribucion, } \mathrm{S} / 850 \text { mil soles, en } \\
\text { el } 2017\end{array}$} & January & S/. 14,541 & 7,271 & 2,908 & 0.15 & \multirow{12}{*}{$\begin{array}{c}\text { Reestructurar } \\
\text { el Forecast }\end{array}$} & \multirow{12}{*}{$\begin{array}{l}\text { Incrementar las } \\
\text { promociones y } \\
\text { la publicidad en } \\
\text { redes sociales }\end{array}$} & 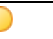 \\
\hline & February & S/. 18,146 & 9,073 & 3,629 & 0.20 & & & \\
\hline & March & S/. 34,124 & 17,062 & 6,825 & 0.20 & & & \\
\hline & April & S/. 33,429 & 16,715 & 6,686 & 0.23 & & & \\
\hline & May & S/. 33,971 & 16,985 & 6,794 & 0.25 & & & \\
\hline & June & S/. 31,604 & 15,802 & 6,321 & 0.30 & & & \\
\hline & July & $S / .44,412$ & 22,206 & 8,882 & 0.30 & & & \\
\hline & August & S/. 37,457 & 18,728 & 7,491 & 0.35 & & & \\
\hline & September & S/. 28,247 & 14,123 & 5,649 & 0.40 & & & \\
\hline & Octuber & $S / .49,123$ & 24,562 & 9,825 & 0.40 & & & \\
\hline & November & $S / .75,450$ & 37,725 & 15,090 & 0.42 & & & D \\
\hline & December & S/. 99,496 & 49,748 & 19,899 & 0.42 & & & \\
\hline & Total & $S / .500,000$ & 250,000 & 100,000 & & & & \\
\hline
\end{tabular}

El plan de contingencia se activara cuando, en las ventas del mes se tenga un déficit mayor al 10\%, en cualquiera de nuestros 3 indicadores (ventas, visitas o likes), las medidas correctivas serán incrementar las promociones y la publicidad en redes sociales, rediseñar y hacer más amigable la Web. Cuando se tenga un exceso mayor al 20\% se reestructurar el Forecast de lo proyectado en el año.

6. Objetivo: Incrementar los mecanismos para dar a conocer nuestro MIX y promociones a los clientes $\mathrm{B} 2 \mathrm{~B}$.

Para este objetivo, se planteó realizar 3 acciones de control y 3 acciones de contingencia, las cuales son independientes una de la otra.

6.1. Desarrollar un Show Room, para cerrar acuerdos comerciales con nuestros clientes de los canales modernos.

Comexa, en su plan de expansión y en cara a mejorar el manejo y acercamiento con los clientes B2B, realizara Show Room para exhibir toda su gama de productos y poder cerrar acuerdos comerciales con sus clientes de los canales modernos. El plan de contingencia se activara cuando en el esperado del mes la ventas a los canales modernos se tenga un déficit mayor al $10 \%$, en tal sentido se tomara medidas correctivas como renegociar márgenes y dar 
mayor soporte promocional a los grandes compradores. Mientras si se tiene un exceso mayor al $20 \%$, se analizara las cantidades a importar y se registrara el incremental para poder darnos abasto con nuestros clientes del canal moderno (ver Tabla 36).

Tabla 36

Plan de Contingencia - Show Room

\begin{tabular}{|c|c|c|c|c|c|}
\hline \multirow{2}{*}{ Objetivo } & \multicolumn{2}{|r|}{ Show Room } & \multicolumn{2}{|c|}{ Plan Contingencia } & \multirow{2}{*}{ KPI } \\
\hline & Mes & Ventas & Exceso $>20 \%$ & Deficit $<10 \%$ & \\
\hline \multirow{13}{*}{$\begin{array}{l}\text { Incrementar los mecanismos para } \\
\text { dar a conocer nuestro MIX y } \\
\text { promociones a nuestros clientes }\end{array}$} & January & S/.61,543 & \multirow{12}{*}{$\begin{array}{l}\text { Analizar las } \\
\text { cantidades a } \\
\text { importar y } \\
\text { regitrar el } \\
\text { incremental }\end{array}$} & \multirow{12}{*}{$\begin{array}{c}\text { Renegociar } \\
\text { margenes y dar } \\
\text { mayor soporte } \\
\text { promocional a } \\
\text { los grandes } \\
\text { compradores }\end{array}$} & \\
\hline & February & S/. 139,963 & & & \\
\hline & March & $S / .1,029,253$ & & & \\
\hline & April & S/. 763,254 & & & \\
\hline & May & S/. 762,186 & & & \\
\hline & June & $S / .723,410$ & & & \\
\hline & July & $S / .1,225,722$ & & & \\
\hline & August & S/. 530,267 & & & \\
\hline & September & S/. 525,796 & & & \\
\hline & Octuber & $S / .1,729,286$ & & & \\
\hline & November & S/. 3,073,126 & & & \\
\hline & December & S/. 180,896 & & & 5 \\
\hline & Total & S/. 10,744,702 & & & \\
\hline
\end{tabular}

6.2 Desarrollo de un APP para los clientes de LEGO.

Con el desarrollo de un App, se pretende hacer más conocida y accesible la marca LEGO para el consumidor peruano. Esto será medido a través de descargas y visitas del app, teniendo como plan de contingencia dos situaciones: cuando se tenga un déficit mayor al $20 \%$, se tomara las medidas de mejorar y hacer más amigable el contenido del App, otra medida será incrementar las promociones donde se ofrecerá un $20 \%$ de descuento por descargar y comprar con el app. Y si se tuviera un exceso mayor al 20\%, se reducirán las promociones en el app para direccionar las ventas a las tiendas y/o el canal moderno (ver Tabla 37). 
Tabla 37

Plan de Contingencia - App LEGO.

\begin{tabular}{|c|c|c|c|c|c|}
\hline \multirow{2}{*}{ Objetivo } & \multicolumn{2}{|r|}{ APP } & \multicolumn{2}{|c|}{ Plan Contingencia } & \multirow{2}{*}{ KPI } \\
\hline & Mes & Visitas & Exceso $>20 \%$ & Deficit $<10 \%$ & \\
\hline \multirow{13}{*}{$\begin{array}{l}\text { Incrementar los mecanismos para } \\
\text { dar a conocer nuestro MIX y } \\
\text { promociones a nuestros clientes }\end{array}$} & January & 262 & & \multirow{12}{*}{$\begin{array}{c}\text { Mejorar el } \\
\text { contenido del } \\
\text { App, } \\
\text { incrementar } \\
\text { las } \\
\text { promociones( } \\
20 \% \text { de } \\
\text { descuento } \\
\text { por descargar) }\end{array}$} & \\
\hline & February & 327 & & & \\
\hline & March & 614 & & & \\
\hline & April & 602 & Reducir las & & \\
\hline & May & 611 & promociones e & & \\
\hline & June & 569 & invertir en & & \\
\hline & July & 799 & generar trafico a & & \\
\hline & August & 674 & las tiendas y/o el & & \\
\hline & September & 508 & canal moderno & & \\
\hline & Octuber & 884 & & & \\
\hline & November & 1,358 & & & \\
\hline & December & 1,791 & & & \\
\hline & Total & 9,000 & & & \\
\hline
\end{tabular}

6.2 Desarrollo de plataforma de E-mail Marketing

Para poder tener una mejor comunicación bidireccional con el cliente que visita nuestras tiendas se desarrollara un plan de E-mailing, el cual será monitoreado a través de indicadores como numero de correos enviados, numero de correos aperturados, numero de correos direccionados (click). Se contara con un plan de contingencia de manera que si se tuviera un déficit mayor al 20\% con respecto a los pronósticos, se realizaran las medidas correctivas como son, cambiar la estrategia en cuanto a frecuencia y mensaje, es decir hacer un mejor análisis y segmentar a nuestra clientela, ya que podría estar recibiendo correos que no son de su interés, lo cual originaria un rechazo a nuestro mailing. Si el exceso es mayor al 20\% se seguirá manteniendo la misma estrategia de comunicación (ver Tabla 38). 
Tabla 38

Plan de Contingencia - Emailing

\begin{tabular}{|c|c|c|c|c|c|c|}
\hline \multirow{2}{*}{ Objetivo } & \multicolumn{3}{|c|}{ Mailing } & \multicolumn{2}{|c|}{ Plan Contingencia } & \multirow{2}{*}{ KPI } \\
\hline & Mes & BB.DD & Clicks & Exceso $>20 \%$ & Deficit $<10 \%$ & \\
\hline \multirow{13}{*}{$\begin{array}{l}\text { Incrementar los mecanismos para } \\
\text { dar a conocer nuestro MIX y } \\
\text { promociones a nuestros clientes }\end{array}$} & January & 5,817 & 291 & \multirow{13}{*}{$\begin{array}{l}\text { Mantener la } \\
\text { estregia de } \\
\text { comunicacion }\end{array}$} & \multirow{12}{*}{$\begin{array}{l}\text { Cambiar la } \\
\text { estrategia en } \\
\text { cuanto a } \\
\text { frecuencia y } \\
\text { mensaje }\end{array}$} & \\
\hline & February & 7,258 & 363 & & & \\
\hline & March & 13,650 & 683 & & & \\
\hline & April & 13,372 & 669 & & & \\
\hline & May & 13,588 & 679 & & & \\
\hline & June & 12,641 & 632 & & & \\
\hline & July & 17,765 & 888 & & & \\
\hline & August & 14,983 & 749 & & & \\
\hline & September & 11,299 & 565 & & & \\
\hline & Octuber & 19,649 & 982 & & & \\
\hline & November & 30,180 & 1,509 & & & \\
\hline & December & 39,798 & 1,990 & & & 2 \\
\hline & Total & 200,000 & 10,000 & & & D \\
\hline
\end{tabular}

7. Objetivo: Recuperar 2 puntos porcentuales más en el margen en el 2017,es decir, pasar de $50 \%$ a $52 \%$

Para medir el impacto del cambio de precios en el margen, se monitoreara cada uno de nuestros canales al cierre de cada mes, de esta manera se podrá detectar si los objetivos con respecto al margen se cumple tal cual se ha pronosticado. El margen que se espera para el canal propio es de $58 \%$ y para el canal moderno es $40 \%$, de encontrar alguna inconsistencia a cierre de mes, se revisara los precios al detalle para encontrar donde existe un diferencia entre lo observado versus lo esperado. De esta manera se podrán tomar acciones correctivas (ver Tabla 39). 
Tabla 39

Plan de Contingencia - Precio

\begin{tabular}{clcccc}
\hline \multirow{2}{*}{ Objetivos } & \multicolumn{1}{c}{ Mes } & $\begin{array}{c}\text { Canal Propio Canal Moderno } \\
\text { Margen Esperado }\end{array}$ & $\begin{array}{c}\text { Margen } \\
\text { menor al }\end{array}$ & KPI \\
\hline & January & $58 \%$ & $40 \%$ & & $\bigcirc$ \\
Recuperar 2 & Mebruary & $58 \%$ & $40 \%$ & Revisar los & $\bigcirc$ \\
puntos & April & $58 \%$ & $40 \%$ & precios al & $\bigcirc$ \\
porcentuales & May & $58 \%$ & $40 \%$ & detalle por & $\bigcirc$ \\
más en el & June & $58 \%$ & $40 \%$ & linea, hasta & $\bigcirc$ \\
margen en el & July & $58 \%$ & $40 \%$ & descubrir las & $\bigcirc$ \\
2017, es decir, & August & $58 \%$ & $40 \%$ & lineas que & $\bigcirc$ \\
pasar de 50\% a & September & $58 \%$ & $40 \%$ & nos estan & $\bigcirc$ \\
$52 \%$ & Octuber & $58 \%$ & $40 \%$ & bajando el & $\bigcirc$ \\
& November & $58 \%$ & $40 \%$ & margen & $\bigcirc$ \\
& December & $58 \%$ & $40 \%$ & & $\bigcirc$ \\
\hline
\end{tabular}

\subsection{Evaluación Financiera}

Para el análisis financiero, hemos hecho una proyección de ventas y del resultado operacional para los años 2017,2018 y 2019, en tres distintos escenarios Sin Plan de Marketing, con Plan de marketing Pesimista y con Plan de Marketing Esperado (ver Tablas $40,41$ y 42$)$.

Tabla 40

Evaluacion Financiera Sin Plan de Marketing

\begin{tabular}{lrrr}
\hline & $107 \%$ & $107 \%$ & $106 \%$ \\
\cline { 2 - 4 } & 2017 & 2018 & 2019 \\
\hline Ventas Esperadas en el marca LEGO & $29,330,582$ & $31,383,723$ & $33,266,746$ \\
Costo de Venta(50\%) & $14,665,291$ & $15,691,861$ & $16,633,373$ \\
Utilidad Bruta & $14,665,291$ & $15,691,861$ & $16,633,373$ \\
Gasto Operativo & $7,524,164$ & $8,073,659$ & $8,588,727$ \\
Resultado Operacional & $7,141,127$ & $7,618,202$ & $8,044,646$ \\
\hline Total Incremento & $24.3 \%$ & $24.3 \%$ & $24.2 \%$ \\
\hline
\end{tabular}


Tabla 41

Evaluación Financiera Pesimista.

\begin{tabular}{lrrr}
\hline & $112 \%$ & $112 \%$ & $112 \%$ \\
\cline { 2 - 4 } & 2017 & 2018 & 2019 \\
\hline Ventas Esperadas en el marca LEGO & $30,701,170$ & $34,385,310$ & $38,511,547$ \\
Costo de Venta(48\%) & $14,736,561$ & $16,504,949$ & $18,485,543$ \\
Utilidad Bruta & $15,964,608$ & $17,880,361$ & $20,026,005$ \\
Gasto Operativo & $8,459,936$ & $9,494,163$ & $10,633,463$ \\
Resultado Operacional & $7,504,672$ & $8,386,198$ & $9,392,542$ \\
\hline Total Incremento & $24.4 \%$ & $24.4 \%$ & $24.4 \%$ \\
\hline
\end{tabular}

Tabla 42

Evaluación Financiera Esperado.

\begin{tabular}{lrrr}
\hline & $123 \%$ & $123 \%$ & $123 \%$ \\
\cline { 2 - 4 } & 2017 & 2018 & 2019 \\
\hline Ventas Esperadas en el marca LEGO & $33,793,678$ & $41,566,224$ & $51,126,455$ \\
Costo de Venta(48\%) & $16,220,965$ & $19,951,787$ & $24,540,699$ \\
Utilidad Bruta & $17,572,712$ & $21,614,436$ & $26,585,757$ \\
Gasto Operativo & $8,908,062$ & $10,976,678$ & $13,547,229$ \\
Resultado Operacional & $8,664,651$ & $10,637,758$ & $13,038,527$ \\
\hline Total Incremento & $25.6 \%$ & $25.6 \%$ & $25.5 \%$ \\
\hline
\end{tabular}

Lo que busca el análisis, es conocer cuál es impacto en las ventas y el resultado operativo que genera realizar un plan de marketing estructurado en los próximos años versus el no hacerlo. Para ello, hemos calculado el incremental en las ventas en cada escenario tomando en cuenta los factores de crecimiento de los mismos, este incremental se ha comparado con el incremental en el gasto de marketing.

Lo que se quiere conocer, es si el aumentar la inversión de marketing, es atractivo para la compañía y como se refleja esto en las ventas y el resultado operativo (ver Tablas 43 y 44). 
Tabla 43

Escenario Pesimista vs. Escenario sin Plan de Marketing.

\begin{tabular}{lccc}
\hline & 2017 & 2018 & 2019 \\
\hline Ventas & $\mathrm{S} / .1,370,588$ & $\mathrm{~S} / .3,001,588$ & $\mathrm{~S} / .5,244,801$ \\
Inv. Marketing & $\mathrm{S} / .684,120$ & $\mathrm{~S} / .766,214$ & $\mathrm{~S} / .858,160$ \\
& $\mathrm{~S} / .2$ & $\mathrm{~S} / .4$ & $\mathrm{~S} / .6$ \\
RO & $\mathrm{S} / .363,545$ & $\mathrm{~S} / .767,996$ & $\mathrm{~S} / .1,347,896$ \\
& $\mathrm{~S} / .0 .5$ & $\mathrm{~S} / .1 .0$ & $\mathrm{~S} / .1 .6$ \\
\hline
\end{tabular}

En la Tabla 43, se visualiza como se incrementan las ventas aplicando un plan de marketing en los años 2017, 2018 y 2019(en un escenario pesimista) versus el resultado de no aplicarlo, este mismo ejercicio se hizo para el resultado operativo y para la inversión de marketing. En ambos casos se obtuvo un ratio, expresado en soles, que nos indica que por cada sol invertido en el plan de marketing nos genera un retorno en las ventas y en el resultado operativo también expresado en soles. Es así que por ejemplo en el año 2017, por cada sol que se invierte en marketing, podemos obtener un incremento de $S / 2$ soles en ventas y de s/0.5 soles en el resultado operativo. Para el año 2018, cada sol invertido generar un incremento de S/ 4 soles en ventas y s/1 en el resultado operativo. Finalmente en el año 2019 por cada sol invertido en marketing, se generara s/6 soles de incremento en las ventas y S/1.6 en el resultado operativo.

Tabla 44

Escenario Esperado vs. Escenario Sin Plan de Marketing.

\begin{tabular}{lccc}
\hline & 2017 & 2018 & 2019 \\
\hline Ventas & $\mathrm{S} / .4,463,096$ & $\mathrm{~S} / .10,182,501$ & $\mathrm{~S} / .17,859,709$ \\
Inv. Marketing & $\mathrm{S} / .684,120$ & $\mathrm{~S} / .891,636$ & $\mathrm{~S} / .1,152,902$ \\
& $\mathrm{~S} / .7$ & $\mathrm{~S} / .11$ & $\mathrm{~S} / .15$ \\
RO & $\mathrm{S} / .1,523,524$ & $\mathrm{~S} / .3,019,556$ & $\mathrm{~S} / .4,993,882$ \\
& $\mathrm{~S} / .2 .2$ & $\mathrm{~S} / .3 .4$ & $\mathrm{~S} / .4 .3$ \\
\hline
\end{tabular}

En la Tabla 44, se visualiza como se incrementan las ventas aplicando un plan de marketing en los años 2017, 2018 y 2019 (en un escenario esperado) versus el resultado de no aplicarlo, 
este mismo ejercicio se hizo para el resultado operativo y para la inversión de marketing. En ambos casos se obtuvo un ratio, expresado en soles, que nos indica que por cada sol invertido en el plan de marketing nos genera un retorno en las ventas y en el resultado operativo también expresado en soles. Es así que por ejemplo en el año 2017, por cada sol que se invierte en marketing, podemos obtener un incremento de $\mathrm{S} / 7$ soles en ventas y de s/2.2 soles en el resultado operativo. Para el año 2018, cada sol invertido generar un incremento de S/ 11 soles en ventas y s/3.4 en el resultado operativo. Finalmente en el año 2019 por cada sol invertido en marketing, se generara s/ 15 soles de incremento en las ventas y S/4.3 en el resultado operativo 


\section{Capítulo IX. Conclusiones y Recomendaciones}

Después de realizar el presente podemos encontrar las siguientes conclusiones:

1. El mercado peruano de juguetes se encuentra en un proceso de expansión, debido a varios factores macro económicos y socio cultural, tales como el crecimiento de la clase media, la expansión del sector retail, la apertura de nuevos centros comerciales y el crecimiento de medios de comunicación no tradicionales como el internet, las redes sociales y las apps. Sin embargo, el cambio de gobierno, la crisis internacional y la variabilidad del dólar podrían desacelerar el crecimiento.

2. Comexa es una empresa que ha logrado posicionar los productos que comercializa de manera adecuada pese a no contar con una estrategia de marketing estructurada para el mercado peruano y tampoco ha realizado investigaciones de mercado para comprender el comportamiento, el perfil y las necesidades de su consumidor. Invertir en marketing en una marca como LEGO suele generar un buen retorno.

3. El consumidor de los productos de la marca LEGO, además de ser fiel a la marca, percibe el producto como de calidad y educativo, para ellos el precio no es un factor determinante a la hora de elegir la marca.

4. Las tiendas especializadas (LEGO STORE), son cada día más atractivas para los padres con hijos menores, al mismo tiempo el canal moderno (tiendas por departamento) es más atractivo para los solteros sin hijos.

5. Los productos de la marca LEGO se encuentra en una etapa de crecimiento en el mercado Peruano existiendo aun un inmenso mercado potencial para el desarrollo de la misma.

De acuerdo a las conclusiones indicadas anteriormente, podemos indicar las siguientes recomendaciones: 
1. El desarrollo del mercado retail peruano, permite desarrollar planes de inversión y crecimiento para el mercado de juguetes, pero debe tenerse en cuenta tener un plan de contingencia adecuado para prevenir y tener capacidad de reacción frente a alguna desaceleración o poco crecimiento.

2. Comexa debe implementar un plan de marketing estructurado basado en una investigación de mercado que le permita conocer a su consumidor actual.

3. COMEXA para su UEN LEGO, deberá fortalecer su estrategia de posicionamiento basado en su valor diferencial de ser un producto educativo y de alta calidad.

4. COMEXA para su UEN LEGO, deberá desarrollar un plan de crecimiento de sus tiendas propias y al mismo tiempo generar una mejor negociación con el canal moderno.

5. COMEXA para su UEN LEGO, debe profundizar en el desarrollo de sus estrategias para todos sus canales, aprovechando la etapa de crecimiento en la que se encuentra. 


\section{Referencias}

Ansoff, I. (1957). Estrategias para la Diversificación. Harvard business Review, 20.

BBC Mundo. (12 de 12 de 2015). Aprueban histórico acuerdo contra el cambio climático en la cumbre de París Recuperado el 09 de 02 de 2016, de BBC.

http://www.bbc.com/mundo/noticias/2015/12/151211_cumbre_clima_paris_cop21_ac uerdo_az

COMEXA. (2016). Organigrama.

Diario Gestión. (11 de Enero de 2016). Inflación repuntaría durante el verano hasta 5\%, considera el Scotiabank. Obtenido de Sitio Web del Diario Gestión:

http://gestion.pe/economia/inflacion-repuntaria-durante-verano-hasta-5-prevescotiabank-2152433

Diario Gestión. (20 de Enero de 2016). Tipo de cambio sigue al alza y cierra en máximo de S/ 3.446. Obtenido de Sitio Web del Diario Gestión: http://gestion.pe/mercados/tipocambio-sigue-al-alza-y-cierra-maximo-s-3446-2153026

DiarioCorreo. (23 de 08 de 2014).Perú tiene alta rotacion de personal. Recuperado el 12 de 03 de 2016, de diarioCorreo.pe: http://diariocorreo.pe/economia/peru-tiene-alta-tasade-rotacion-de-personal-9770/

DIGESA - Dirección General de Salud Ambiental. (20 de Enero de 2015). Registro Nacional para el fabricante, importador, comercializador y distribuidor, (incluyendo el responsable del almacenamiento) de juguetes y útiles de escritorio. Obtenido de Sitio Web de la DIGESA - Dirección General de Salud Ambiental: http://www.digesa.sld.pe/DEPA/juguetes_utiles/procedimientos_administrativos.asp 
El Comercio. (07 de 04 de 2015).Mercado de Tables. Recuperado el 12 de 03 de 2016, de http://elcomercio.pe/paginas/smartphones-tablets/mercado-apps-tiene-muchopotencial-peru-noticia-1753855

El Comercio. (25 de 12 de 2015). El Mercado de Juguetes. Recuperado el 12 de 03 de 2016, de elcomercio: http://elcomercio.pe/economia/peru/mercado-juguetes-peru-creceria15-2016-noticia-1866618

Euromoney. (10 de 01 de 2014). Clase Mediaal 2021. Recuperado el 09 de 02 de 2016, de Peru 21: Fuente: http://peru21.pe/economia/clase-media-seria-65-poblacionbicentenario-2165061

INEI - Instituto Nacional de Estadística e Informática. (20 de Enero de 2016). Comportamiento de la Economía Peruana en el Tercer Trimestre de 2015 (Noviembre). Obtenido de Sitio Web del INEI - Instituto Nacional de Estadística e Informática: https://www.inei.gob.pe/media/MenuRecursivo/boletines/informetecnico-n04_pbi-trimestral_2015iii.pdf

Ivan Valdez, C. P. (01 de Junio de 2015). Plan de Negocio de la jugueteria Fantasia. Plan de Negocio de la jugueteria Fantasia. Lima, Lima, Perú.

K., L. J. (2007). Sistemas de informacion gerencial. New York: Pearson education.

LaRepublica. (10 de 06 de 2015).Uso de smartphone en el Perú. Recuperado el 12 de 03 de 2016, de La Republica: http://larepublica.pe/marketing/4540-uso-de-smartphones-enperu-es-uno-de-los-mas-crecientes-en-latinoamerica

Peñaranda, C. (14 de 09 de 2015).La economia avanza. Recuperado el 09 de 02 de 2016, de Semana Economica: http://semanaeconomica.com/article/sectores-yempresas/consumo-masivo/169453-se-abriran-15-centros-comerciales-en-el-peruentre-el-2015-y-el-2016-segun-la-ccl/

Porter, M. (1990). Estrategia competitiva. New York: The Free Press. 
Radio Nacional. (27 de 07 de 2015). Radio Nacional. Recuperado el 09 de 02 de 2016, de Radio Nacional: http://www.radionacional.com.pe/informa/fiestaspatrias/seg-n-elinei-al-2021-la-poblaci-n-peruana-sobrepasar-los-33-millones

Renvoise, P. (2006). Neuromarketing el nervio de la venta. Barcelona: Universitat Oberta de Catalunya.

SUNAT. (04 de Diciembre de 2015). SUNAT. Obtenido de Sitio Web de la Superintendencia Nacional de Aduanas y de Administración Tributaria - SUNAT: http://www.sunat.gob.pe/

Takehara, J. (12 de 12 de 2014). Tendencias del Consumidor. Recuperado el 28 de 02 de 2016, de codigo: http://www.codigo.pe/marketing/4-tendencias-del-consumidorperuano-para-el-2015/ 


\section{Apéndice}

\section{Apéndice 1: Guía de indagación del grupo de enfoque.}

USIL

Curso: Proyecto de Marketing Aplicado

Profesora: Dra. Niria Goñi A.

Focus Group

Guía de Pautas, Guía de Indagación o Guía de Preguntas

1. Introducción

\section{PRESENTACIÓN Y ESTABLECIMIENTO DE LAS NORMAS}

Buenas noches, mi nombre es Veo el nombre de cada uno de los

participantes para facilitar la comunicación.

Bien, ahora quisiera que me digan si saben para que estamos reunidos?

En realidad estamos acá para hablar de un tema en el cual sabemos que nos pueden ayudar, por tal razón me gustaría decirles que sean totalmente sinceros y que no se dejen influenciar por nadie. Además me interesa que sepan que no existen respuestas correctas ni incorrectas, todas las respuestas son igualmente válidas.

También quisiera solicitarles su autorización para grabar estas sesión, ya que sus opiniones son tan importantes y mi memoria tan frágil que pudiera olvidarme de información útil que me entreguen. 
2. Características Sociodemográficas - Psicográficas y Conductuales

1. Me gustaría saber su edad y el lugar donde viven.

2. ¿A que se dedican? ¿Estudian, trabajan? ¿Dónde?

3. ¿Tienen hijos? ¿Qué actividades suelen hacer con ellos? Por favor listen sus lugares favoritos.

4. ¿Suelen ingresar a redes sociales como Facebook, twitter, Instagram, etc? ¿Cuál de ellas prefieren?

5. ¿Sus hijos tienen acceso a estas redes sociales? ¿Cuáles?

6. ¿Dónde suelen comprar juguetes?

7. Al momento de decidir comprar, ¿Saben qué marca comprar o lo deciden en el momento?

Y ¿por qué?

8. Cuando ustedes compran juguetes, ¿Suelen fijarse mucho en el precio?

9. ¿Cuál es el aspecto que principalmente valoran en un juguete?

10. ¿En qué ocasiones usted compra juguetes?

11. ¿Cuánto suele gastar en juguetes cuando ud compra?

3. Percepción de la marca

12. ¿Cuál es su marca de preferencia? o ¿cuál es la que más recuerda?

13. ¿Cuál cree Uds. que es la mejor marca? Y ¿Por qué?

14. ¿Porque prefieres esa marca? O ¿Por qué es la que más recuerdas?

15. ¿Ustedes conocen la marca LEGO?

16. ¿Porque razón comprarían la marca LEGO?

17. ¿Qué características creen Uds. que tienen los productos de la marca LEGO?

18. Si no encuentras la marca de tu LEGO ¿consumes otra marca?

19. ¿Conocen alguna tienda LEGO STORE?

20. ¿Qué opinión tienen de las tiendas Lego Store? 
21. Si tuvieras una tienda LEGO STORE en tu ciudad, ¿La visitarías?, ¿porque?

22. ¿Qué te gustaría que tenga?

23. ¿Cómo te gustaría que fuese la tienda?

24. ¿Te gustaría que se desarrolle algún tipo de actividad?

25. ¿Con que frecuencia irías a la tienda LEGO STORE? veces por año.

26. ¿Dónde te gustaría encontrarla? En algún centro comercial en especial, ¿en cuál?

4. Cierre

1.- Si alguno de ustedes tuviera un comentario adicional con referencia al tema tratado, agradecería que nos lo pueda indicar para así redondear el tema y dar por culminada esta reunión.

2.- La participación de cada uno de ustedes ha sido muy productiva para nosotros, agradezco mucho el apoyo brindado.

3.- Procederemos a entregarles un presente, agradeciéndole por habernos brindado parte de su tiempo y su disposición a participar de esta reunión la cual nos ayudará a continuar con nuestro proceso de aprendizaje.

Gracias por su atención. 


\section{Apéndice 2: Transcripción del grupo de enfoque.}

Moderador

Buenas noches, mi nombre es Julio, gracias por estar aquí. Me gustaría saber sus nombres para poder comenzar, voy a tratar de atenderlos lo más rápido posible.

¿Usted es Nadia?

- Sí, mi nombre es Nadia.

Nadia, nosotros hacemos el focus. Tú eres Nadia, ¿tú?

- Laura.

- Inés.

- Mónica.

- Pamela.

- Macarena.

Repetimos: Macarena, Pamela, Mónica, Inés, Laura y Nadia. Perfecto. ¿Saben para qué estamos aquí reunidos? No sean tímidas, cuéntenme, ¿por qué estamos aquí reunidos? Necesitamos que ustedes nos den...

- Justo iba a decir...

Vamos a hablar de un tema por lo cual creemos que todas ustedes nos pueden ayudar un montón y voy a pedirles autorización para poder grabar esta sesión. Ahí está la cámara, a ver, saluden.

Me gustaría saber para comenzar su edad y el lugar donde viven. Comenzamos por aquí.

- Yo tengo 40 años y vivo en Lima.

40 años y vives en Lima. ¿Y tú?

- 32 y también vivo en Lima.

32 y vives en Lima. ¿Mónica?

- 37 y Lima. 
37 y vives en Lima.

- Yo tengo 32 y también vivo en Lima.

32 y vives en Lima.

- $\quad$ Tengo 30 años y vivo en Trujillo.

Vives en Trujillo.

- Tengo 33 años y vivo en Chiclayo.

33 años y vives en Chiclayo. ¿A qué se dedican? ¿Estudian, trabajan y dónde están laborando?

- Yo trabajo en RENIEC.

Tú trabajas en la RENIEC.

- Yo trabajo en una consultora, soy secretaria.

Una consultora y es secretaria. ¿Mónica?

- En un laboratorio farmacéutico, soy asistente de gerencia.

Perfecto.

- Yo trabajo en laboratorio farmacéutico en el área de marketing.

En el área de marketing.

- Yo trabajo como secretaria en una empresa inmobiliaria.

Inmobiliaria.

- Yo trabajo como asistente de gerencia en una empresa avícola.

Genial, cuéntenme, ¿tienen hijos? ¿Qué actividades suelen hacer con ellos? ¿Cuáles son los lugares favoritos a donde suelen ir con sus hijos? No necesariamente tienen que responder por orden, no hay problema. ¿Quién quisiera contarme? ¿Tienen hijos, qué suelen hacer con ellos? 
- Yo tengo un hijo de doce años, le gusta salir al campo, le gusta ir al cine, jugar fútbol, natación.

Básicamente tu hijo va por el deporte.

- No, o sea, sí también, pero también le gusta reunirse con amigos, jugar playstation. Tiene diferentes actividades.

El colega nos pide que alcemos un poco más la voz para que la cámara pueda grabar mejor. ¿Quién más?

- Yo tengo tres niños, mi hijo mayor tiene diez años, Axel. Le gusta más lo que es la natación, le gusta la bicicleta, juegos electrónicos. André, tiene siete años y le gusta más lo que son los rompecabezas, play doh, origami y Ana tiene dos años y todavía está descubriendo sus actividades.

¿Quién más? ¿Quién más quisiera contarnos si tienen hijos?

- Yo tengo dos niños: el mayor tiene tres años y el menor tiene nueve meses. Al de tres años le encanta ir al parque, correr, scooter. Su otra afición son los carritos, le encanta los carritos y el fútbol. La bebe todavía está descubriendo cosas.

¿Quién más?

- Yo tengo una niña de siete años que se llama Luana. A ella le gusta todo el tema deportivo, es una niña atlética. Le gusta salir al parque, correr, saltar, brincar, todo lo que sea trepar le fascina, la bicicleta también y también tiene su lado pinki que le gustan las muñequitas y esas cosas.

Genial, ¿quién más? Cuéntenme.

- Yo tengo dos niños: uno de doce, él sí es viciosazo del play y el fútbol. Y el segundo de siete años que es también..., loco carros, carritos.

Colecciona carritos de todo tipo.

- Sí, sus cajones están llenos de carritos. 
¿Quién más? ¿Quién más falta?

- Yo no tengo hijos, pero tengo mi ahijado que vive en mi casa. Por ejemplo, a Daniel le gusta coleccionar todo lo que es Star Wars, de los superhéroes, de Superman, Batman, todas esas cosas de Advenger.

Perfecto. Tenemos entonces un público variado, a algunos les gusta los deportes y otros se van más por el tema de playstation, otros más por el tema de juguetitos: carritos, muñequitas, ¿no?

Cuéntenme, ¿suelen ingresar a redes sociales? ¿Cuáles son las redes sociales a las que ingresan más? ¿Cuál prefieren? ¿Mónica?

- El Facebook.

Tú entras más a Facebook. Y, digamos, a la semana, ¿cuántas veces ingresas?

- Lo tengo en el celular, así que constantemente estoy conectada.

Ah, genial. ¿Los demás? A ver cuéntenme.

- Facebook e Instagram.

Facebook e Instagram. ¿Tomas mucho selfie?

- Me gusta ver las fotos y yo también subo muchas fotos.

- Solo Facebook, igual lo tengo en el celular, entonces todo el tiempo estoy..., tengo Linkeding también, que es como...

Claro, más profesional. Las demás, cuéntenme.

- Solo Facebook.

- Yo también Facebook, publico todas las cosas que hago.

¿Solo Facebook o sueles usar otras redes también?

- No, solo Facebook

Facebook.

- Facebook, también instalado en el teléfono. 
Genial, y díganme, ¿sus hijos también tienen acceso a esas redes sociales?

- No.

- Mi hijo..., el mío sí, recién hace unos meses le doy permiso para que se cree su cuenta de Facebook. Yo siempre estoy viendo lo que hace y lo usa muy poco.

- El mío, el mayor sí tiene su cuenta...

Lo tienes agregado...

- Sí, yo soy la que acepto.

¿Tú Mónica?

- Todavía.

- Bueno, en mi caso mi hijo mayor sí utiliza Facebook pero me cuenta, ha agregado a sus amigos que son de su edad y bueno, conversa y yo los tengo en ININTELIGIBLE descubriendo, investigando páginas, explorando ahí, pero todavía no tienen una buena ININTELIGIBLE solamente en el Facebook.

¿En el caso de ustedes?

- No, no tiene Facebook.

No tiene Facebook todavía. ¿Tu ahijado todavía?

- No, sí tiene, pero me manda a mí, voy visitando.

Bueno, y hablando un poco más de las cosas que le gustan a los niños, cuéntenme un poco dónde suelen comprar ustedes juguetes para ellos, en general, ¿dónde suelen comprar juguetes?

- Centro comercial.

Ya, en centros comerciales.

- Tiendas por departamento.

- En las jugueterías. 
Tiendas de juguetes, ya. ¿Las demás?

- Centro comercial, a veces me ha pasado que he buscado algo en especial y lo he visto en internet... a ver qué tiendas o también he encontrado algunos por Facebook.

Por Facebook.

- Sí, he encontrado cosas por Facebook que me han interesado y decidimos...

- También teníamos ININTELIGIBLE de algunas casas de algunas ideas que nos hablan dónde llegan promociones o algunas que están en el momento, algunas películas que han lanzado...

- Sí, afiches ININTELIGIBLE y de hecho que veo precios y comparo y veo si conviene comprar.

Y en el momento en que van a comprar, ¿saben qué marca comprar o lo deciden en el momento recién, cuando van a la tienda por departamento, no sé?

- Normalmente tú sabes lo que vas a comprar.

- Sí.

- Voy pensando...

- Tienen sus preferencias, yo sé que dos marcas le encantan. Casi siempre le formulo eso.

O sea, van directo, digamos.

- No directo, pero es en el momento. Si hay, por ejemplo, una película... no sé, Frozen, tú tienes que buscar el libro de Frozen que lo puede vender Disney o lo puede vender Mattel, pero todo absolutamente del muñeco. O sea, el muñeco puede salir en varias marcas y tú puedes comprar todas esas marcas pero del personaje.

Personaje de la temporada básicamente.

- En mi caso, mi hijo mayor que tiene tres años está viendo Discovery Kids y Disney Junior, entonces, en estos canales pasa casi todo el día comerciales de juguetes y cuando quiere algo, ya está en la edad en que me dice "eso quiero" y ya sé qué juguete es y ya sé qué buscar, y ese juguete ININTELIGIBLE dónde lo venden, pero de frente estoy buscando el juguete que más o menos quieren y usualmente es lo que ven en los canales de dibujos. 
Y ustedes creen que quizás sus hijos influyen mucho en su decisión de compra.

- Por supuesto.

- Sí.

- Sí.

- Sí, ellos saben qué comprar.

- Ellos ya te dicen y hasta dónde lo puedes comprar.

- Hasta ellos saben dónde venden.

- Dónde lo puedes comprar y cuánto te va a costar, ellos ya saben.

- Definitivamente uno tiene la idea del regalo, pero el niño quiere otra cosa y uno termina aceptando lo que el niño quiere y cómo lo quiere.

Y cuanta más edad tiene el niño influye más.

- Claro.

- Sí.

- Y es más caro también.

- Ya tienen bien definido lo que quieren y nadie lo va a mover.

Y hablando de lo caro, ustedes al momento de comprar juguetes, ¿se suelen fijar en el precio?

- Sí.

- Sí.

- Sí.

- Yo, ofertas. Siempre que hay exclusivas, y si la tienda donde normalmente encuentro está en oferta, me voy.

- Yo de preferencia antes sí compraba bastante, pero desde que descubrí Amazon ando adquiriendo todo por ahí, porque es súper más barato.

Ah, tú sueles comprar mucho por internet, en Amazon.

- Sí, lo que es ropa..., juguetes ya no mucho para mis hijos, por el tema de que el mayor es más juego de play que mayormente encuentro. 
¿También sueles entrar a las tiendas on line de las mismas tiendas?

- Claro, también. Por ejemplo, acá en Lima es Linio, también es más barato que los centros comerciales.

Y las demás, ¿suelen fijarse mucho en el precio también?

- Sí, yo suelo comparar, busco lo que quiere y busco en las tiendas, Saga, Ripley y por internet o sino por Megatienda, o también en Facebook mucha gente vende juguetes y tal vez son más baratos y estoy chequeando eso, voy a verlo y depende eso decido más o menos qué comprar.

- Pero hay marcas que van a vender al mismo precio siempre.

- Ah, sí.

- Esa marca siempre va a tener un precio aquí, o sea, va a bordear por unos cuántos soles más, pero igual esa marca va a variar el precio, pero igual lo compran.

- La diferencia es mínima.

- Pero igual lo voy a comprar así sea dos soles o tres soles.

Digamos, en ese tipo de marca no te fijas en el precio...

- No, porque es una marca que es buena, es didáctica, qué sé yo, tiene un montón de valores que me indican que yo pueda pagar la cantidad que valga para mí.

- Claro, por ejemplo, yo he visto que a veces Saga y Ripley tienen algunas ofertas que sí son diferentes, es el mismo producto en otra tienda y yo lo he comparado. Debe ser porque la cantidad de ventas de Saga y Ripley y su compra de productos es muchísimo mayor y a un costo menor, que lo compran en la misma tienda de la marca y lo he visto en el centro comercial. He ido a una tienda, no me sé el nombre, vi u producto para mi bebe y me he ido a Saga y la diferencia sí la encuentras. Cuando pregunté por qué, era porque ellos compran mil y la tienda compra cien mil.

Y has optado por el más barato.

- Sí, primero..., si no lo encontraba yo regresaba al primero de todas maneras, pero si lo encontré más cómodo ININTELIGIBLE.

¿Qué es lo que más valoran cuando compran un juguete?

- La cara de felicidad de mi hijo... 
En tu caso valoras que le guste a tu hijo.

- Claro.

- Yo valoro lo que le guste, puede ser una tontería. A veces me ha pasado que he comprado algo que ha sido o mi esposo me ha dicho "qué es esto", pero mi hijo estaba feliz y jugando, después lo rompió y no importa, pero en ese momento era feliz.

Como qué consideras que es así algo que no..., o cuéntanos tu experiencia.

- Son juguetes que lo ha rayado..., el tema de los carritos, a él le gusta mucho los carritos, los carritos Hot Wheels tiene un montón. Entonces, cada vez que compro me dicen “¿para qué le compras más si tiene?”, pero esa imagen de cómo él..., él sí lo nota.

- Es otro modelo.

- Él nota que tiene otro carro y si de casualidad me equivoqué y le compré uno igual, porque a veces hay ofertas de la tira de tres y le compré, dice "iqué lindo, ahora tengo dos! Uno para la casa de Claudia y uno para mi casa”. Entonces, la crítica que a veces me puede dar mi esposo es "qué haces comprando tanto carro", pero verlo a él que le encanta y todo...

Básicamente que a él le guste.

- Que le guste, es lo que más buscamos, que le guste, porque si no... como que no..., reciben un regalo o un presente así medio..., pero sí tú le llevas algo que le guste, que les agrada, definitivamente la cara de felicidad no la vas a cambiar por nada.

O sea, cuando compran ese juguete que le guste al niño, pero no es que valoren tanto algo en el objeto importante.

- Bueno, que sea de buena calidad el material del juguete.

- Para que te dure.

- Antes yo compraba en Lima, en el centro de Lima, porque sabía que lo iba a agarrar un rato y se iba a aburrir, pero ya cuando empezó a crecer y ahora que está más grande ya no..., eso ya no pues, ahora le compro cosas de buena calidad que sé que le van a durar porque él le da bastante uso, también eso lo valoro. 
Claro, que sea sostenible en el tiempo. En el caso de ustedes, cuéntenme.

- En mi caso, por ejemplo, es diferente, porque mi sobrino tiene diez años, y bueno, ya pasó de tener los juguetitos, ahora sí..., ellos están tan metidos, porque tengo dos sobrinos, pero los dos están tan metidos en sus colecciones, que, por ejemplo, para su cumpleaños ellos más o menos nos van diciendo qué quieren, pero no es, por ejemplo, cualquier muñeco de..., no sé, Advenger, ya, cualquiera no, no es cualquiera. Por ejemplo, ellos buscan que las manos se muevan, sean articulares, por qué, porque es de colección, o sea, no es que van a jugar en sí con eso, sino que lo van a guardar toda su vida. Lo tienen ahí y lo guardan y todo. Ahorita, por ejemplo, están con la fiebre de Dragón Ball y de Star Wars. Esta navidad fue todo Dragón Ball, los muñecos carísimos sinceramente. Carísimos y era solamente porque venía con la base y el muñequito ahí parado. Pero bueno, a ellos les encanta, igual las esferas del Dragón. Buscando por todos lados dónde venden esa gracia, porque uno las ve pues ININTELIGIBLE con eso no se juega, son unas bolas así tipo de cristal, pero bueno, ellos felices de verlo y lo tienen ahí, porque tiene que estar en la misma caja, o sea, es un tema de las colecciones. Igual de Star Wars, cualquier cosa que ellos tienen de Star Wars también, es parte de la colección. Por ejemplo, en mi caso, como no es frecuente que le compre seguido los regalos, pero en ocasiones especiales en realidad no escatimo en cuanto al dinero.

Y has dicho un punto importantísimo, las ocasiones especiales. ¿En qué ocasiones suelen ustedes comprar más juguetes? ¿En qué momento?

- Navidad.

- Cumpleaños.

- Día del niño.

- El día del niño ahora se ha vuelto, pero...

- Es una ley.

- El día del niño es navidad...

- Por ejemplo, mi hijo mayor ya no es niño y sin embargo ININTELIGIBLE ¡tú no eres niño! -este año sí- me dice, -todavía me toca-

- Navidad para mí. Me voy a comprar para mi hijo, los sobrinos. Ahí es una compra más grande todavía, porque no son solamente tus hijos, porque vienen los sobrinos. 
- Y se lo inculcan desde colegio. En el caso de mi hijito que está en el nido, sabe que es el día del niño y tienen que darle un regalito.

- Es más, hay que llevarle un regalo al colegio para saber compartir.

Ah, ¿sí?

- Hay un compartir y hay que llevar un regalo o a veces hacen un sorteo, que es el caso del salón de mi hijo menor o llevar un regalito para cada niño, para mi hijo en este caso o sorteo.

Entonces coincidimos que es en Navidad, en los cumpleaños y en el día del niño. ¿Alguna otra fecha que ustedes consideren que también compran juguetes o solo esos tres?

- En mi caso eso es todo.

Esos tres.

- Así juguetes especiales solamente esos.

¿Y cuál es la marca, digamos, de su preferencia? ¿Cuál es la marca que ustedes más recuerdan de juguetes?

- A mi hijo le encanta Lego y Nerf.

Lego y Nerf. Ya, ¿en caso de las demás?

- A mi hija también le gusta Lego, porque para el lado de niñas es Lego Friends.

¿Lego Friends?

- Lego Friends, sí. Entonces, cada cierto tiempo mandaban una colección, entonces ella tenía una antigua y después sale una colección nueva y ella ya quiere tener una nueva colección y si coincidentemente es navidad le compran toda la colección, o sea, todo lo nuevo que sale porque ella lo quiere tener.

Porque es coleccionable.

- Sí, claro, y porque uno es complemento del otro. O sea, tú te compras el carrito, no sé, y tienes otra cosita y lo vas complementando, es como hacer una mini

ININTELIGIBLE comienza la colección. 
- En mi caso es el Lego, el Fisher Price y el ININTELIGIBLE es muy chiquita. En el caso de Lego siempre en la televisión sale toda la tendencia que estamos viendo, si es de Star Wars, si es los nuevos capítulos que van avanzando, siempre hay novedades.

- ININTELIGIBLE se pueden quedar con la colección antigua.

- Ellos saben, "ya salió, hay que cambiar", ya te piden.

¿Y las demás? ¿Cuál es la marca que más recuerdan?

- Hasbro, por los muñecos. Nerf también.

Pero los Nerf qué cosa es...

- Son las pistolas...

- Para verano es con agua...

Ah, genial. Y díganme, ¿cuál creen ustedes que es la mejor marca y por qué?

- En mi caso que están más chicos: Fisher Price o Little Tikes que son mega block.

Y por qué crees tú, por ejemplo, que esas marcas Fisher Price son...

- Porque yo siento que estoy comprando productos de calidad. Creo que ahora en el Perú está muy bien puesto el tema de que hay que tener cuidado con los productos chinos, los materiales con los que se hacen, que le hacen daño a la salud, porque los bebes se meten los juguetes a la boca o un juguete de un plástico muy delicado se rompe y ese juguete que se rompe ya le puede cortar. Entonces, me da más seguridad de que son productos de calidad. Y cuando los he comprado no he tenido ningún problema. Hay juguetes de mi hijo mayor que estaba jugando a la ININTELIGIBLE y se nota ahí el tipo de producto.

¿En el caso de los demás?

- Sí Hot Wheels, los carritos.

¿Por qué prefieres Hot Wheels?

- Porque es un metal muy resistente.

- No se oxida, no pasa nada.

- Ahora está los que los mojas y cambian de color. 
En el caso de las demás.

- Para mí siempre fue Lego, porque le ayuda a desarrollar su creatividad, la habilidad de construir cosas. Él juega solo y luego en su cuarto, pues a veces no tiene amigos, no tiene primos, ni vecinitos para jugar. Esta solo y se inventará su mundo en su cabeza y está armando y desarmando. No solamente viene una caja con un nave específica, por ejemplo, en el caso de Star Wards, pero él puede desarmar eso y hacer otra cosa que a él se le ocurra. Está en un personaje y le cambia ININTELIGIBLE, o sea, tiene diez mil posibilidades con esas piezas. Entonces, para mí eso es mejor para su desarrollo. También le encanta el Nerf, pero son ININTELIGIBLE, aunque también le gusta más cuando estaba con amigos, ahí sí porque hacen sus equipos, agarran mi sala, mi mueble como si fuera una carpeta y se disparan, es más social, pero el Lego puede hacerlo solo o en grupo. Para mí, que es hijo único es súper.

- A mi hijo le encanta los mega bloques, ya va a pasar al tema de Lego porque tiene dos primos que los ve siempre y los primos son hincha de Lego, pero las piezas a veces son muy chiquitas y tengo que ver cuál le compro, pero el Lego Friends tiene a veces un poquito más...

- No, pero en el caso para bebes, yo le compro a mi sobrino es Lego ININTELIGIBLE que son así...

- Que son más gorditas.

- Son gruesas.

- Porque a él lo voy a pasar ya a otra cosa, porque le encanta armar y él es hombrecito y nuestra bebe todavía está chiquita y él juega solo, y eso es cierto, a veces para jugar los hombres es un montón, como que su imaginación..., ya hace roles, ya inventa cosas. Pero estoy viendo que lo voy a pasar a otro tipo de juguete, pero quiero ver el tipo de juguete porque él está chico y todavía tengo que ver...

Tú nos habías comentado algo interesante, decías: Lego Friends, yo intuyo que tú prefieres Lego Friends, o qué otra marca...

- Claro, definitivamente también mi hija pide muñecas de la moda, cada película nueva que saca Disney siempre pide, pero mayormente siempre es uno, la marca es Mattel, pero pide un ratito y la deja ahí y después siempre pide sus legos y juega con sus legos. A veces, ponte vas al supermercado de un centro comercial y pasaste por una tienda y aunque sea cosas chiquitas de Lego te pide y va sumando a su colección. Y 
cada vez que ella va te lleva "vamos a ver nada más", pero ese vamos a ver es..., "solo voy a mirar mamá, no quiero que me compres", okey, solo vamos a mirar, “pero mamá, está barato, está en oferta”, para ir sumando su colección.

En el caso de ustedes, ¿qué marca prefieren y por qué?

- Bueno, en el caso mío, Fisher Price siempre..., cuando era más chiquita, porque tiene diferentes modelos. Los Legos, ha hecho que mi hijo menor, que es el que más le gusta, porque siempre desde que era pequeñito con el rompecabezas y el Lego, ya cuando vio por la televisión todo lo que podía armar. Por ejemplo, te dicen todo lo que puedes crear. Entonces, es un reto y siempre hay eso de que se te perdió una fichita y desarmaba todo el juego y para poder armarlo dice "no, mi castillo está incompleto", y esa imaginación que le hace crear y volar, es lo que me hace decidir por esa marca.

¿Y en tu caso?

- El primer regalo que yo le hice a mi ahijado cuando cumplió un año, fue la estación de bomberos de Lima.

¿Y por qué le regalaste eso?

- Porque, por ejemplo, yo me acuerdo que cuando era chiquita mi primo tenía un cuarto que estaba lleno de legos, tenía un castillo, tenía varias cosas y yo cada vez que iba a jugar con él me encantaba, toda la vida me gustó. Entonces, cuando ya tuve a mi sobrino, ahijado, le di algo especial, algo que va a durar y algo que se hace una colección en realidad y así ha sido. Empezó con eso, después, bueno, mi hermana también le fue comprando otras cosas, después salió de Meteoro también, cuando se puso de moda hace tiempo. Esas cosas, por ejemplo, sí Legó sí es una marca que te va a durar años, y bueno, sobre todo tienes que cuidarlo, porque si se pierde una pieza no es lo mismo. Bueno, menos mal que siempre lo ha sabido cuidar, y hasta el día de hoy, Bruno tiene su cuarto bien puesto y desde que lo armó con mi cuñado hasta el día de hoy.

Y es interesante porque ustedes han coincidido en una marca que es Lego, todos conocen la marca Lego, y díganme, ¿por qué razón comprarían la marca Lego, seguirían comprando esta marca? 
- Es que es bien innovadora.

- Programas que salgan, películas que salgan ellos van a sacar...

- Y lo más gracioso es que es armable, o sea, cositas chiquitas, por ejemplo, ellos que ahorita están más jovencitos, por ejemplo, siempre encontramos los llaveros de Star Wards...

- Y hasta grandes...

- Son lindos, no solo lo usan los niños.

- Por ejemplo, a mi enamorado le encanta los legos.

- ININTELIGIBLE alguna nave de Star Wards, pero como salió la película nueva han sacado la misma nave, pero renovada, o sea, con algunos cambios que ha tenido el personaje.

Y si ustedes van, por ejemplo, a comprar Lego y no encuentran esa marca, ¿consumen otra?

- No.

- Lego es único.

- Salió una “CREO”, pero no eran iguales las fichas. Bueno, mi hijo el menor es fanático de los Transformers, en todo lo que tiene que ver con los carritos, y un día le compré "CREO” y mi hijo el mayor, que es más espeso, "ay, eso es bamba”, dice. Es que ellos ya saben. Después cuando ellos estaban un poquito más chicos habían unos robots que eran para armar, estaban los de Lego y estaban los otros, pero creo que eran chinos, no sé, algo así, que vienen en una caja...

- Ah, esos son los Payónicos...

- TODOS HABLAN AL MISMO TIEMPO.

- Por ejemplo, CREO tiene los Transformers, a mi hijo le gusta, pero está más enganchado con Star Wards, porque también lo juega en el playstation, tiene dibujos en la televisión que son de Star Wards. Yo también soy fan de Star Wards desde niña y entonces tengo mis muñecos. Entonces, ya tiene esa preferencia por Legos de Star Wards, le gustan otros, pero eso es lo que más le gusta. En CREO no hay Star Wards, por eso es que más se lo han regalado.

Entonces, si no encuentran definitivamente buscan Lego.

- Lego. 
- En mi caso van a decir “no mamá, esto no es”, ya están identificados con el Lego, lo aman como dicen.

- En especial los mayorcitos son los que siguen...

- Sí, ya se dan cuenta.

Y ustedes conocen, todos conocen o cuéntennos su experiencia con las tiendas Lego Store, ¿han escuchado las tiendas Lego Store? ¿Tú has escuchado las tiendas Lego Store?

- En el Jockey Plaza hay uno, creo.

- Hay uno.

- La verdad que no he entrado..., bueno, he entrado un par de veces, pero no he visto ofertas por eso no compré. Cuando he comprado ha sido en Infanti, de repente en Wong, siempre buscando ofertas, incluso me han traído familiares de Estados Unidos, que cuando han viajado me han traído, pero en la tienda Lego no he...

Y las demás, ¿conocen la tienda Lego?

- Sí.

- En el Jockey y en San Miguel.

En Chiclayo no hay tiendas Lego.

- No, en Chiclayo no hay, entonces solamente encuentro en tiendas por departamento, y yo asumo que en Lima hay, pero no tiene lo mismo que tiene una tienda exclusiva.

¿Y qué opinión tienen de las tiendas Lego Store?

- A mí me encanta.

¿Por qué te encanta? A ver, cuéntanos.

- Paso por ahí con mi hijo y le encanta las figuras armadas, es lo primero que llama la atención.

- Y es bien colorida la tienda.

- HABLAN TODOS.

- Puedes encontrar ahí todo armado, definitivamente lo que más impacta.

- Llama totalmente la atención.

- Y tienen un espacio donde tienen un montón de fichitas sueltas y hasta en la misma tienda se sientan y empiezan a armar sus cositas. 
Y qué opinión, digamos, si tuvieran una tienda Lego Store, en tu caso que eres del norte, ¿la visitarías?

- Sí, claro, porque a mi hija le gusta y de repente si no encuentra en un Saga o un Ripley, yo asumo que en esta tienda sí lo va a encontrar... (Se cortó el audio)

Bueno, retomando la pregunta de que si hubiera una tienda de Lego Store en su ciudad, ¿qué le gustaría que tenga esa tienda?

- Todo lo que vendan.

- Todas las líneas y que haya ofertas.

Todas las líneas de Lego y buenas ofertas.

- Otro sería que tengan armado, como he visto por internet algunas figuras grandes ININTELIGIBLE

No has visto eso mucho...

- No, solamente lo he visto por internet, fotos. Es un espacio ya armado para que los chicos vean y se guíen poniendo las...

¿En el caso de ustedes?

- Bueno, creo que debería de haber más sitios, porque yo tengo familia en provincia, en el norte y en navidad que los chicos piden juguetes que a veces no han encontrado y yo les he hecho el encargo de comprarlo acá, y cuando en algún momento han venido y han visitado la tienda se han quedado maravillados.

¿Y cómo les gustaría que fuese esa tienda? Digamos, si se abre en provincia.

- Grande, colorida, con bastante aire acondicionado por el calor.

Ah, la del Jockey es muy pequeña.

- Sí, más amplia debe ser.

- O sea, yo entiendo que ahora está un poco pequeña de lo que empezó a ahora tal vez tienen más cosas y hay mucha gente, es que llama mucho la atención de los niños. 
Que llame mucho la atención creo que también es importante.

- Eso es importante.

- Sí, creo que la tienda es nueva, porque en la tienda hay..., no sé cuánta gente hay, pero ININTELIGIBLE.

- Y tiene colores que jalan.

- Y ese rojo y amarillo y el muñeco no deben sacarlos.

Colores muy llamativos.

- Claro.

¿Y les gustaría que desarrollen un tipo de actividad en estas tiendas?

- Sí, sobre todo en esas grandazas.

- Lo que yo le comentaba, que quiero que mi hijo pase al cambio de juguetes

ININTELIGIBLE desde que era yo una niña y que me muestre las opciones que hay de juguetes y que se sienten con ellos a enseñarles y...

Lo guíen.

- Claro.

- Yo he visto en internet, que una vez hicieron una ININTELIGIBLE en San Miguel, que construyeron un camión de bomberos de Lego y los niñitos que pasaban ayudaban a construir ese camión y a la vez se llevaban un diploma de Lego Constructor, una cosa así, le daban su carro, le daban su foto y le daban su poster, pero regalaban un carrito de Lego chiquitito de bombero. Cosas así deberían hacer...

- Que los motive.

Que los motive. ¿Qué otras actividades les gustaría que hagan en esas tiendas?

- Bueno, por ejemplo, mi sobrino que está más grande: a mí me gustaría que hagan una exposición de todo..., por ejemplo, de Star Wards que está de moda, podrían hacer una exposición ININTELIGIBLE.

- En la tienda de videojuegos hacen torneos en los centros comerciales de este juego de Mario que hay u otro tipo de juegos, deberían hacer para los chicos una especie de concurso, invitar a los niños, darle fichas y lo que cada uno vaya armando y al mejor 
le dan un regalo. Eso creo que llamaría bastante la atención y a los niños creo que le dan cuatro cosas y ven qué hacen con esas cuatro cosas.

- El reto de competir con otro niño de ININTELIGIBLE habilidades.

En caso de ustedes...

- De repente cuando uno acumule compras te den algún descuento adicional o ese tipo de cosas.

- TODOS HABLAN.

¿Y con qué frecuencia, digamos, bueno, si es que han ido van a las tiendas Lego o irían a las tiendas Lego en el año o en general?

- Clavado tres meses al año: Navidad, cumpleaños y día de niño.

Tres veces al año como mínimo.

- Sí o sí, mínimo sí.

- Si voy al centro comercial de todas maneras doy una pasadita pora ahí, a ver si hay alguna oferta y vuelvo hasta navidad.

O sea, siempre que vas al centro comercial y hay una tienda Lego ustedes sí o sí van.

- Entramos.

¿Y dónde les gustaría encontrar más tiendas Lego?

- En el centro comercial.

En más centros comerciales, ¿dónde más deberían haber más tiendas Lego?

- En Lima hay un montón de centros comerciales y veo que solo hay dos tiendas y en el resto del Perú no hay, entonces, falta eso.

- Creo que hay, pero en centros comerciales, falta las tiendas.

¿Y en qué otros centros comerciales o en qué lugares sugerirían ustedes que se abran estas tiendas?

- En el Congreso, para que ahí hagan algo. 
- En centros comerciales, porque uno va al centro comercial por cualquier tipo de necesidad y de paso para poder ININTELIGIBLE.

- Sí, porque parece mentira, uno cuando ya es mamá, antes era otro mundo, cuando uno ya es mamá ve un juguete y boom voltea, parece que has visto un vestido y es un juguete.

- Eso es verdad.

- Creo que nosotras somos las dos obsesivas con las criaturas.

- Es que si el niño pide puede ser, nosotros se lo compramos.

- Me ha pasado eso.

Y díganme, algún comentario adicional sobre el tema que alguien quisiera añadir, decir, quizás para redondear el tema o algo que nos pueda ayudar.

- Yo diría que amplíen la red en provincias, que sea más accesible.

- Que sea más accesible para que tengan entrada también con los chicos, con la población en provincias.

- En centros comerciales.

- En provincias está todo más modernizado.

Ha sido un gusto conversar con ustedes, son encantadoras todas, un aplauso. 
Apéndice 3: Ficha de resumen del grupo de enfoque 1.

\begin{tabular}{|c|c|}
\hline Variable & Respuestas \\
\hline Edad & 40 (1) 32 (2) 37 (1) 30 (1) 33 (1) \\
\hline Ciudad de Residencia & Lima (4), Trujillo (1), Chiclayo (1) \\
\hline Estudio / Trabajo & Trabajo (6) \\
\hline Hijos & Hijos (5) S/hijos (1) \\
\hline Actividades de los Hijos & $\begin{array}{l}\text { Campo (1), Cine (1), Deporte (5), PlayStation } \\
\text { (3), Jugar con Amigos (1), Rompecabesas (1), } \\
\text { PlayDoo (1), Carritos (2), Parque (2), Bicicleta } \\
\text { (2), Muñecas (2) }\end{array}$ \\
\hline $\begin{array}{l}\text { Redes Sociales que usa la } \\
\text { madre }\end{array}$ & Facebook (6), Instagram (1), Linkelind (1) \\
\hline Usan los hijos redes sociales & Si (2), No (4) \\
\hline Donde compran juguetes & $\begin{array}{l}\text { Centro comercial (2), Tiendas por departamento } \\
\text { (2), Tiendas de juguetes (1), Internet (1), } \\
\text { Facebook (1) }\end{array}$ \\
\hline $\begin{array}{l}\text { En la compra, se decide la } \\
\text { marca en el momento o se } \\
\text { sabe que se va a comprar }\end{array}$ & $\begin{array}{l}\text { Sabe que comprar (5), Se decide en el momento } \\
\text { (1) }\end{array}$ \\
\hline $\begin{array}{l}\text { Los hijos influyen en la } \\
\text { decisión de compra }\end{array}$ & $\mathrm{Si}(6)$, No (0) \\
\hline El precio influye & $\mathrm{Si}(6)$, No (0) \\
\hline Suelen comprar por internet & Si (5), No (1) \\
\hline Valor de un juguete & $\begin{array}{l}\text { Que guste (1), Calidad (2), Durabilidad (2), } \\
\text { Coleccionable (1) }\end{array}$ \\
\hline $\begin{array}{l}\text { En que fechas compran } \\
\text { juguetes }\end{array}$ & Navidad (6), Cumpleaños (6), Dia del niño (4) \\
\hline Marca Favorita & $\begin{array}{l}\text { Lego (3), Nerf (2), Fisher Price (2), Hasbro (1), } \\
\text { Litle Tikets (1) }\end{array}$ \\
\hline Mejor Marca & $\begin{array}{l}\text { Fisher Price (1), Little Tikets (1), Hotwells (1), } \\
\text { Lego (3), Nerf (1), }\end{array}$ \\
\hline Por que Lego & Innovadora (1), Armable (1), Relacionada a \\
\hline
\end{tabular}




\begin{tabular}{|c|c|}
\hline & Peliculas de moda (1) \\
\hline $\begin{array}{l}\text { Cambiar Lego si no } \\
\text { encuentran }\end{array}$ & Si (0), No (6) \\
\hline Conocen Lego Store & Si (5), No (1) \\
\hline Que buscan en Lego Store & Variedad (4), Ofertas(2) \\
\hline Que le falta & $\begin{array}{l}\text { Mas tiendas en provincia (1), Mas espacio (1), } \\
\text { Figuras armadas (1) }\end{array}$ \\
\hline $\begin{array}{l}\text { Actividades que les gustaria } \\
\text { en Lego Store }\end{array}$ & $\begin{array}{l}\text { Armado de figuras grandes (1), Aire } \\
\text { acondicionado (1), Concurso de armado (2), } \\
\text { actividades con instituciones (1), Exposiciones } \\
\text { (1) }\end{array}$ \\
\hline $\begin{array}{l}\text { Frecuencia de Visita a Lego } \\
\text { Store }\end{array}$ & $\begin{array}{l}\text { Siempre que va al centro comercial con los } \\
\text { niños (2), Tres veces al año (4) }\end{array}$ \\
\hline $\begin{array}{l}\text { Donde le gustaria encontrar } \\
\text { Lego Store }\end{array}$ & Centros comerciales (3), provincias (2) \\
\hline
\end{tabular}


Apéndice 4: Ficha de resumen grupo de enfoque 2.

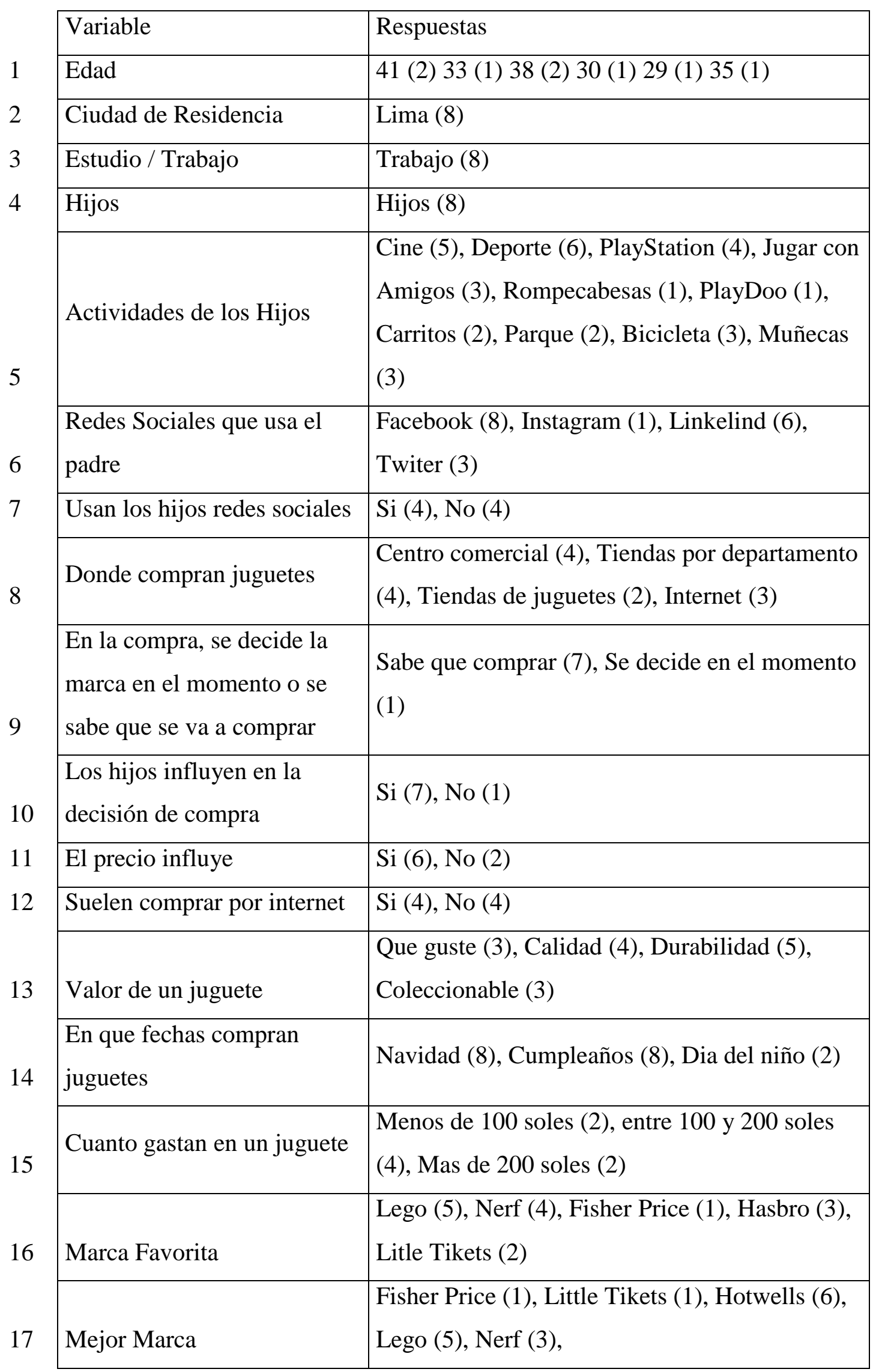




\begin{tabular}{|c|c|c|}
\hline 18 & Por que Lego & $\begin{array}{l}\text { Innovadora (1), Armable (2), Relacionada a } \\
\text { Peliculas de moda (4), Calidad (5) }\end{array}$ \\
\hline 19 & $\begin{array}{l}\text { Cambiar Lego si no } \\
\text { encuentran }\end{array}$ & $\mathrm{Si}(0)$, No (8) \\
\hline 20 & Conocen Lego Store & $\mathrm{Si}(7)$, No (1) \\
\hline 21 & Que buscan en Lego Store & Variedad (6), Ofertas(3), Colecciones (2) \\
\hline 22 & Que le falta & $\begin{array}{l}\text { Mas tiendas en provincia (2), Mas espacio (2), } \\
\text { Figuras armadas (4) }\end{array}$ \\
\hline 23 & $\begin{array}{l}\text { Actividades que les gustaria } \\
\text { en Lego Store }\end{array}$ & $\begin{array}{l}\text { Armado de figuras grandes (4), Aire } \\
\text { acondicionado (1), Concurso de armado (1), } \\
\text { actividades con instituciones (1), Exposiciones } \\
\text { (5) }\end{array}$ \\
\hline 24 & $\begin{array}{l}\text { Frecuencia de Visita a Lego } \\
\text { Store }\end{array}$ & $\begin{array}{l}\text { Siempre que va al centro comercial con los } \\
\text { niños (3), Tres veces al año (6) }\end{array}$ \\
\hline 25 & $\begin{array}{l}\text { Donde le gustaria encontrar } \\
\text { Lego Store }\end{array}$ & Centros comerciales (6), provincias (3) \\
\hline
\end{tabular}




\section{Apéndice 5: Cuestionario para la encuesta de LEGO.}

Cuestionario de Juguetes

$\mathrm{N}^{\circ}$

Buenas ...... somos estudiantes de la Maestría en Dirección de Marketing \& Gestión Comercial de la Escuela de Postgrado de la Universidad San Ignacio de Loyola. Quisiéramos por favor pueda brindarnos algunos minutos de su valioso tiempo para responder una breve encuesta. ¡Muchas gracias!

¿Compra o ha comprado alguna vez juguetes?
(a) Sí
(b) No

Si su respuesta es SI, pasar a la pregunta uno.

Si su respuesta es NO, muchas gracias por su tiempo.

\section{PRIMERA PARTE}

1. ¿Tiene hijos?
(a) Sí
(b) No

2. ¿Con qué frecuencia suele comprar juguetes?

Elija solo una opción.
(a) Nunca
(b) Una vez al año
(c) Dos veces al año
(d) Tres veces al año
(e) Más de tres veces en un año

3. ¿En qué lugares suele comprar juguetes?

Puede elegir más de una opción.
(a) Supermercados (Plaza Vea, Tottus, Wong, Metro, Vivanda, etc.)
(b) Tiendas por departamento (Ripley, Saga Falabella, Paris, Oeschle, etc.)
(c) Tiendas especializadas (Tai Loy, etc.)
(d) Jugueterías (Alex, Caramba, Zigzag, Lego, JK You World, etc.)
(e) Mercados / Mercado Informal
(f) Internet
(a) Otros (especifique)

4. ¿Cuál es la marca de juguetes que más suele comprar?

Puede elegir más de una opción.
(a) Nerf
(b) Mega Bloks
(c) Playmobil
(d) Mattel
(e) Hasbro
(f) Marvel
(g) PlayDoo
(h) Little tikes
(i) Fisher-Price
(j) Lego 
(k) Otros (especifique)

5. De las siguientes afirmaciones elija la opción que usted considere:

\begin{tabular}{|c|c|c|c|c|c|c|}
\hline & PREGUNTAS & $\begin{array}{c}\text { Muy en } \\
\text { Desacuerdo }\end{array}$ & $\begin{array}{c}\text { En } \\
\text { Desacuerdo }\end{array}$ & $\begin{array}{l}\text { Ni de } \\
\text { acuerdo } \\
\text { ni en } \\
\text { desacuerdo }\end{array}$ & $\begin{array}{l}\text { De } \\
\text { acuerdo }\end{array}$ & $\begin{array}{l}\text { Muy de } \\
\text { acuerdo }\end{array}$ \\
\hline 5.1 & $\begin{array}{l}\text { El precio es importante para } \\
\text { decidir qué juguete comprar. }\end{array}$ & & & & & \\
\hline $\begin{array}{l}5.2 \\
\cdot\end{array}$ & $\begin{array}{l}\text { La marca es importante para } \\
\text { decidir qué juguete comprar. }\end{array}$ & & & & & \\
\hline $\begin{array}{l}5.3 \\
\cdot\end{array}$ & $\begin{array}{l}\text { La calidad es importante para } \\
\text { decidir qué juguete comprar. }\end{array}$ & & & & & \\
\hline 5.4 & $\begin{array}{l}\text { El tipo de juguete es } \\
\text { importante para la decisión de } \\
\text { compra. (educativos, de } \\
\text { guerra, deportivos, etc) }\end{array}$ & & & & & \\
\hline 5.5 & $\begin{array}{l}\text { EL niño influye en la decisión } \\
\text { de compra de un juguete. }\end{array}$ & & & & & \\
\hline $\begin{array}{l}5.6 \\
.\end{array}$ & $\begin{array}{l}\text { Que un juguete sea } \\
\text { coleccionable es importante } \\
\text { para la decisión de compra. }\end{array}$ & & & & & \\
\hline
\end{tabular}

6. ¿Cuál es el atributo que más valora al momento de comprar un juguete?

Puede elegir más de una opción.
(a) Precio
(b) Calidad
(c) Marca
(d) Creatividad
(e) Coleccionable
(f) Desarrollo de habilidades cognitivas
(g) Otros (especifique)

7. ¿En qué ocasiones suele comprar juguetes?

Puede elegir más de una opción.
(a) Navidad
(b) Cumpleaños
(c) Día del Niño
(d) Año Nuevo
(e) Otros (especifique)

8. ¿Cuál cree que es la mejor marca de juguetes?

Puede elegir más de una opción.
(a) Nerf
(b) Mega Bloks
(c) Playmobil 

(d) Mattel
(e) Hasbro
(f) Marvel
(g) PlayDoo
(h) Little tikes
(i) Fisher-Price
(j) Lego
(k) Otros (especifique)

9. ¿Cuánto destina a la compra de juguetes

$\mathrm{S} /$.

10. ¿Conoce la marca LEGO?
(a) Sí
(b) No

Si su respuesta es SI, pasar a la pregunta 11.

Si su respuesta es NO, muchas gracias por su tiempo.

11. ¿Compra o ha comprado alguna vez productos de la marca LEGO?
(a) Sí
(b) No
Si su respuesta es SI, pasar a la
Si su respuesta es No, Pasar a la pregunta 17. pregunta12.

12. ¿En qué lugares compró la marca LEGO?

Puede elegir más de una opción.
(a) Supermercados (Plaza Vea, Tottus, Wong, Metro, Vivanda, etc.)
(b) Tiendas por departamento (Ripley, Saga Falabella, Paris, Oeschle, etc.)
(c) Tiendas especializadas (Tai Loy, etc.)
(d) Jugueterías (Alex, Caramba, Zigzag, Lego, JK You World, etc.)
(e) Mercados / Mercado Informal
(f) Internet
(g) Otros (especifique)

13. ¿Por qué motivo compró la marca LEGO?

Puede elegir más de una opción.
(a) Innovación
(b) Calidad
(c) Moda
(d) Producto educativo
(e) Colección
(f) Otros (especifique) 
14. ¿En promedio cuánto gastó en su última compra?

$\mathrm{S} /$.

15. ¿En el último año cuántas veces compró los productos de la marca LEGO?

16. ¿Para quién compró los productos de la marca LEGO? Puede elegir más de una opción.
(a) Hijos
(b) Regalos a terceros (Niños)
(c) Regalos a terceros (Adultos)
(d) Uno mismo
(e) Otros (especifique)

FIN DE LA PRIMERA PARTE. CONTINÚE A LA PÁGINA 5.

17. ¿Por qué no compró la marca LEGO?

Puede elegir más de una opción.
(a) Precio
(b) Desconocimiento del lugar de venta
(c) Poca variedad de productos
(d) No es un producto atractivo
(e) Otros (especifique)

FIN DE LA PRIMERA PARTE. CONTINÚE A LA PÁGINA 5.

LEGO® es una empresa que se ha convertido en una de las líderes internacionales en la fabricación de juguetes. Fiel a su lema, "Only the best is good enough" ("Sólo lo mejor es lo suficientemente bueno"), la empresa tiene un firme compromiso con el desarrollo infantil, que consiste en inspirar y desarrollar a los constructores del mañana mediante el juego y el aprendizaje creativo.

Ahora que conoce la marca LEGO, ¿estaría dispuesto a comprar productos de LEGO?
(a) Sí
(b) No

Si su respuesta es SI, pasar a la pregunta18. Si su respuesta es No, pasar a la Segunda Parte.

18. ¿Cuánto está dispuesto a pagar por un producto de la marca LEGO?

$\mathrm{S} /$. 


\section{SEGUNDA PARTE}

1. ¿Qué actividades realiza en sus ratos libres?

Puede elegir más de una opción.
(a) Deportes
(b) Actividades sociales (reuniones, fiestas, etc.)
(c) Estudios
(d) Tiempo en familia
(e) Actividades artísticas
(f) Otros (especifique)

2. ¿Qué actividades realiza en sus ratos libres?

Puede elegir más de una opción.
(a) Deportes
(b) Actividades sociales (reuniones, fiestas, etc.)
(c) Estudios
(d) Tiempo en familia
(e) Actividades artísticas
(f) Otros (especifique)

3. Por favor indique su rango de edad:
(a) De 18 a 23 años
(b) De 24 a 29 años
(c) De 30 a 35 años
(d) De 36 a 44 años
(e) De 45 a más años

4. Por favor indique su sexo:
(a) Hombre
(b) Mujer

5. ¿Qué ocupación tiene usted?

Elija solo una opción.
(a) Empleado
(b) Independiente
(c) Estudiante
(d) Ama de casa
(e) Otros (especifique)

6. Por favor mencione su distrito de residencia 